\title{
Implementação de um cluster de computadores e desenvolvimento de seu sistema de gerenciamento'
}

\author{
Fernando Yuichi Tanaka
}

Orientador: Prof. Dr. Dilvan de Abreu Moreira

Dissertação apresentada ao Instituto de Ciências Matemáticas e de Computação - ICMC-USP como parte dos requisitos para obtenção do título de Mestre em Ciências de Computação e Matemática Computacional

"VERSÃO REVISADA APÓS A DEFESA"

Data da Defesa: 29/11/2004
Visto do Orientador:ten Xem Lioru n...

São Carlos

Novembro/2004

${ }^{9}$ Trabalho rcalizado com auxilio financeiro do CNPq. 
Este trabalho é dedicado aos meus pais, irmãos e parentes, que apesar da distância, sempre me apoiaram. Dedico-o ainda à família Doihara pelos momentos felizes que me proporcionou. 


\section{Agradecimentos}

Agradeço primeiramente a Deus por me ter concedido forças pra lutar e buscar meus ideais.

Aos meus pais pelos suportes emocional e financeiro, fundamentais para conseguir vencer essa jornada.

Ao professor Dilvan pela confiança, orientação e incentivo. Obrigado pela ajuda nas horas de dúvidas e por ter acrescentado muito na minha formação.

Aos meus irmãos Márcio e Elizabeth e suas respectivas famílias pela amizade, incentivos e conselhos.

A todos os professores do ICMC-USP, em especial ao Eduardo Simões e Edson Moreira pelas contribuições no Exame de Qualificação.

Ao amigo Bruno, conterrâneo e companheiro de república, que apesar de ser preguiçoso é um amigo pra todas as horas. Obrigado pela amizade incentivo, conselhos, papos furados etc.

A todos os amigos do Laboratório Intermídia, em especial a Elaine pelas sugestões e correções dadas a este texto.

A todos os meus familiares, em especial a minha prima Lie pelas conversas de descontração e prospeç̧ão.

A Izumy, apesar de tudo você fez parte da minha vida e muito me incentivou e aconselhou sobre as diversas decisões que tomei.

Aos amigos da pós-graduação e graduação da USP: Leonardo, Jean, Valter, Waldo, Rodrigo Borges, Fodra, Magoo, Balan, Ovo, Erika, Omar, Mário, Bulcão, Nilson, Márcio, Lucas, Topeira, Baila, Marmota, pessoal do futebol, e muitos outros, pela amizade e muita conversa fora.

Aos funcionários da portaria, da secretaria de pós-graduação, da limpeza e do STI do ICMC.

Ao CNPq pelo suporte financeiro. 


\section{Resumo}

Nos últimos anos, clusters de computadores vêm ganhando popularidade, principalmente nos meios corporativos e acadêmicos, como servidores $W e b$. Isso se deve, principalmente, por eles oferecerem um custo/beneficio bastante atraente. No entanto, esses clusters (conhecidos como Web Farms) possuem uma maior complexidade de gerenciamento e, principalmente os clusters de alta disponibilidade, necessitam de um monitoramento intensivo para manter os seus serviços sempre disponíveis.

Este trabalho apresenta a implementação de um Web Farm Cluster e o desenvolvimento de um sistema de monitoramento e controle desse tipo de cluster (iCluster) utilizando a tecnologia de agentes de software. O sistema utiliza a tecnologia de agentes de software para implementar módulos de computação autônoma, permitindo dessa forma o monitoramento, o controle e a visualização de estados e serviços de um Web Farm Cluster com o mínimo de intervenção humana. 


\section{Abstract}

Recently, clusters of computers are gaining popularity, especially among corporations and universities, as Web servers. This happens, mainly, because they offer a very attractive cost/benefit ratio. However, these clusters (known as Web Farms) are more complex, difficult to manage and, in the case of high available systems, need intensive monitoring to maintain their services always online.

This work presents a Web Farm Cluster implementation and a system that can monitor and control this kind of clusters, based on software agent technology. This system uses software agents to implement an autonomic system (iCluster), capable of monitoring, maintaining and showing a collection of hardware states and services offered by a Web Farm Cluster with reduced human intervention. 


\section{Sumário}

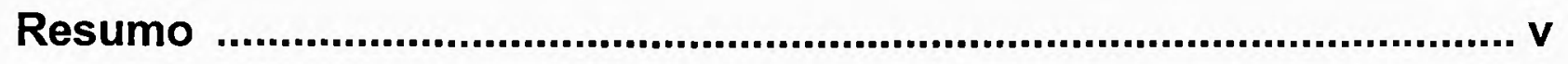

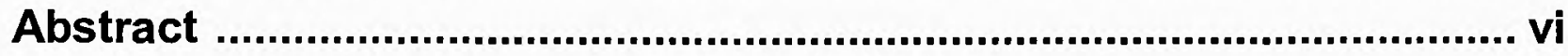

Sumário .......................................................................................... vii

Lista de Figuras .................................................................................... $\times$

Lista de Tabelas......................................................................................

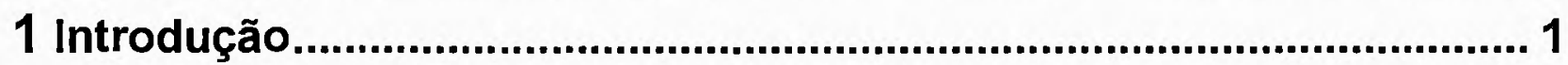

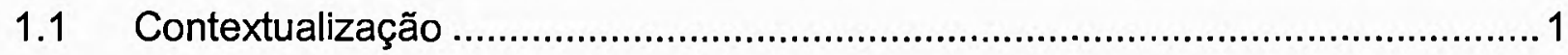

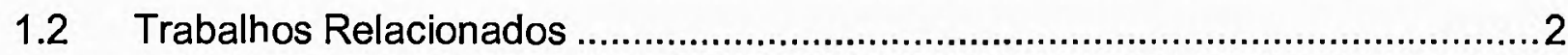

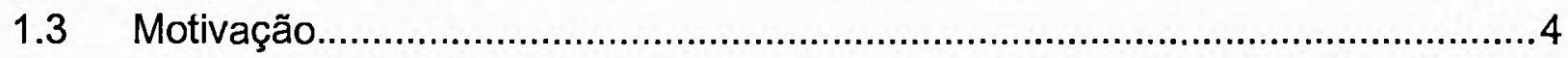

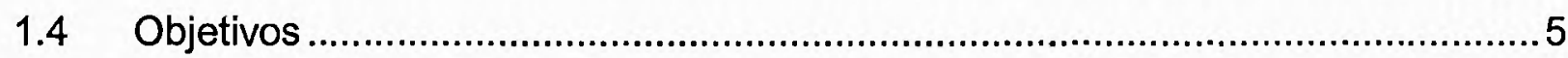

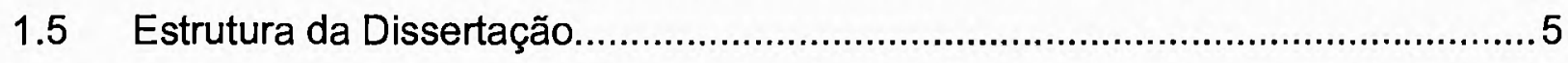

2 Clusters de Computadores.............................................................. 7

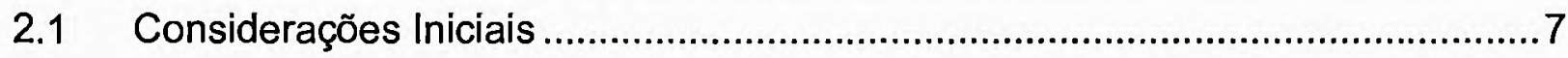

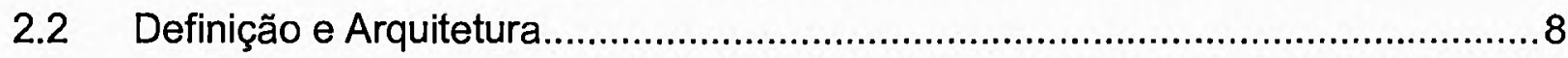

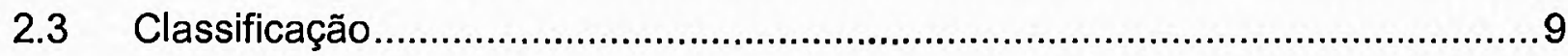

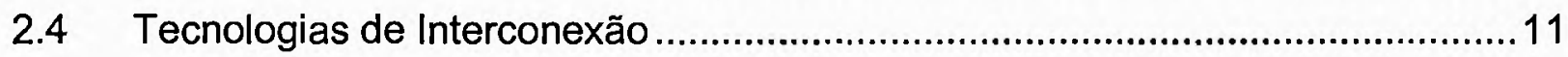

2.4.1 Protocolos de Comunicaçăo .........................................................................11

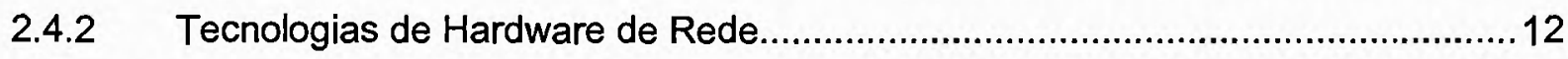

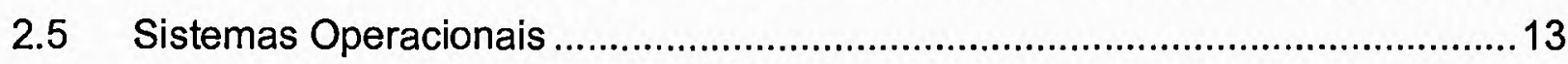

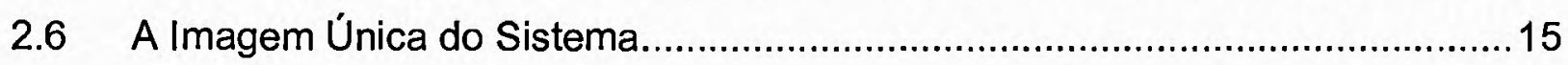

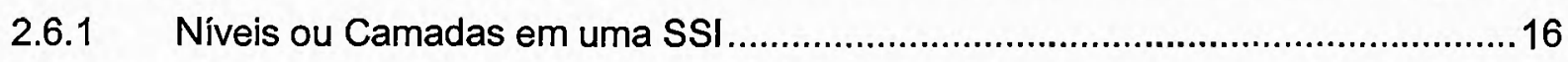

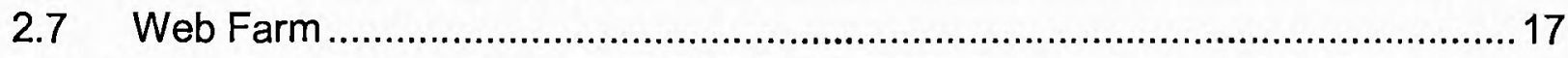

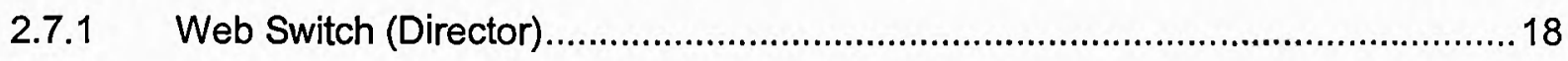

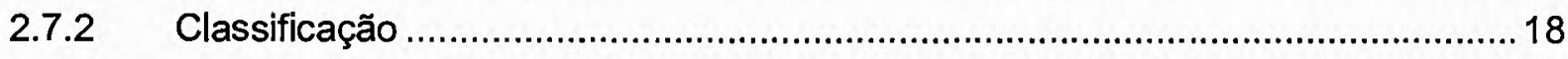

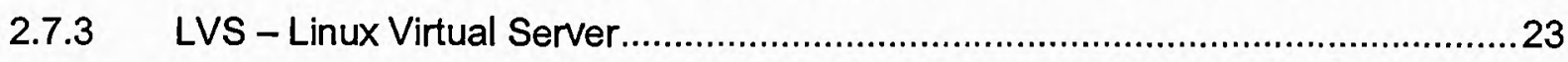

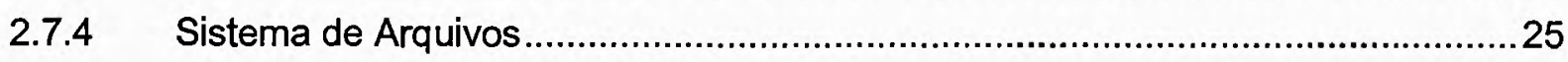

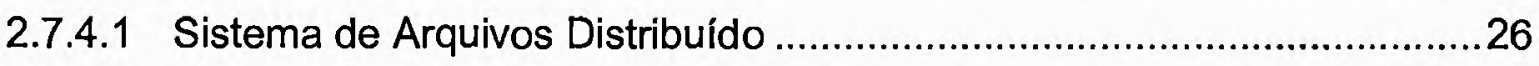

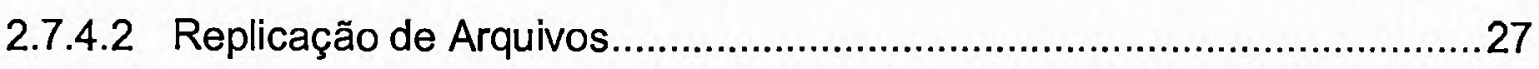

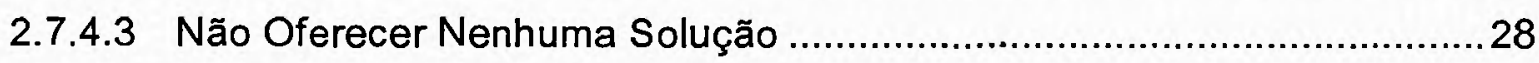

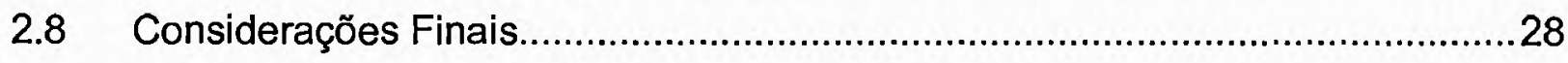

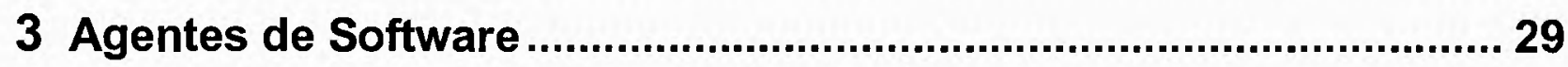

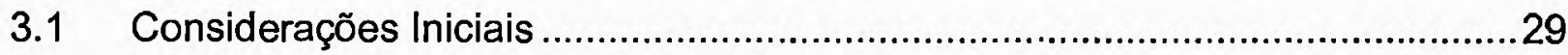




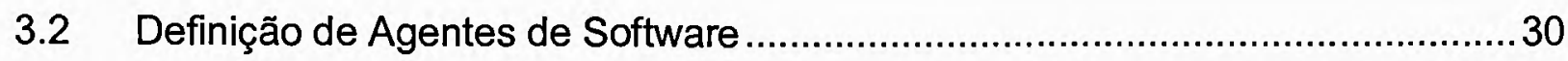

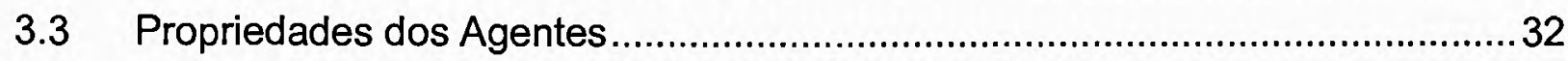

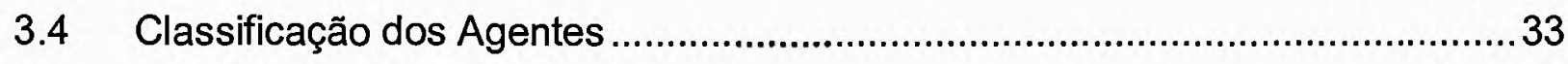

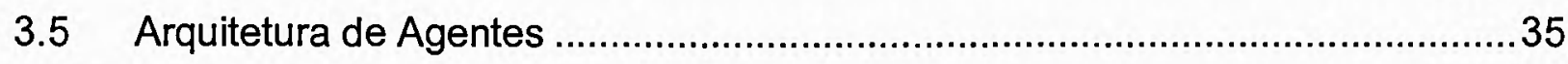

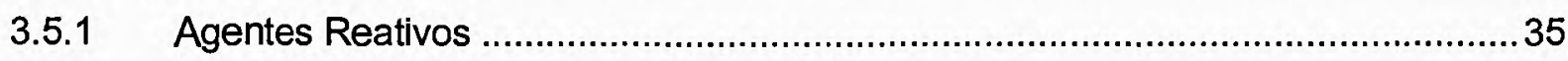

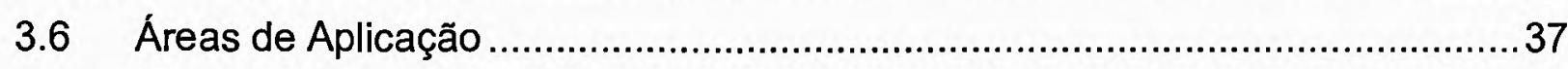

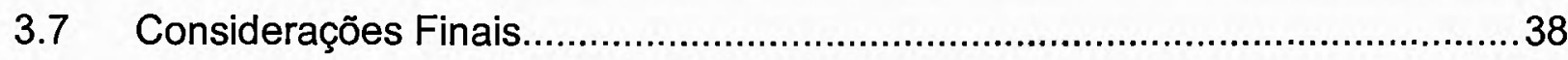

4 Sistemas de Computação Autônoma ............................................ 40

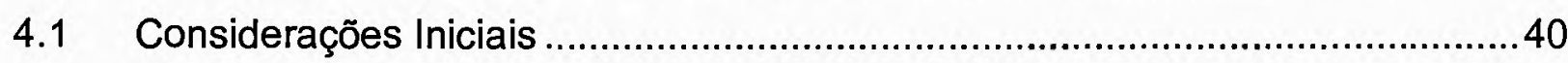

4.2 Origem da Computação Autônoma.................................................................40

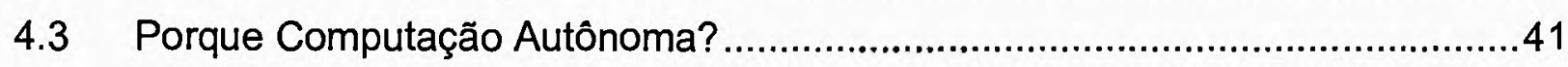

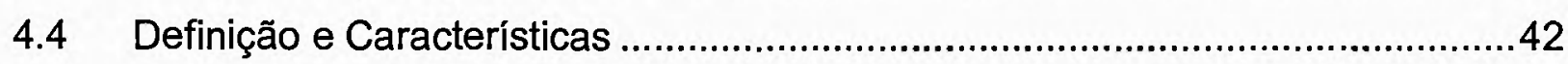

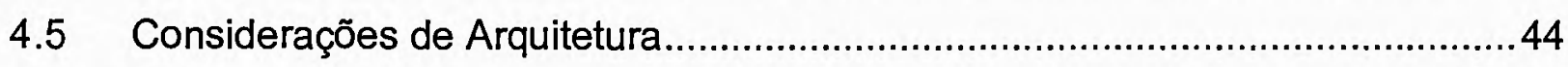

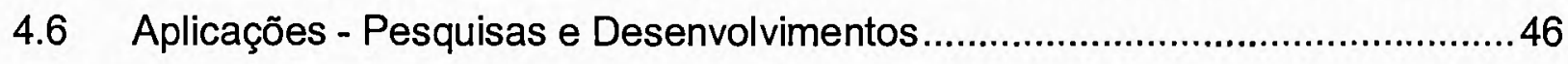

4.6.1 Computação Autônoma aplicada a Cluster de Computadores...............................49

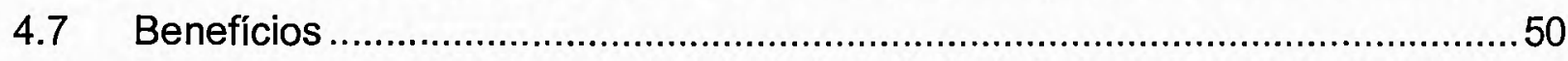

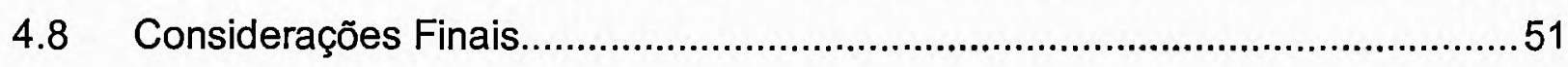

5 Cluster do Intermidia.................................................................... 53

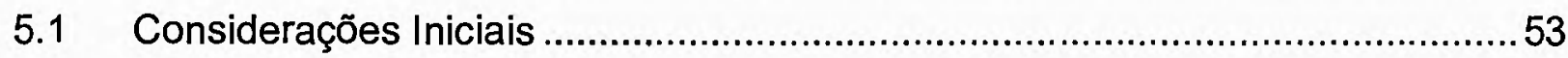

5.2 Arquitetura do Cluster do Laboratôrio Intermídia ..............................................54

5.3 Infra-estrutura de hardware do Web Farm Cluster............................................55

5.4 Infra-estrutura de Software do WFC do Laboratôrio Intermídia ..........................58

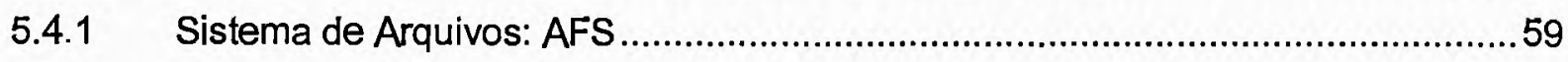

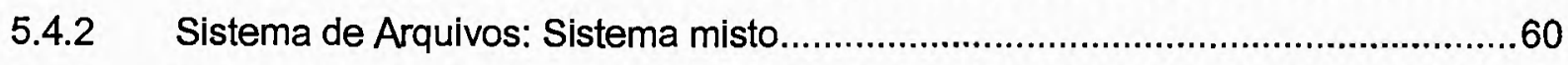

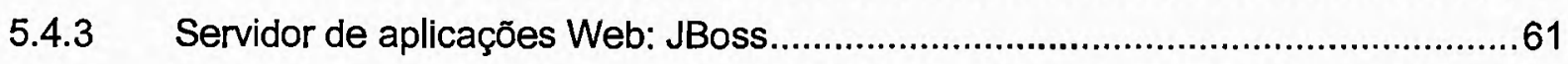

5.4.4 Base de Dados: Servidor MySQL Redundante ...............................................61

5.5 Testes de Escalabilidade e Performance ........................................................63

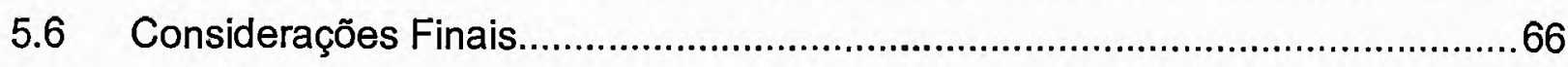

6 iCluster - Sistema de Gerenciamento de Web Farm Cluster ............ 67

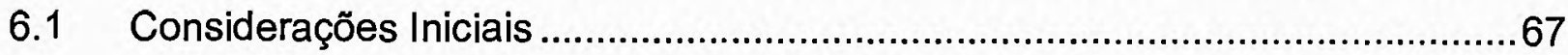

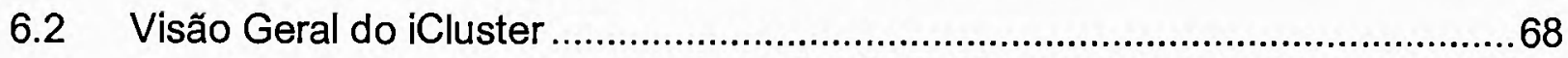

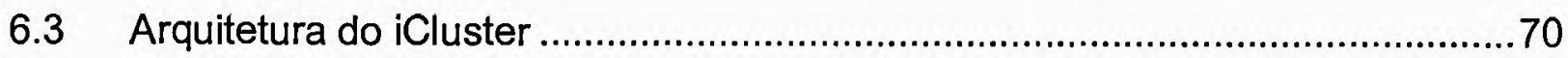

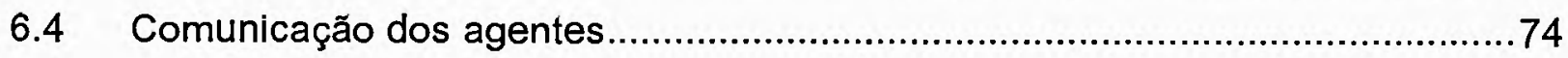

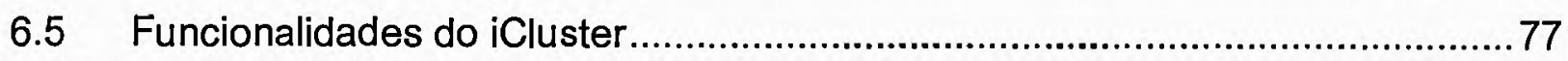

6.5.1 Visualização dos Estados das Variáveis do WFC ................................................78

6.6 Controle das variáveis pelo Administrador do iCluster........................................84 


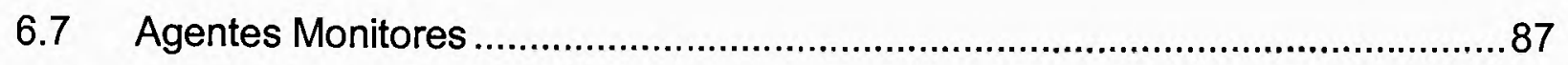

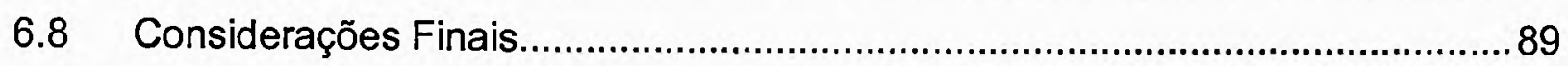

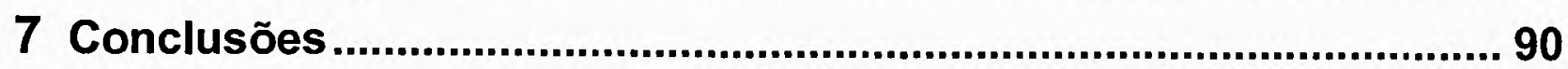

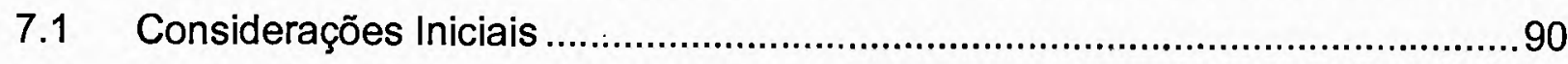

7.2 Resultados e Contribuições ................................................................91

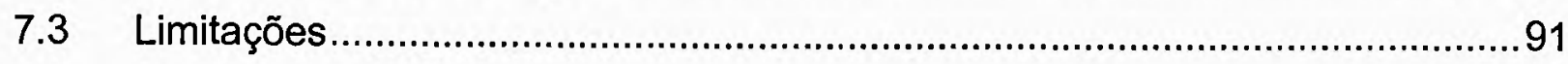

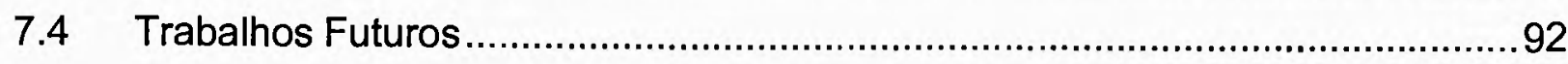

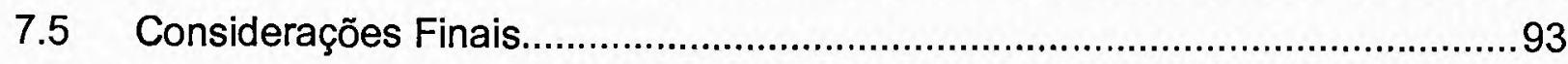

Referências Bibliográficas............................................................... 94

Apêndice A- Descrição dos Agentes Monitores................................. 102

A.1 Services Monitor Agent ........................................................................ 102

A.2 Nodes Monitor Agent................................................................................ 103

A.3 Fans Monitor Agent ........................................................................... 103

A.4 Hard Disk Monitor Agent ....................................................................... 103

A.5 Memory Monitor Agent ....................................................................... 103

A.6 Temperatures Monitor Agent................................................................. 104

A.7 Voltages Monitor Agent ........................................................................... 104

Apêndice B - Diagrama de Ciasses UML. ......................................... 105 


\section{Lista de Figuras}

Figura 2.1 - Arquitetura de um cluster de computadores (BUYYA, 1999) ................................. 8

Figura 2.2 - Arquitetura típica de um Web Farm Cluster (CARDELLINI et al., 2002) ................ 17

Figura 2.3 - Arquitetura NAT (CARDELLINI et al., 2002)........................................................ 19

Figura 2.4 - Arquitetura Reescrita de Pacote (CARDELLINI et al., 2002).................................. 20

Figura 2.5 - Arquitetura IP Tunneling (CARDELLINI et al., 2002) .......................................... 21

Figura 2.6 - Arquitetura Roteamento Direto (CARDELLINI et al., 2002) .................................. 22

Figura 2.7 - Visão da arquitetura de um LVS (Adaptado de (ZHANG, 2000)) ........................... 24

Figura 3.1 - Agentes Reativos Simples (LUCENA, 2003) ...................................................... 36

Figura 4.1 - Estrutura de um elemento autónomo e suas interações (KEPHART; CHESS, 2003) . 45

Figura 5.1 - Arquitetura física do Cluster do Laboratório Intermídia.............................................. 54

Figura 5.2 - Estante com as máquinas do cluster................................................................... 57

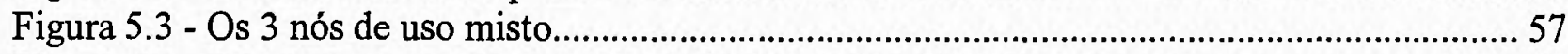

Figura 5.4 - Princípio de funcionamento do C-JDBC (CECCHET et al., 2004) ............................. 63

Figura 5.5 - Tela do JMeter mostrando os gráficos do teste 3 com 3 nós ..................................... 65

Figura 6.1 - Modelo em camadas dos agentes do iCluster .......................................................... 71

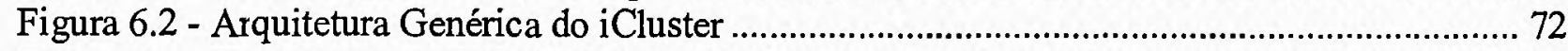

Figura 6.3 - Arquitetura em níveis do iCluster ........................................................................ 74

Figura 6.4 - Estrutura das mensagens utilizadas para a comunicação entre os agentes no

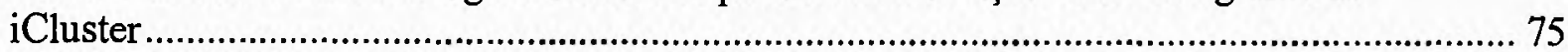

Figura 6.5 - Diagrama de casos de uso dos atores do iCluster ................................................. 77

Figura 6.6 - Página principal de acesso ao iCluster .................................................................. 78

Figura 6.7 - Visualização da rotação das ventoinhas.................................................................... 79

Figura 6.8 - Visualização da utilização dos discos rígidos ........................................................... 79

Figura 6.9 - Processo de visualização dos estados das variáveis monitoradas ................................. 80

Figura 6.10 - Processo de visualização dos serviços monitorados ............................................. 81

Figura 6.11 - Visualização e controle dos serviços monitorados................................................ 82

Figura 6.12 - Processo de visualização dos nós monitorados ...................................................... 83

Figura 6.13 - Processo de visualização da lista de serviços para distribuição de requisições do

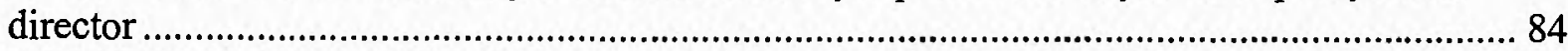

Figura 6.14 - Visualização da lista de serviços para distribuição de requisições do director........... 84

Figura 6.15 - Processo de ađição ou remoção de serviços monitorados pelos SMAgs ................... 85

Figura 6.16 - Processo de adição ou remoção de serviços da lista de serviços para distribuição de

requisições do director ................................................................................................... 86

Figura 6.17 - Página de adição e remoção de serviços da lista de serviços para distribuição de

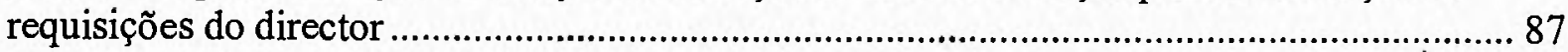

Figura A.1 - Interação do SMAg e NMAg com o ManAg dos directors ..................................... 102

Figura B.1 - Diagrama de classes UML do ManagerAgent ....................................................... 105

Figura B.2 - Diagrama de classes UML do MailAgent........................................................... 106

Figura B.3 - Diagrama de classes UML do FanMonitorAgent .................................................. 106

Figura B.4 - Diagrama de classes UML do HardDiskMonitorAgent ....................................... 107

Figura B.5 - Diagrama de classes UML do MemoryMonitorAgent ........................................... 108

Figura B.6 - Diagrama de classes UML do NodesMonitorAgent ......................................... 108

Figura B.7 - Diagrama de classes UML do ServicesMonitorAgent .......................................... 109

Figura B.8 - Diagrama de classes UML do TemperatureMonitorAgent....................................... 110

Figura B.9 - Diagrama de classes UML do VoltageMonitorAgent ........................................... 111 


\section{Lista de Tabelas}

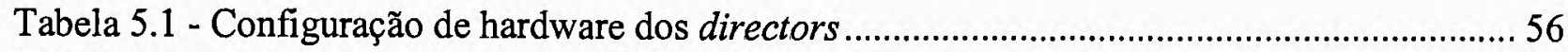

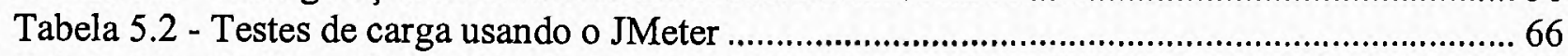

Tabela 6.1 - Performativas utilizadas na comunicação entre os agentes do iCluster ....................... 75

Tabela 6.2 - Subjects para a performativa Request ........................................................................ 76

Tabela 6.3 - Subjects para a performativa Propagate ................................................................ 76

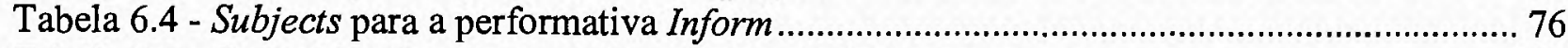

Tabela 6.5 - Conteúdos focalizados pelos agentes do iCluster .................................................... 77

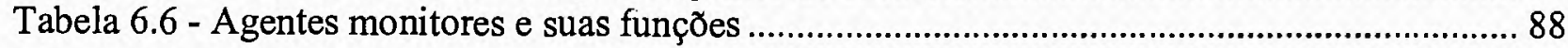




\section{Introdução}

\subsection{Contextualização}

O crescimento no uso da Internet para desenvolvimento e disponibilização de diversos tipos de serviços e aplicações, tais como comércio eletrônico, consultas bancárias, ensino à distância, reuniões virtuais, diagnósticos médicos etc, faz surgir a necessidade de máquinas (servidores) mais rápidas que forneçam alta disponibilidade desses serviços e aplicações. Atualmente uma maneira bastante utilizada para hospedar esses tipos de serviços e aplicações é a utilização de clusters de computadores.

Um cluster de computadores, basicamente, é um sistema que compreende dois ou mais computadores que trabalham em conjunto para executar aplicações ou realizar outras tarefas como se fossem um computador único (BUYYA, 1999). Um cluster é capaz de oferecer alta performance para suas aplicações porque as requisições e processos são distribuídos entre seus nós. Além disso, ele pode oferecer alta disponibilidade de serviços e aplicações pelo uso de máquinas tolerantes à falhas ou pela replicação de dados e serviços entre seus vários nós.

Apesar de um cluster de computadores poder oferecer alta performance simplesmente distribuindo requisições ou processos entre os vários nós que o compõe, a alta disponibilidade de serviços e aplicações pode não ser garantida, devido a falhas que podem ocorrer no software que provê os serviços e nos componentes físicos dos computadores (ventoinhas, disco rígido etc). Por essa razão, é necessária uma forma de monitoramento e controle dos estados das variáveis ou recursos que compõem cada nó de um cluster (serviços, temperatura dos processadores, rotação das ventoinhas, discos rígidos etc) para garantir que os serviços e aplicações existentes nesses clusters estejam sempre disponíveis.

Nesses casos, essa alta disponibilidade de serviços e aplicaçőes pode ser obtida por meio do desenvolvimento de sistemas utilizando um novo modelo de computação denominada computação autônoma. A utilização de um sistema baseado em computação autônoma permite o auto-gerenciamento de um cluster, reduzindo assim, a necessidade de intervenção humana. 
Uma tecnologia que pode ser utilizada para o desenvolvimento de um sistema autônomo é a de agentes de software. O uso de agentes de software, no desenvolvimento de aplicações em geral, tem sido visto como um novo paradigma de desenvolvimento que parte do princípio que programas autônomos e inteligentes devem ter a capacidade de alcançar objetivos determinados, tais como obter saldos bancários, marcar compromissos, gerenciar mensagens eletrônicas, pagar contas, buscar informações específicas, dentre outros (Lucena, 2003). Logo, torna-se vantajosa a aplicação de agentes de software no desenvolvimento de um sistema autônomo.

Este trabalho apresenta a implementação de um Web Farm Cluster (WFC) - um cluster que hospeda servidores web (CARDELLINI et al., 2001) - e o desenvolvimento do sistema iCluster - um sistema que realiza o monitoramento e controle dos principais serviços e variáveis de um WFC no intuito de manter os serviços do WFC sempre disponíveis. O iCluster foi desenvolvido utilizando-se os conceitos de computação autonômica e a tecnologia de agentes de software.

\subsection{Trabalhos Relacionados}

Diversos projetos têm sido desenvolvidos no sentido de monitorar os vários recursos existentes em redes de computadores e alguns em clusters.

Monit (HAUKELAND et al., 2004) é um software que faz o monitoramento e gerenciamento de processos, arquivos, diretórios e equipamentos em sistemas Unix. Ele realiza reparos e manutenções automáticas como, por exemplo, a reinicialização de um processo parado ou a interrupção de um processo por exceder a quantidade de recursos utilizados. O Monit pode, ainda, monitorar o funcionamento de hosts remotos e enviar mensagens de alerta quando encontra alguma condição de erro em qualquer elemento monitorado. $\mathrm{O}$ acesso e controle do sistema podem ser via console ou via web.

A VA Cluster Manager é uma ferramenta que disponibiliza ao administrador várias opções de gerenciamento, tanto do hardware local quanto remoto, tais como: ligar, desligar e reiniciar um computador; recuperar inventário de hardware (como: fabricante, nome do produto, número serial etc); listar falhas de hardware; recuperar informações de temperatura de processador, rotação de ventoinha e voltagem de componentes (MEHAT et al., 2000). Como pode ser visto, essa ferramenta disponibiliza várias funcionalidades, mas essas funcionalidades têm de ser manipuladas pelo administrador do sistema. 
Nagios (GALSTAD, 2002) é um programa que realiza o monitoramento de hosts, recursos de hosts e serviços e, além disso, envia mensagens de alerta de diferentes maneiras (email, mensagens instantâneas, SMS etc) relatando os problemas ocorridos em uma rede de computadores. Para adição de hosts e serviços a serem monitorados pelo Nagios, é necessário adicionar plugins externos. O Nagios disponibiliza visualização das suas informações pela web.

Mon (TROCK, 2004) é uma ferramenta utilizada para o monitoramento de serviços e recursos, e envio de alertas. Ele envia mensagens de alerta quando detecta a parada de algum serviço ou quando um serviço volta a operar. Ela disponibiliza acesso ao sistema via console e $w e b$. Uma característica interessante desta ferramenta é a utilização de uma correlação de dependências entre os elementos monitorados. Por exemplo, quando um serviço A, cujo funcionamento depende do serviço $\mathrm{B}$, pára de funcionar devido à parada do serviço $\mathrm{B}$, $\mathrm{a}$ mensagem de alerta é enviada somente com referência ao serviço B. Um aspecto negativo desta ferramenta é com relação à adição de serviços para monitoramento. Para que um serviço seja monitorado é necessário implementar um monitor específico para esse serviço em linguagem Perl. Isso se torna um inconveniente para pessoas que não possuam conhecimentos nessa linguagem, pois terão que aprendê-la, para só então, implementar um monitor.

Keepalived (CASSEN, 2002) é um software, em fase de testes, que faz o monitoramento dos nós de um cluster para fazer o controle da lista de distribuição de requisições do LVS (Linux Virtual Server). Esse programa é instalado no director do LVS. O monitoramento dos nós é feito por módulos que checam conexões TCP, HTTP e SSL. Se um nó do cluster nã̃o estiver respondendo a uma dessas conexões, então, esse nó é retirado da lista de distribuição de requisições do LVS. Ele permite, ainda, a redundância de directors, isto é, realiza o monitoramento de um segundo director para que, quando o primeiro director sair de operação, este segundo director possa substituí-lo.

Existem outros programas que tratam do monitoramento de serviços em redes de computadores, sendo que a maioria deles apresenta funcionalidades semelhantes. No entanto, a maioria desses programas não realiza um controle de consistência de serviços e nós da lista de serviços do director. A ausência desse controle pode ocasionar a falha no atendimento a uma requisição, pois essa requisição pode ser enviada a um nó desativado do cluster ou a um nó cujo serviço esteja fora de operação. 
Os sistemas que mais se assemelham ao iCluster são o Keepalived e o Mon. A diferença fundamental é que o Keepalived, que é utilizado em clusters de computadores, realiza somente o monitoramento de hosts para fazer o controle da lista de serviços do director, enquanto que o iCluster faz o monitoramento tanto dos hosts quanto de cada serviço individualmente, além de monitorar o estado do hardware de cada máquina (como temperatura, rotação das ventoinhas etc). No caso do Mon, ele também realiza o monitoramento de hosts e serviços, mas para fazer o controle da lista de serviços do director, é necessário implementar um pequeno programa em Perl. No iCluster, para realizar o monitoramento de hosts e serviços, basta colocar o nome (ou endereço IP) dos nós e o nome dos serviços, respectivamente, em dois arquivos (nodes.cluster e services.cluster). O Mon também não monitora o estado do hardware de cada nó.

Mais importante é o fato de nenhum dos sistemas pesquisados usar a idéia de computação autónoma, ou seja, eles não tentam produzir sistemas menos dependentes da intervenção humana e, por isso, mais fáceis de usar e mais baratos de operar.

\subsection{Motivação}

Apesar dos clusters de computadores oferecerem alto poder de processamento, as máquinas que constituem os nós de um cluster, principalmente máquinas desktop, estão sujeitas a diversos tipos de falhas, tais como: falhas nos componentes, como cooler, ventoinha etc; falhas operacionais de serviços; falha de sobrecarga, dentre outras. Estas falhas podem degradar a performance do cluster, principalmente em clusters com alto fluxo de requisições, além de poderem, até mesmo, causar a indisponibilização de alguns de seus serviços.

A principal motivação para a realização deste trabalho residiu no fato de que a maioria dos programas existentes para monitoramento de serviços e recursos de um WFC não fazem uso da idéia de computação autônoma e, por isso, não tentam implementar soluções menos dependentes da intervenção humana. Como uma grande parte do Total Cost of Ownership (TCO) de sistemas complexos (como clusters) é atualmente composta de custos relacionados ao gerenciamento e manutenção desses sistemas, a construção de sistemas mais autỏnomos é uma necessidade urgente para que esse TCO não torne a disseminação de clusters de computadores baratos impossível. 


\subsection{Objetivos}

O objetivo geral do projeto descrito nesta dissertação é a implementação de um Web Farm Cluster (WFC) e o desenvolvimento de um sistema, o iCluster, que controle e monitore os principais serviços e estados das variáveis desse cluster, aplicando conceitos de computação autônoma.

A implementação do Web Farm Cluster consiste, basicamente, na definição de uma arquitetura, um balanceador de carga, um sistema de arquivos e uma solução para manter a alta disponibilidade dos serviços.

O controle que o sistema iCluster realiza está relacionado com a manutenção da consistência dos serviços e dos nós existentes no cluster. Para isso, várias variáveis são monitoradas pelo sistema, por exemplo: rotação das ventoinhas, temperatura dos processadores, voltagem dos componentes da placa mãe, espaços em discos rígidos, memória etc.

O sistema tem ainda alguns objetivos secundários:

- montagem de um WMF para o Laboratório Intermídia (ICMC-USP), tanto para uso e teste desse projeto como para uso de outros projetos de pesquisa e ensino do laboratório;

- implementação de uma interface web para que administradores ou usuários possam verificar o estado dos nós de um WFC;

- implementação de uma interface web para que administradores possam modificar parâmetros de funcionamento de um WFC a distância.

\subsection{Estrutura da Dissertação}

Iniciando a descrição deste trabalho, no Capítulo 2 são apresentados os conceitos, arquiteturas e tecnologias relacionadas a clusters de computadores. No Capitulo 3 são descritos, de maneira sucinta, os principais conceitos sobre Agentes de Software, suas características e algumas áreas de aplicação. No Capítulo 4 são introduzidos conceitos, características e aplicações da computação autônoma. No Capítulo 5 é descrito o Web Farm Cluster (WFC) implementado no Laboratório Intermídia (ICMC-USP). No Capítulo 6 é apresentado o iCluster - nome dado ao sistema de gerenciamento de clusters desenvolvido no contexto deste trabalho - destacando-se sua arquitetura, a comunicação entre os agentes que o compõe e as suas principais funcionalidades. Finalmente, no Capítulo 7 são apresentadas as conclusões 
deste trabalho, considerando as dificuldades encontradas e as suas contribuições, bem como algumas idéias para continuação e extensão deste trabalho. 


\section{Clusters de Computadores}

\subsection{Considerações Iniciais}

Atualmente a Internet tem sido considerada como um poderoso meio de distribuição de informação. De modo especial, a web se destaca dentre os serviços disponíveis na Internet por atrair um grande número de usuários dispersos por todo o mundo, além de ser um meio de baixo custo tanto para a produção quanto para o acesso à informação. A popularização da Internet, em conjunto com o crescente interesse pelo uso de computadores pessoais, tem proporcionado o crescimento da população de usuários da Internet. Tal crescimento, frequentemente ocasiona congestionamentos de acesso a web sites. Uma solução natural para aumentar a capacidade de servidores $w e b$ e diminuir esse tipo de congestionamento é a utilização de clusters de computadores para serviços web.

A idéia inicial dos clusters de computadores foi desenvolvida na década de 60 pela IBM como uma alternativa para ligar mainframes e oferecer uma forma efetiva de paralelismo (BUYYA, 1999). Porém, a idéia de cluster de computadores ganhou maior notoriedade quando a Digital Equipment Corporation (DEC) lançou o VAXclusters formado por seus minicomputadores VAX que compartilhavam um fluxo de trabalho comum (LAMB, 2002). O VAXcluster parecia um único computador para os usuários, desenvolvedores e administradores do sistema. Desde então, os clusters de computadores vêm ganhando popularidade, sobretudo em projetos académicos. Entre os tipos de cluster pode-se citar o Beowulfi (BECKER, 2003), Berkeley NOW (CULLER et al., 1997), HPVM (CHIEN; PADUA, 2003; CHIEN et al., 1997) e Web-Farm ou Web Cluster (WOLF; YU, 2001; ANDREOLINI et al., 2004).

O surgimento dos clusters de computadores de baixo custo, que utilizam equipamentos de menor custo, como os computadores pessoais, tem ocasionado um declínio no uso dos supercomputadores paralelos. Isto se deve, em grande parte, a algumas vantagens que esses clusters de computadores oferecem, tais como: baixo custo na obtenção de alta performance, habilidade de incorporar novas tecnologias, escalabilidade, plataforma de desenvolvimento de código aberto e independência de um fornecedor em particular (BUYYA, 1999). 
Para um melhor entendimento sobre clusters de computadores, neste capítulo são abordados alguns conceitos sobre esta tecnologia. A Seção 2.2 apresenta a definição e a arquitetura de um cluster. A Seção 2.3 apresenta algumas classificações de cluster de computadores. A Seção 2.4 descreve as tecnologias para sua interconexão. A Seção 2.5 apresenta algumas características desejáveis em um sistema operacional para clusters. A Seção 2.6 apresenta alguns serviços que podem ser implementados em um cluster, de modo a fornecer uma imagem única do sistema. A Seção 2.7 discorre sobre um tipo de cluster bastante utilizado atualmente, o Web Farm. E, finalizando, a Seção 2.8 aponta algumas considerações finais deste capítulo.

\subsection{Definição e Arquitetura}

Um cluster de computadores, conhecido também como rede de estações de trabalho (NOW) ou cluster de estações de trabalho (COW) (BUYYA, 1999 p.7), é definido como um tipo de sistema de computação distribuído ou paralelo formado por um grupo de máquinas (nós) e sistemas de software independentes e interconectados (incluindo equipamentos montados em rede de alta velocidade, sistema operacional e bibliotecas de comunicação) que trabalham juntos para prover serviços aos usuários de forma transparente (BUYYA, 1999 p.9; CARDELLINI; COLAJANNI; YU, 2002). Cada nó de um cluster pode ter um ou mais processadores, memória própria, equipamentos de entrada/saída (I/O) e sistema operacional.

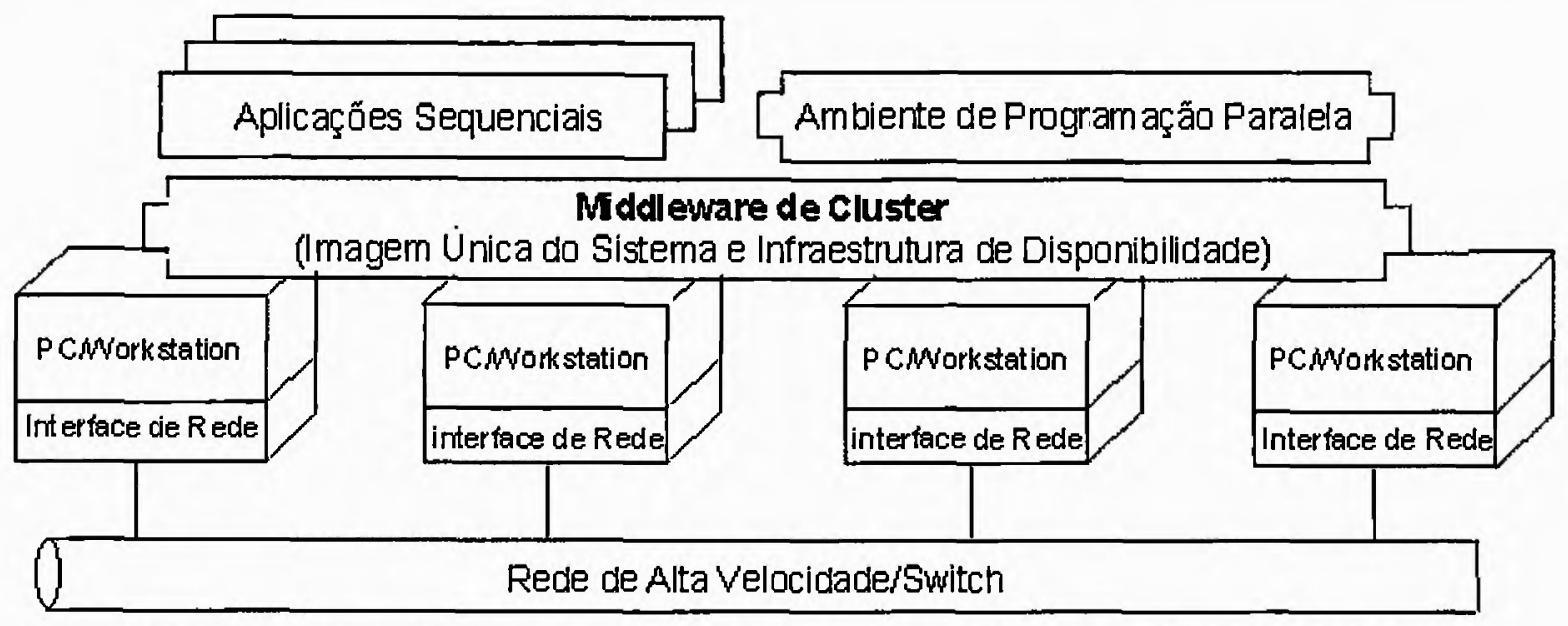

Figura 2.1 - Arquitetura de um cluster de computadores (Adaptado de (BUYYA, 1999)) 
A arquitetura típica de um cluster de computadores, como apresentado na Figura 2.1, tem os seguintes componentes (BAKER et al., 2001):

- Vários computadores de alta performance: podem ser computadores pessoais (PCs), estações de trabalho (workstations) ou computadores com multiprocessadores simétricos (SMPs).

- Sistemas Operacionais: podem ser baseados em camadas ou em micro-kernel.

- Switchs e redes de alta performance, tais como Ethernet, Gigabit Ethernet ou Myrinet.

- Cluster Middleware: este componente da arquitetura é caracterizado pelo fornecimento de uma imagem única do sistema (SSI - Single System Image), que será discutida na Seção 2.6, e pela infra-estrutura de disponibilização do sistema.

- Ferramentas e ambientes de programação paralela, tais como servidores de aplicações, compiladores, bibliotecas como PVM (Parallel Virtual Machine) e MPI (Message Passing Interface) etc.

- Aplicações: podem ser sequenciais, paralelas ou distribuídas.

A interface de rede age como um processador de comunicação e é responsável pela transmissão e recebimento de pacotes de dados entre os nós do cluster. Os nós do cluster podem trabalhar conjuntamente, como um recurso único e integrado, ou podem operar individualmente para processar determinadas requisições ou processos. O cluster middleware é responsável por oferecer a ilusão de uma imagem única do sistema. $O$ ambiente de programação pode oferecer a portabilidade, a eficiência e a facilidade de uso de ferramentas para o desenvolvimento de aplicaçốes (BUYYA, 1999).

\subsection{Classificação}

Como visto na arquitetura apresentada na seção anterior, um cluster de computadores nada mais é que uma rede de computadores com alguns programas específicos para criar uma imagem única dessa rede e fornecer serviços aos usuários. Dependendo da função que será exercida pelo cluster, diferentes tipos de programas podem ser utilizados. As funções que um cluster pode exercer são as seguintes (BUYYA, 1999; FOX et al., 1997; BUYYA; PAPRZYCKI, 1999; VAIDYA; CHRISTENSEN, 2001; BAKER, 2000): 
- Alta disponibilidade de dados e serviços: esta função é oferecida pelo cluster por meio da utilização de várias máquinas para a realização de serviços de modo que, se alguma máquina falhar, uma outra pode substituí-la de forma transparente.

- Alta performance: esta função é oferecida pelo cluster por meio da disponibilidade de redes ou dispositivos de rede e processadores de alta-performance.

- Balanceamento de carga: envolve a divisão da tarefa que um servidor tem que realizar entre dois ou mais computadores, fazendo com que a tarefa seja executada mais rapidamente.

- Processamento paralelo: para muitas aplicações, instruções de programas podem ser divididas entre múltiplos processadores, fazendo com que o tempo de execução total do programa seja reduzido.

- Escalabilidade: envolve a capacidade de proporcionar maior performance quando se adicionam novos componentes (à medida que as necessidades computacionais aumentam).

Um cluster de computadores pode alcançar poder de processamento semelhante ao dos supercomputadores modernos, porém, com custos bastante reduzidos. Esse baixo custo e alto poder de processamento têm levado os pesquisadores a aplicarem a tecnologia de clusters em diversas áreas.

Clusters de computadores podem ainda ser classificados levando-se em consideração fatores como (BUYYA, 1999):

- Fins de aplicação: cluster de computadores podem ser utilizados para aplicações convencionais ou de missão-crítica (dois tipos: os clusters de alta performance e os clusters de alta disponibilidade).

- Propriedade dos nós: um cluster pode ser dedicado ou não. Clusters dedicados são aqueles cujos nós e recursos são dedicados somente à execução de processos, enquanto que clusters não dedicados possuem nós que podem ser utilizados como estações de trabalho.

- Sistema operacional dos nós: um cluster pode ser identificado de acordo com o sistema operacional utilizado. Como exemplo, tem-se: Linux Clusters (ex: Beowulf), 
Solaris Clusters (ex: Berkeley NOW), NT Clusters (HPVM) e AIX Clusters (IBM SP2).

- Configuração dos nós: um cluster pode ser identificado de acordo com a arquitetura do nó, podendo ser um cluster homogêneo, quando todos os seus nós têm a mesma arquitetura e rodam o mesmo sistema operacional; ou um cluster heterogéneo, quando seus nós têm arquiteturas diferentes e rodam sistemas operacionais diferentes.

Um dos pontos importantes na construção de um cluster é a escolha da tecnologia de interconexão, tratada na próxima seção.

\subsection{Tecnologias de Interconexão}

Como visto na Seção 2.2, um cluster de computadores envolve um grupo de máquinas e sistemas de software independentes e interconectados. Desse modo, para que um cluster ofereça o desempenho desejado, é importante considerar alguns aspectos relacionados às tecnologias de interconexão ou tecnologias de rede.

\subsubsection{Protocolos de Comunicação}

O protocolo TCP/IP (Transfer Control Protocol/Internet Protocol) foi o primeiro protocolo a ser utilizado em clusters de computadores. Apesar de ainda ser bastante utilizado, devido, principalmente, à facilidade de uso e à tradicional utilização em redes de computadores (APON; BAKER, 2001; BUYYA, 1999), o protocolo TCP/IP tem sua performance prejudicada pelo tipo de implementação de seu processo de envio de mensagens. No TCP/IP, primeiro a mensagem é construída no espaço de memória da aplicação, depois transferida para a memória do sistema (pelo sistema operacional) e, só então, enviada para a rede. Essa necessidade de intervenção do sistema operacional ocasiona um custo adicional de processamento e armazenamento, gerando um tempo maior no envio das mensagens (APON; BAKER, 2001).

No sentido de anular essa intervenção do sistema operacional e diminuir a latência das mensagens, alguns protocolos foram desenvolvidos, dentre os quais estão: Active Messages, Fast Messages, U-Net, entre outros (APON; BAKER, 2001).

O Active Messages, desenvolvido pela Berkeley Network of Workstation, é baseado no conceito de um protocolo de requisição-resposta, isto é, para a transferência de um dado, o processo receptor aloca um buffer na memória de usuário e envia uma requisição ao emissor. 
O processo emissor responde copiando a mensagem do seu buffer diretamente para a rede. Então, a mensagem é transferida da rede para o buffer do receptor. Esse processo dispensa a intervenção do sistema operacional (EICKEN et al., 1992).

O Fast Messages, desenvolvido na Universidade de Illinois, é similar ao Active Messages. Uma das diferenças é que o Fast Messages utiliza um fluxo de controle para garantir a chegada ordenada das mensagens, evitando, assim, que emissores rápidos não sobreponham mensagens em um receptor mais lento (PAKIN; LAURIA; CHIEN, 1995).

O U-net, desenvolvido na Universidade de Cornell, também é semelhante ao Active Messages. A diferença é que ele adota uma interface virtual de rede para cada conexão de uma aplicação de usuário, evitando a intervenção do sistema operacional (BASU et al.,1995).

As pesquisas em protocolos de baixa latência tiveram progressos consideráveis a ponto de pesquisadores desenvolverem padrões. O VIA (Virtual Interface Architecture) e o InfiniBand são exemplos de padrões que combinam algumas das melhores características dos protocolos de baixa latência (APON; BAKER, 2001).

O VIA é baseado no conceito de interface virtual de rede podendo ser implementado de duas formas, nativo ou emulado. A implementação nativa transfere parte do processamento de envio e recebimento das mensagens para um hardware especial que fica na interface de rede. Já na implementação emulada, o processamento é feito no processador local da máquina (DUNNING et al., 1998).

O InfiniBand suporta acesso direto à memória remota, permitindo que um processador leia ou escreva conteúdos de memória de outro processador. O envio de pacotes suporta seis tipos de métodos de transferência, que são: conexão confiável e não confiável; datagrama confiável e não confiável; conexão multicast; e pacotes brutos (JIN; CORTES; BUYYA, 2001).

\subsubsection{Tecnologias de Hardware de Rede}

As tecnologias de hardware estão geralmente ligadas à camada física ou camada de enlace, para a construção de clusters. Neste aspecto, podem-se citar as seguintes tecnologias: Fast Ethernet, Gigabit Ethernet, Giganet, Myrinet, SCI (Scalable Coherent Interface), HIPPI (High Performance Parallel Interface), ATOLL (Atomic Low Latency), entre outros (BUYYA, 1999; APON; BAKER, 2001). 
A tecnologia Ethernet (com taxa de transmissão de 10Mbps), até há pouco tempo atrás, era bastante utilizada em redes locais, mas atualmente, com o desenvolvimento de computadores mais rápidos, a sua taxa de transmissão tornou-se insuficiente. Foi desenvolvido então a FastEthernet e a Gigabit Ethernet com taxas de 100Mbps e 1Gbps respectivamente. A vantagem destas tecnologias em relação às outras é seu custo relativamente baixo (porém elas não suportam padrões como o VIA nativo).

A Giganet foi desenvolvida com o objetivo de suportar VIA nativo. Ela tem suporte a adaptadores PCI e opera a uma taxa de transmissão de 1,25Gbps.

A Myrinet opera a uma taxa de $1,28 \mathrm{Gbps}$ e possui um processador onboard programável que permite sua adequação aos protocolos de comunicação.

A SCI foi a primeira tecnologia desenvolvida como padrão para aplicação em cluster de computadores. A sua taxa de transmissão está entre 400 e $1000 \mathrm{Mbytes} / \mathrm{s}$.

A HIPPI foi primeiramente desenvolvida, na década de 80 , para interligar computadores paralelos de alta performance. Atualmente é conhecida com GSN (Gigabit System Network) e opera a uma taxa de 6400Mbps.

A ATOLL é uma das mais novas tecnologias para cluster de computadores e a sua taxa de transmissão é de aproximadamente 200Mbytes/s.

A escolha da tecnologia de interconexão para clusters depende de alguns fatores, como compatibilidade com o hardware e sistema operacional do cluster, preço e performance.

Além das tecnologias de interconexão, o desempenho de uma aplicação é influenciado também pelo sistema operacional usado. Ou seja, para que um cluster tenha bom funcionamento e a performance desejável, é preciso que o sistema operacional ofereça suporte adequado.

\subsection{Sistemas Operacionais}

Para que um cluster de computadores funcione adequadamente e com a performance desejável ao propósito a que se destina, é necessário que seus nós rodem sobre um sistema operacional adequado que possua, no mínimo, suporte à multitarefa, multithreading, rede e ao 
multiprocessamento simétrico (é comum que os nós de um cluster possuam mais de um processador).

Sendo assim, um sistema operacional adequado para clusters terá que possuir características como (BAKER et al., 2001):

- Gerenciabilidade - envolve a facilidade na administração do sistema, tanto local quanto remoto.

- Estabilidade - é a característica mais importante e refere-se à robustez, ou seja, a capacidade do sistema manter-se em funcionamento sob quaisquer condições.

- Performance - está relacionada com o desempenho e a eficiência na execução de serviços, como gerenciamento de memória, de processos etc.

- Extensibilidade - refere-se à facilidade com que o sistema operacional integra extensões especificas para clusters, tais como programas adicionais, drivers etc.

- Escalabilidade - refere-se tanto à adição de nós no cluster quanto ao aumento do número de CPUs (Central Processing Unit) em cada nó. Logo, o sistema operacional deverá ser capaz de utilizar todo o potencial de performance da interconexão, assim como trabalhar com multiprocessamento simétrico.

- Suporte - envolve disponibilidades com relação a ferramentas, drivers de hardware e ambientes de middleware.

- Heterogeneidade - está relacionada com a capacidade do sistema operacional executar sobre diferentes tipos de arquiteturas. Em um cluster, novos nós podem ser adicionados (ou antigos substituídos) e nem sempre eles serão do mesmo tipo dos nós já existentes no cluster.

Atualmente, um sistema operacional bastante utilizado para cluster é o Linux (BAKER et al., 2001) porque, além das características apresentadas, esse sistema operacional possui ainda três outras:

- $\quad \dot{E}$ gratuito: pode-se escolher livremente entre as várias distribuições disponíveis.

- É de código aberto: o código fonte está disponível e pode-se adaptá-lo de acordo com as necessidade específicas de cada cluster. 
- É de fácil utilização: um grande número de usuários e desenvolvedores Linux criou várias ferramentas, assim como documentação e web sites que facilitam bastante o uso do sistema.

Além do Linux, há também os sistemas operacionais proprietários que geralmente são utilizados em clusters comerciais. Como exemplo, têm-se o AIX da IBM, o Solaris da Sun, o IRIX da SGI, Non Stop Unix e Unixware 7 da Tandem, Tru64 da Compaq e o Windows NT/2000 da Microsoft (BAKER et al., 2001).

Apesar de o sistema operacional possuir papel importante no suporte aos serviços de um cluster, é importante destacar que o conjunto de nós que formam um cluster deve se comportar como um sistema único do ponto de vista dos usuários. Essa transparência pode ser obtida por meio de ferramentas que disponibilizam uma imagem do sistema único (Single System Image - SSI).

\subsection{A Imagem de Sistema Único}

Uma característica muito importante em clusters de computadores é a capacidade de oferecer transparência de suas operações e da organização física do sistema. Essa transparência de um sistema único é conhecida como Imagem do Sistema Único.

Especificamente, SSI é uma propriedade que "esconde" a heterogeneidade e a natureza distribuída dos recursos disponíveis no cluster e os apresenta como se fossem um sistema de computação único (BAKER, 2000; BUYYA, 1999). A SSI pode ainda garantir que um sistema continue a funcionar mesmo que algum nó ou algum serviço de um nó falhe.

Os serviços que a SSI oferece, incluem (BUYYA, 1999; WALKER, 2001):

- Ponto único de entrada: o usuário pode se conectar ao cluster como um host virtual, isto é, embora o cluster possa ter vários nós servindo uma sessão de login, a conexão do usuário não é em apenas uma máquina. O sistema, transparentemente, distribui a requisição de conexão do usuário para diferentes nós, a fim de balancear a carga.

- Interface única do usuário: capacidade de oferecer uma única interface gráfica de usuário.

- Espaço único de processo: todos os processos, não importando onde eles se encontram, têm um único identificador de processo no cluster. 
- Espaço único de memória: capacidade de dar a ilusão de uma memória principal centralizada que, na realidade, pode ser um conjunto de memória distribuída.

- Espaço único de I/O: permite a qualquer nó realizar operações de I/O em discos e periféricos locais ou remotos.

- Hierarquia única de arquivos: permite ao usuário "enxergar" um sistema de arquivos único, isto é, o sistema transparentemente integra os vários discos locais dando ao usuário uma hierarquia única de arquivos e diretórios.

Os beneficios mais importantes que uma SSI pode oferecer são os seguintes (BUYYA, 1999; WALKER, 2001):

- Oferecer uma visão simples e direta de todas as atividades e recursos do sistema de qualquer nó do cluster.

- Liberar o usuário da tarefa de saber onde a aplicação é executada.

- Reduzir o risco de erro pelo operador do cluster.

- Permitir centralizar/descentralizar o controle e gerenciamento do sistema, anulando a necessidade de administradores especializados.

- Permitir o uso de recursos de forma transparente de localização.

- Permitir que o administrador gerencie todo o cluster como uma entidade simples.

\subsubsection{Niveis ou Camadas em uma SSI}

O suporte a uma SSI pode existir em níveis diferentes de um sistema, sendo que sua implementação pode ser em um ou mais dos seguintes níveis (BUYYA, 1999):

- Hardware: sistema de compartilhamento de memória distribuída.

- Sistema operacional: escalonamento de programas paralelos, identificando recursos ociosos no sistema (como processadores, memória, rede) e oferecendo acessos globalizados a eles.

- Middleware: sistema de arquivos para cluster e ambientes de programação.

- Aplicação: interface única do sistema para o usuário.

Uma boa SSI é geralmente obtida pela cooperação entre todos esses níveis (um nível inferior pode facilitar a implementação do nível superior). 


\subsection{Web Farm}

A performance em sistemas baseados na web tem sido motivo de preocupação por parte de corporações e grupos de pesquisadores devido à proliferação de equipamentos heterogêneos de acesso a web, à necessidade de autenticação em sistemas de segurança, ao aumento de conteúdos dinâmicos e criptografados, e ao aumento da complexidade de aplicações e middleware, que incorrem em uma carga computacional maior aos servidores web. Pesquisas recentes mostram que os servidores web contribuem com, aproximadamente, $40 \%$ do atraso em transações via web (CARDELLINI; COLAJANNI; YU, 2002).

Uma forma de amenizar o problema do tempo de resposta dos servidores web é utilizar Web Farm Clusters (WFC). Um WFC é uma coleção de máquinas, hospedadas em um único local, interconectadas através de uma rede de alta velocidade, que abrigam servidores web em cada máquina para tratar requisições de usuários de forma transparente, apresentando uma imagem única do sistema (podem abrigar um ou mais web sites) (CASALICCHIO; CARDELLINI; COLAJANNI, 2002; CARDELLINI et al., 2001; ARON et al., 2000; ANDREOLINI et al., 2004).

A arquitetura distribuída de um cluster fica escondida para um cliente HTTP (HiperText Tranfer Protocol) por meio de um único IP Virtual (VIP). Esse IP virtual é endereçado para uma máquina que age como um representante do web site, conhecida como Web Switch ou Director. Na Figura 2.2 é mostrada a arquitetura típica de um WFC.

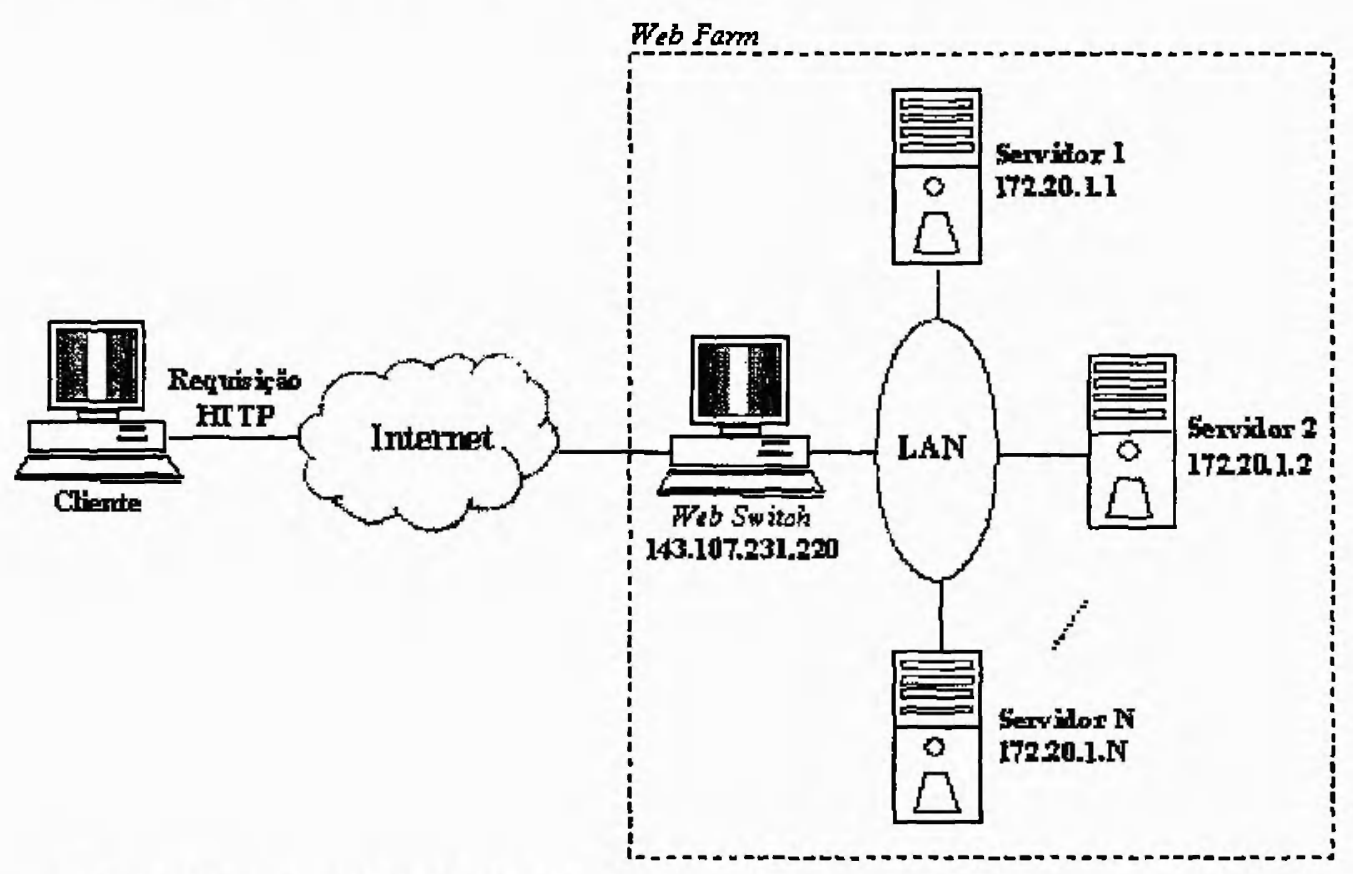

Figura 2.2 - Arquitetura típica de um Web Farm Cluster (Adaptado de (CARDELLINI et al., 2002)) 


\subsubsection{Web Switch (Director)}

Um WFC é formado pelos nós que abrigam os servidores web, as aplicações e as bases de dados de um web site particular, e por uma máquina que atua como uma interface entre os nós e a Internet, denominada web switch ou director.

O director age como um intermediador entre o cliente e os nós que formam o WFC. Ele recebe todos os pacotes que os clientes enviam para o endereço VIP e, por meio de um mecanismo de escalonamento, os encaminha para algum nó (ARON et al., 2000; CARDELLINI et al., 2001; CASALICCHIO; CARDELLINI; COLAJANNI, 2002). O director é capaz de identificar cada nó do WFC por um endereço privado, que pode ser tanto um endereço IP como um endereço MAC (Media Access Control).

O fluxo de pacotes no WFC entre o director e os nós pode ser unidirecional (one way) ou bidirecional (two way) (CARDELLINI et al., 2001; ANDREOLINI et al., 2001). O fluxo unidirecional é quando a requisição do cliente é encaminhada do director ao nó escalonado e depois a resposta é enviada diretamente do nó ao cliente (sem passar pelo director). Já no fluxo bidirecional, tanto a requisição do cliente quanto a resposta do servidor passam pelo director.

\subsubsection{Classificação}

Existem várias técnicas para desenvolver um WFC, mas em todas essas técnicas o papel mais importante e imprescindível é o do director. Portanto, a classificação da arquitetura de um WFC está relacionada com o roteamento (pelo director) dos pacotes para os nós baseado na pilha de camadas do protocolo OSI, mais especificamente nas camadas 4 (transporte) e 7 (aplicação) (CARDELLINI; COLAJANNI; YU, 2002).

Na camada 4 (transporte), o director realiza o roteamento "cego" de conteúdo, também conhecido como ligação imediata. Isso porque o director determina um nó quando o cliente estabelece uma conexão TCP/IP, impedindo que o pacote cliente chegue na camada de aplicação. Para manter o controle das conexões, o director mantém uma tabela de ligação que associa cada sessão TCP cliente com o nó escolhido, impedindo que pacotes pertencentes a conexões existentes abram novas conexões.

Na camada 7 (aplicação), o director executa o roteamento consciente de conteúdo, também conhecido como ligação com atraso. Nela, o director primeiramente estabelece uma conexão 
TCP completa com o cliente para depois examinar a requisição HTTP em nível de aplicação e, só então, encaminhá-la para o nó.

A classificação da arquitetura de um WFC baseada nestas duas camadas pode ainda ser especificada com relação aos fluxos unidirecionais e bidirecionais dos pacotes.

A seguir são descritos os tipos de arquiteturas para WFC com base nas camadas 4 e 7 do protocolo OSI e nos fluxos unidirecionais e bidirecionais:

- Camada 4

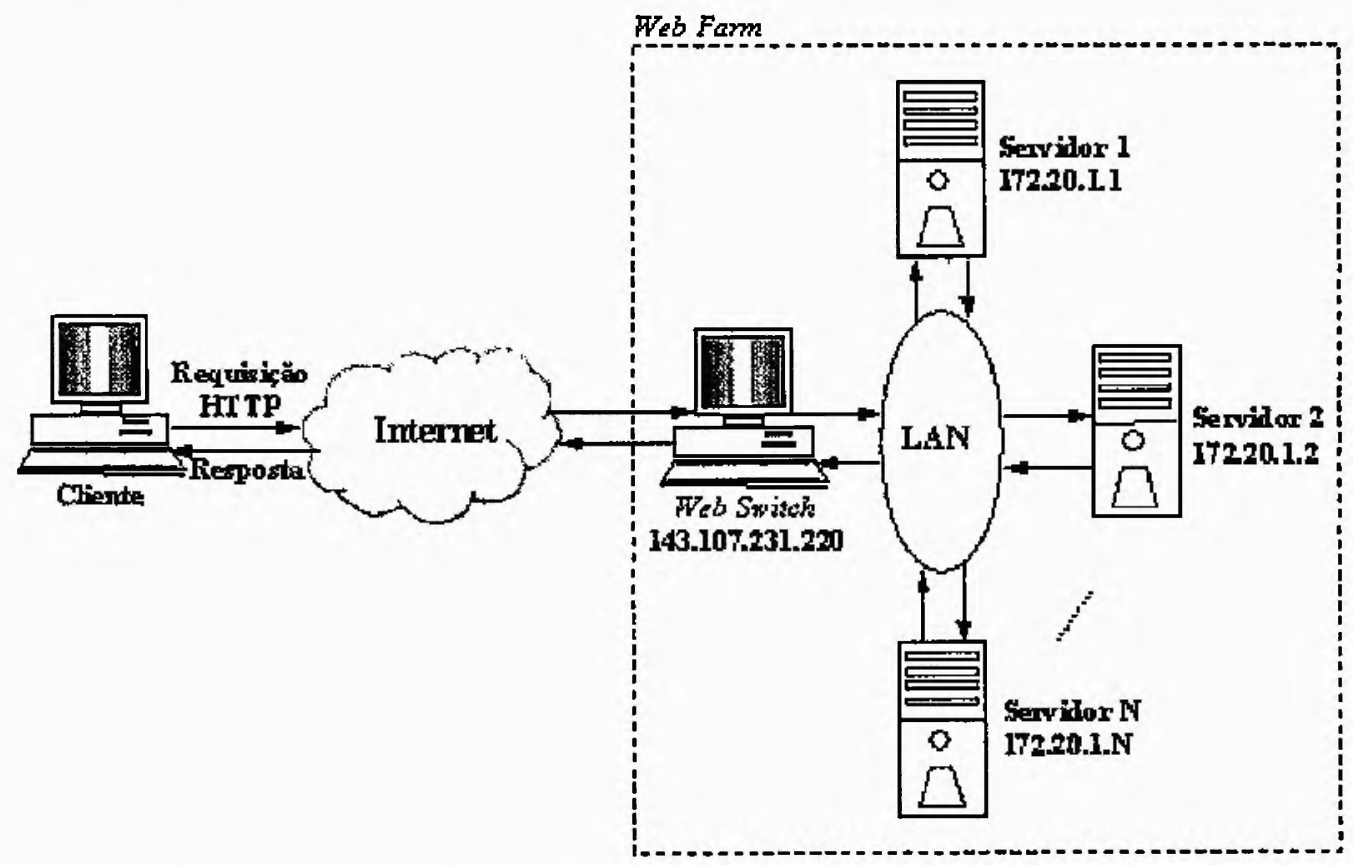

Figura 2.3 - Arquitetura NAT (Adaptado de (CARDELLINI et al., 2002))

\section{Arquitetura bidirecional}

Conforme mencionado, neste tipo de arquitetura tanto o pacote de requisição do cliente quanto o pacote de resposta do servidor passam pelo director. Nessa arquitetura (apresentada na Figura 2.3), que é baseada no NAT (Network Address Translation), o director deve possuir um endereço IP Virtual (VIP) de acesso a Internet e um endereço IP privado, e cada nó deve possuir um endereço IP privado para que o director possa identificá-lo. Quando a requisição de um cliente chega ao director pelo endereço VIP, o director reescreve o pacote trocando o endereço VIP pelo endereço IP privado do nó escalonado. Esse nó, após receber e processar a requisição, envia a resposta para o director, que por sua vez troca o endereço de 
origem (do nó) para o endereço VIP e o envia de volta ao cliente. Existem implementações via hardware, como LocalDirector (CISCO SYSTEMS, 2004b) e ServerIron (FOUNDRY NETWORKS, 2004). E existem implementações via software, como Magicrouter (ANDERSON; PERTERSON; BREWER, 1996), cujo projeto está estagnado, e o LVS (Linux Virtual Server) que é discutido na Seção 2.7.3.

\section{Arquitetura unidirecional}

Neste tipo de arquitetura, o pacote do cliente é enviado ao director, que o envia ao nó escalonado e este, por sua vez, envia o pacote de resposta diretamente ao cliente (sem passar pelo director). Para este tipo de arquitetura, os nós precisam de uma conexão de rede extra para enviar o pacote de resposta ao cliente. Existem três tipos bastante conhecidos de roteamento de pacotes para os nós desta arquitetura, que são: reescrita única de pacote, tunelamento de pacote e roteamento direto (ou tradução de endereço MAC). Na reescrita única de pacote, ilustrado na Figura 2.4, o director troca o endereço VIP do pacote pelo endereço IP privado do nó escalonado e envia o pacote ao nó. Após receber e processar a requisição, o próprio nó troca o endereço IP privado do nó pelo endereço VIP e o envia de volta ao cliente. Um exemplo de sistema para este tipo de arquitetura é o TCP Router (DIAS et al., 1996).

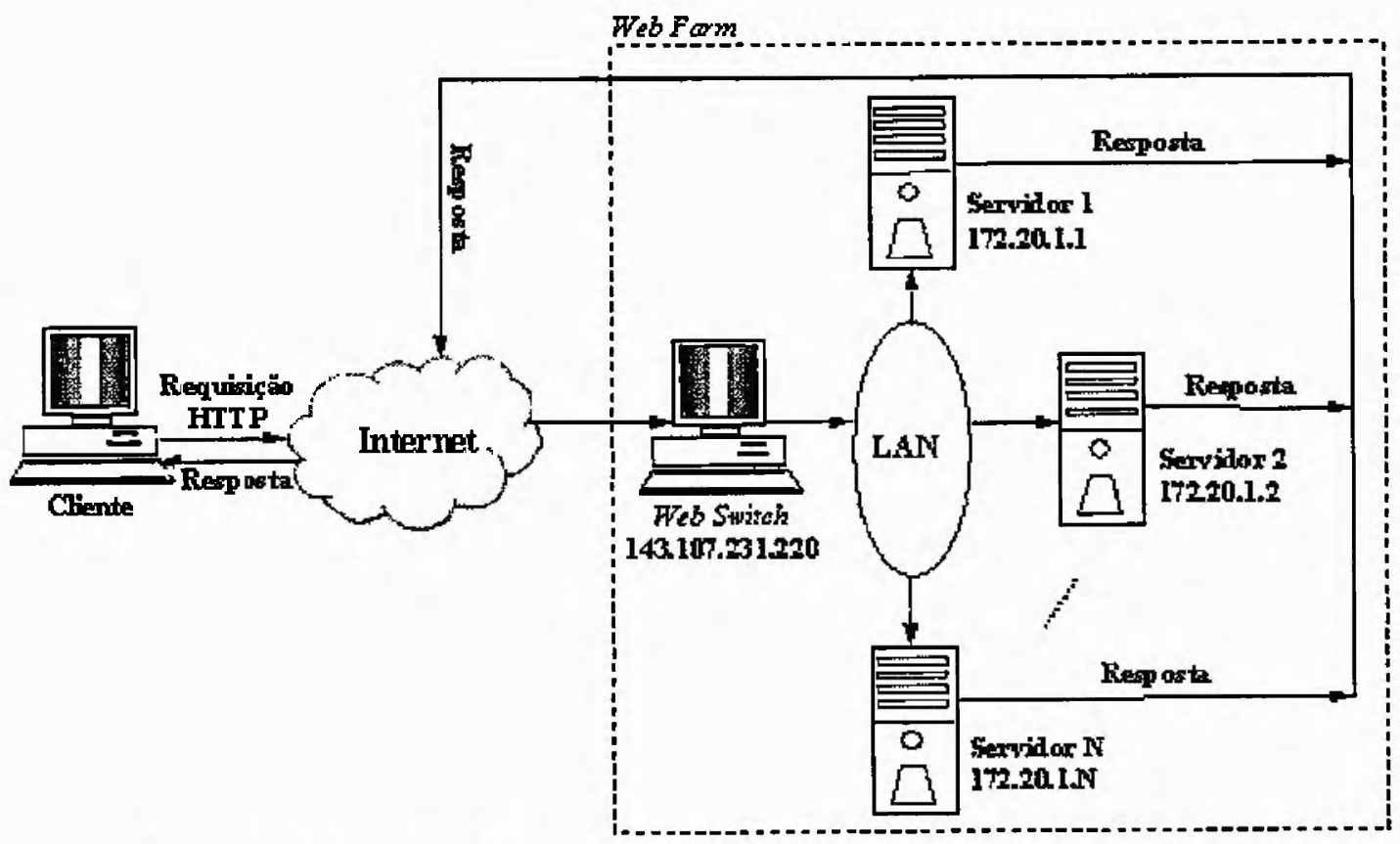

Figura 2.4 - Arquitetura Reescrita de Pacote (Adaptado de (CARDELLINI et al., 2002)) 
No tunelamento de pacote, ilustrado na Figura 2.5, o director encapsula o pacote dentro de um datagrama IP. O cabeçalho deste datagrama contém o endereço VIP como origem e o endereço IP do nó escalonado como destino. Este mecanismo requer que todos os servidores tenham suporte para o tunelamento de IP e os equipamentos de túnel estejam configurados com o VIP. Quando o nó escalonado recebe o pacote encapsulado, ele retira o cabeçalho, verifica o endereço de origem $\mathrm{e}$ envia o pacote de resposta diretamente para o cliente. Um exemplo de sistema que disponibiliza esse tipo de arquitetura é o LVS.

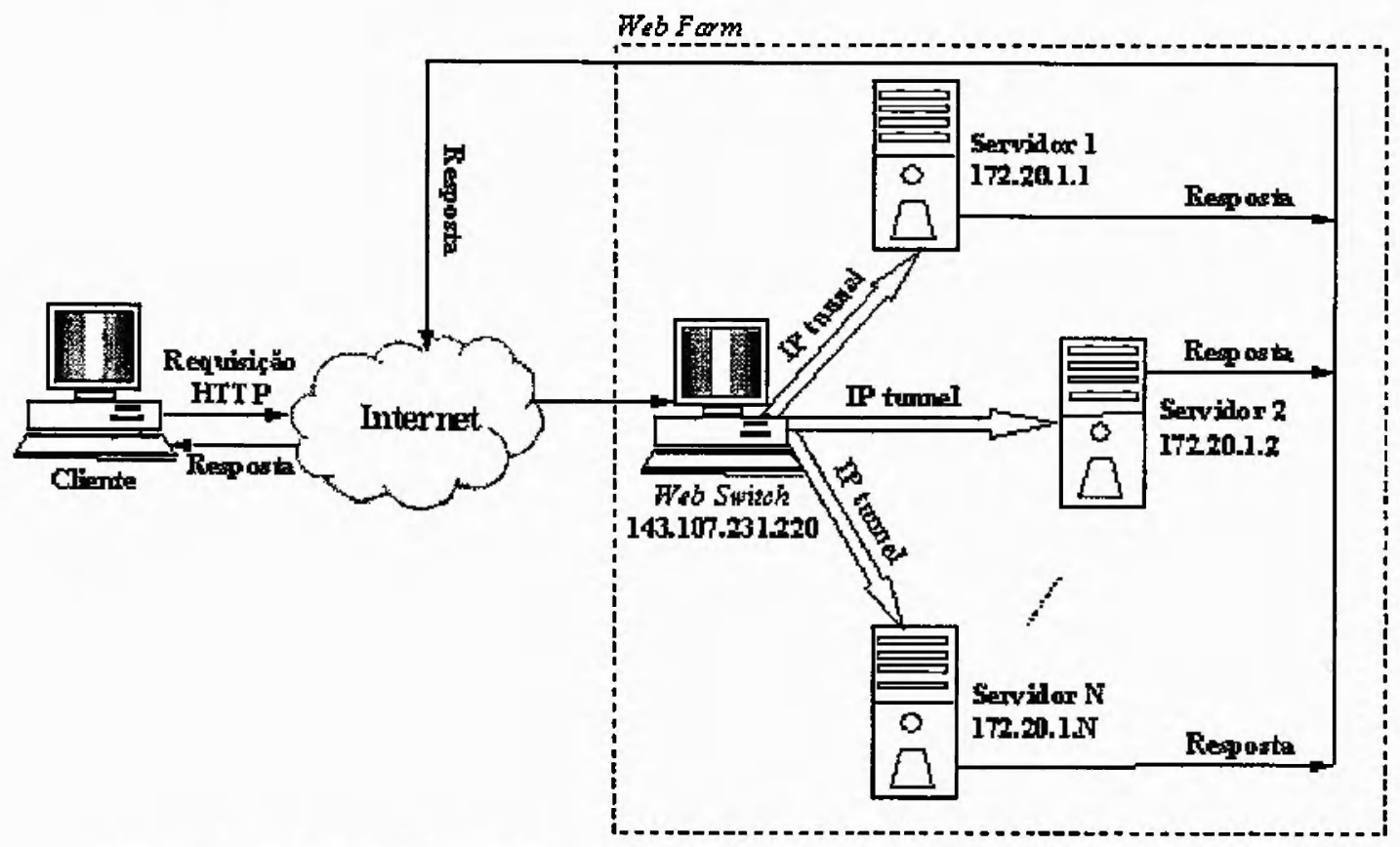

Figura 2.5 - Arquitetura IP Tunneling (Adaptado de (CARDELLINI et al., 2002))

No roteamento direto, ilustrado na Figura 2.6, o endereço VIP é compartilhado pelo director e pelos nós do cluster por meio do uso de endereçamento primário e secundário de IP. Para isto, os nós devem estar com o protocolo de resolução de endereços (ARP - Address Resolution Protocol) desabilitado. Ao receber a requisição, o director encaminha o pacote para o nó escalonado utilizando o endereço MAC do nó que, por sua vez, envia o pacote de resposta diretamente para o cliente, já que o nó compartilha o mesmo endereço VIP. Como exemplos dessa arquitetura têm-se: em nível de hardware - Network Dispatcher, BIG-IP e ServerIron - em nível de software - LVS e ONE-IP (DAMANI et al., 1997). 


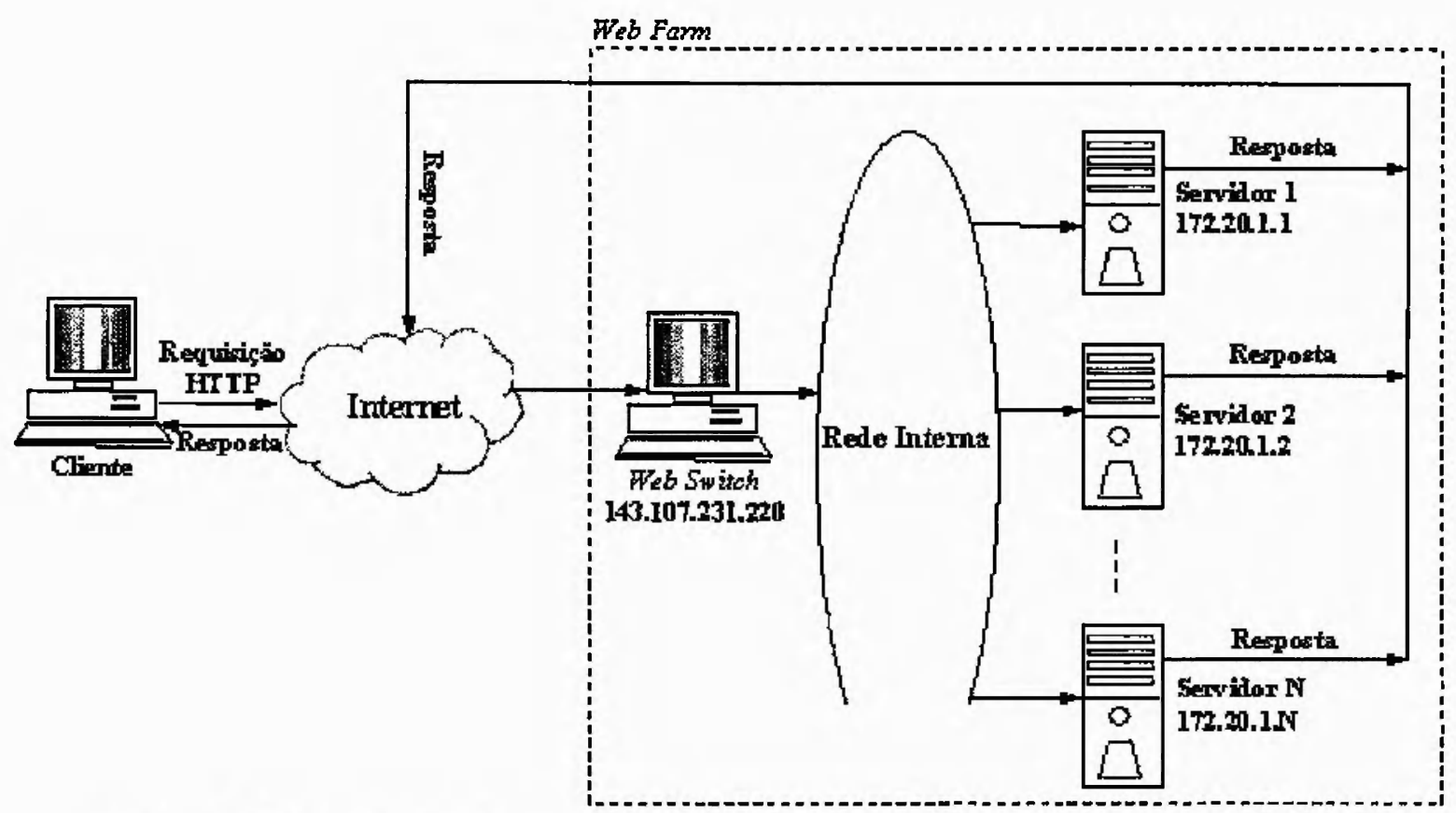

Figura 2.6 - Arquitetura Roteamento Direto (Adaptado de (CARDELLINI et al., 2002))

\section{- Camada 7}

\section{Arquitetura bidirecioual}

Arquitetura TCP gateway: Nesta arquitetura, um proxy no director media a comunicação entre o cliente e os nós do cluster. Esse proxy mantém abertas as conexões TCP com os nós e encaminha a requisição do cliente para o nó escalonado. O nó processa a requisição e envia a resposta para o proxy, que a envia para o cliente. Como exemplos dessa arquitetura têm-se: em nível de hardware - CSS (Content Services Switches) (CISCO SYSTEMS, 2004a), L5 (APOSTOLOPOULOS et al., 1999) e Alteon Web OS (NORTEL NETWORKS, 2004) - em nível de software - HACC (Harvard Array of Cheap Computers) (ZHANG et al., 1999) e ClubWeb (Cluster-based Web) (CASALICCHIO; COLAJANNI, 2001).

\section{Arquitetura unidirecional}

Arquitetura TCP hand-off: $O$ director encaminha a requisição para o nó e repassa a conexão do cliente para o nó de modo que o mesmo possa se comunicar diretamente com o cliente. Esta arquitetura requer modificações no sistema operacional do director e dos nós. Como exemplos têm-se: ClubWeb e Central Dispatch (CARDELLINI; COLAJANNI; YU, 2002). 


\subsubsection{LVS - Linux Virtual Server}

Linux Virtual Server é uma ferramenta de software que direciona conexões de rede para vários servidores, de acordo com um algoritmo de escalonamento (ZHANG, 2000). Ele faz a distribuição de carga entre os nós de um cluster, fazendo com que as requisições dos clientes sejam direcionadas para os nós distintos, evitando, assim, a sobrecarga de um determinado nó.

O LVS confere ao cluster a aparência de ser um servidor único, chamado servidor virtual, para um cliente externo, permitindo o oferecimento dos serviços aos usuários finais de forma transparente.

O LVS pode ainda ser usado para oferecer alta escalabilidade e serviços de alta disponibilidade. A alta escalabilidade pode ser obtida por meio da simples adição ou substituição máquinas (nós) ou componentes do cluster. Já a alta disponibilidade pode ser obtida através de programas que detectam falhas em nós ou em daemons de serviços e que reconfiguram o sistema apropriadamente, de forma que a carga possa ser assumida pelos nós restantes do cluster.

A arquitetura de um LVS pode ser vista em 3 níveis, como mostra a Figura 2.7 (ZHANG, 2000). 


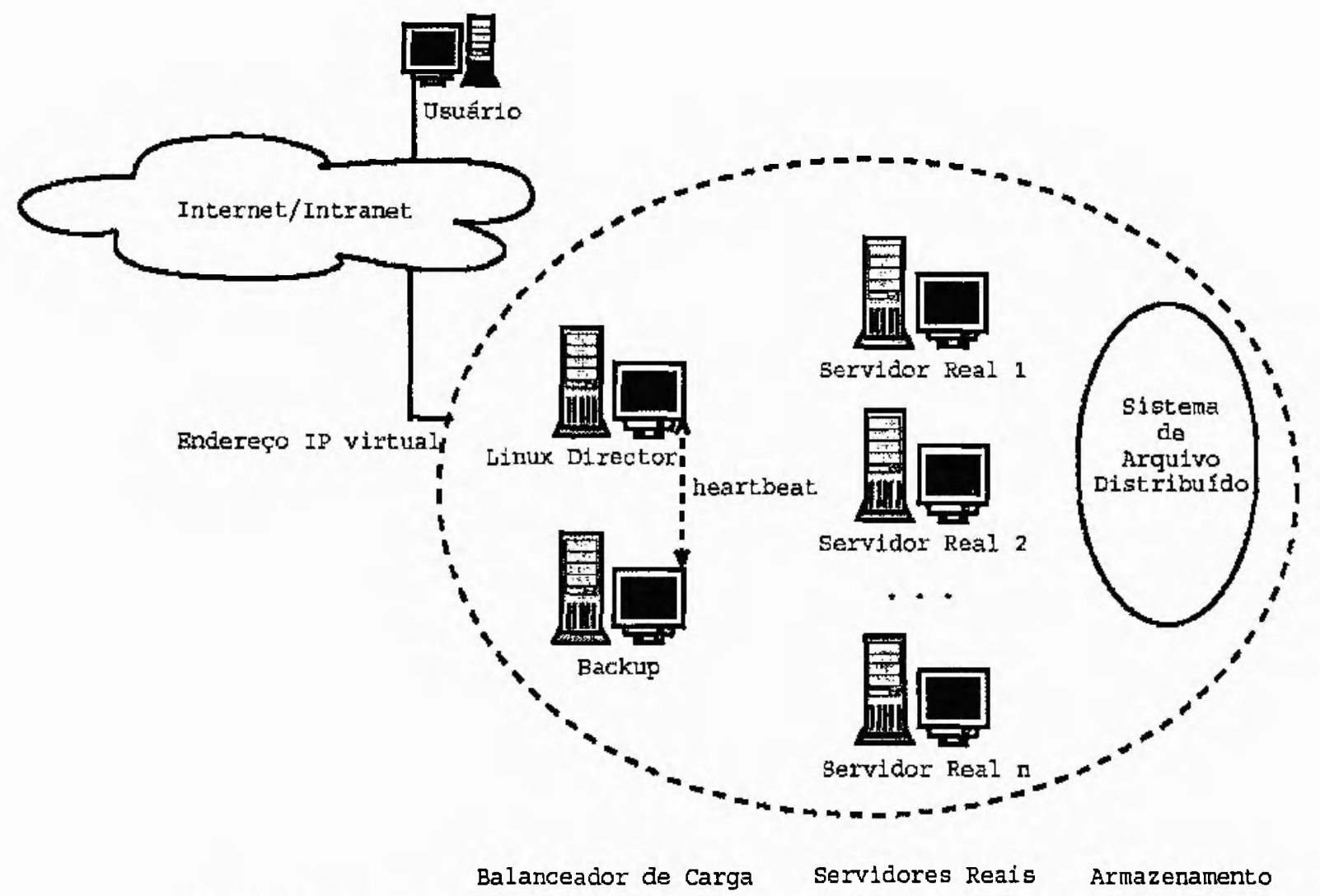

Figura 2.7 - Visão da arquitetura de um LVS (Adaptado de (ZHANG, 2000))

O primeiro nível está relacionado ao director (identificado pelo IP virtual - VIP) que atua como balanceador de carga ou distribuidor de requisições. $O$ segundo nível está relacionado aos servidores reais ou nós do cluster. Esse nível é formado por um conjunto de nós que implementam serviços, tais como $w e b$, ftp, mail, dns etc. Cada nó é identificado por um endereço IP privado, que é conhecido pelo director. O terceiro, e último nível, está relacionado ao armazenamento. Esse nível corresponde aos meios para permitir que os servidores (nós) tenham os mesmos conteúdos e forneçam os mesmos serviços.

No LVS, existem oito (8) algoritmos de escalonamento implementados, que são:

- Round Robin: este algoritmo de escalonamento distribui sequencialmente cada requisição ao próximo nó da lista de nós. Ele trata todos os nós da mesma forma, ou seja, todos os nós têm os mesmos pesos com relação ao recebimento de requisições.

- Weighted Round-Robin: este algoritmo de escalonamento distribui cada requisição seqü̉encialmente entre os nós, porém, atribuindo mais requisições aos nós com maior capacidade de processamento. Essa capacidade é indicada através do fator peso, que pode ser ajustado de acordo com as informações de carga de cada servidor. 
- Least Connection: este algoritmo de escalonamento distribui mais requisições aos nós com menos conexões ativas. Isso é feito mantendo-se um controle das conexões com os nós por meio da tabela do IPVS (IP Virtual Server).

- Weighted Least-Connection: este algoritmo de escalonamento distribui mais requisições aos nós com menos conexões ativas, porém leva em consideração a capacidade de cada nó.

- Localy-Based Least-Connection: este algoritmo de escalonamento distribui requisições a um nó que está ativo e abaixo da sua carga máxima. Se o nó escolhido estiver sobrecarregado e existe um outro nó com a metade de sua carga, então a conexão é redirecionada para esse nó.

- Localy-Based Least-Connection with Replication: este algoritmo de escalonamento segue um processo semelhante ao Localy-Based Least-Connection. A diferença é que o Localy-Based Least-Connection with Replication mapeia o endereço de destino a um subconjunto de nós, tal que a requisição é enviada ao nó com menor número de conexões. Se todos os nós do subconjunto estiverem acima da capacidade, um novo nó é replicado para o endereço de destino, isto é, um nó com menor número de conexões é adicionado ao subconjunto e, então, o nó com maior carga é eliminado do subconjunto.

- Destination Hashing: este algoritmo de escalonamento distribui requisições aos nós por meio da pesquisa em uma tabela hash determinada estaticamente pelos endereços IPs de destino.

- Source Hashing: este algoritmo de escalonamento distribui requisições aos nós por meio da pesquisa em uma tabela hash determinada estaticamente pelos endereços IPs de origem.

O LVS possui 3 métodos diferentes de roteamento de pacotes (ZHANG, 2000), sendo que todos eles são baseados na camada 4 do protocolo OSI: o NAT, tunelamento de pacote e roteamento direto (descritos anteriormente).

\subsubsection{Sistema de Arquivos}

Para que as requisições sejam atendidas igualmente por qualquer um dos nós servidores de um WFC é necessário que todos esses nós tenham acesso aos dados necessários pelos seus 
serviços e que estes dados não fiquem armazenados na mesma máquina (single point of failure). Para resolver esse problema é possível:

- utilizar um sistema de arquivos distribuído,

- replicar os dados em todos os nós,

- ou, deixar esse problema a cargo da aplicação web rodando no WFC.

\subsubsection{Sistema de Arquivos Distribuído}

Existem alguns sistemas de arquivos distribuídos que são de distribuição gratuita e estão disponíveis na Internet como o AFS (Andrew File System), o CODA, o GFS (Global File System) e o PVFS.

O AFS é um sistema de arquivos distribuído, desenvolvido em 1980 na Carnegie Mellon University (CMU). Ele permite aos usuários visualizarem e, dependendo dos direitos de acesso, compartilharem e acessarem todos os arquivos armazenados em uma rede de computadores de forma tão simples quanto se eles estivessem acessando arquivos armazenados em uma máquina local (SATYANARAYANAN, 1990; ZAYAS, 2001; TANENBAUM, 2003). O AFS pode rodar em plataformas Windows, Mac OS e as baseadas em Unix e seu principal objetivo é disponibilizar uma maneira para os usuários recuperarem informações de qualquer local da rede, permitindo o compartilhamento de informações. Com relação à segurança, o AFS tem um forte mecanismo para proteção de arquivos e diretórios. Ele utiliza ACLs (Access Control List) para proteger arquivos e diretórios, empregando 7 tipos de permissões (read, list, insert, delete, write, lock e administer). Esses tipos de permissões não podem ser mapeados diretamente para os 3 tipos (read, write e execute) do Unix. O AFS ignora os bits de proteção Unix para diretórios e considera somente os bits para os proprietários de arquivos. Isso pode gerar muitos problemas para a instalação e a configuração de programas em sistemas Unix.

O CODA é um sistema de arquivos distribuído também desenvolvido na Carnegie Mellon University (CMU). Ele possui as seguintes características (BRAAM, 2004):

- Alta performance através da utilização de cache persistente no lado cliente.

- Não interrupção de operações mesmo durante falhas na rede.

- Semântica bem definida de compartilhamento, mesmo na presença de falhas na rede.

- Adaptação à banda de rede. 
- Replicação de servidores.

- Autenticação baseada no sistema Kerberos.

- Utilização de listas de controle de acessos (ACL).

O GFS é um sistema de arquivos que gerencia dados em uma SAN (Storage Area Network). Ele oferece alta performance, reduz a complexidade do gerenciamento de dados redundantes, elimina pontos únicos de falha e permite alta escalabilidade (PRESLAN et al., 2004).

O PVFS é um sistema de arquivos paralelo que é mantido pelo Laboratório de Pesquisa de Arquitetura Paralela da Clemson University e pela Divisão de Matemática e Ciência da Computação do Laboratório Nacional de Argonne. Ele possui as seguintes características (LATHAM, 2004):

- Suporta clusters heterogêneos.

- Possui uma arquitetura modular que permite adaptação à novas tecnologias de rede.

- Distribuição flexível de dados.

- Não guarda o estado das conexões entre servidores e clientes (stateless).

- Realiza redundância de dados e metadados.

\subsubsection{Replicação de Arquivos}

Uma solução, mais simples do que a de sistemas de arquivos distribuídos, é a replicação dos dados em todos os nós do cluster. Nessa solução pode-se obter o máximo de redundância dos dados, porém se gasta muito espaço de disco e a informação tem de ser reescrita a cada modificação. Essa solução só é recomendável para quantidades de dados pequenas (em relação ao espaço total de disco disponível no cluster) e que não sofram alterações constantes.

O programa rsync implementa essa replicação de forma eficiente. Ele permite enviar cópias de arquivos de uma máquina para outra através da rede. Ele faz essas cópias enviando somente as diferenças existentes entre o conjunto de arquivos da máquina remota e o conjunto de arquivos que serão transferidos.

O rsync suporta vários tipos de operações de cópias de arquivos ou diretórios, como:

- Cópias locais.

- Cópias de uma máquina local para uma máquina remota.

- Cópias de uma máquina remota para uma máquina local. 


\subsubsection{Năo Oferecer Nenhuma Solução}

Muitos programas que implementam serviços web já têm soluções proprietárias para rodar em clusters que incluem o gerenciamento dos arquivos entre nós. Nesse caso é possível delegar a esses programas a solução para o problema dos arquivos no cluster.

\subsection{Considerações Finais}

Clusters de computadores representam uma alternativa econômica para se conseguir um alto poder computacional, bem como uma alta disponibilidade de serviços.

Neste Capítulo foram descritos os conceitos principais sobre clusters, tais como suas características, tipos, arquiteturas e alguns pontos importantes que devem ser considerados na montagem dos mesmos. Algumas tecnologias de software e hardware foram apresentadas, bem como alguns padrões empregados na construção de clusters.

A montagem do cluster do Laboratório Intermídia foi baseada no conhecimento sobre todos esses aspectos. Detalhes de como esse cluster foi montado, tais como tecnologias, arquiteturas e protocolos utilizados, são descritos posteriormente no Capítulo 5 . No próximo capítulo são apresentados alguns conceitos relacionados a Agentes de Software. 


\section{Agentes de Softwarle)}

\subsection{Considerações Iniciais}

A evolução e expansão das redes de computadores e da Internet abriram caminho para o desenvolvimento de aplicações complexas e distribuídas e permitiram o avanço da Computação e da área de Inteligência Artificial Distribuída.

A Inteligência Artificial Distribuída (IAD), uma subárea de Inteligência Artificial (IA), surgiu no final da década de 70 e vem se desenvolvendo com o objetivo de estudar soluções para uma classe de problemas cuja distribuição é inerente (GARCIA; SICHMAN, 2002). A IAD é composta por sistemas cujo funcionamento depende de um determinado conjunto de partes menores para resolver, de modo cooperativo, um determinado problema. Ela divide-se em três áreas: Resolução de Problemas Distribuídos (RPD), Inteligência Artificial Paralela (IAP) e Sistemas Multiagentes (SMA). A RPD trata da decomposição de problemas em módulos que cooperam entre si e dividem conhecimento e controle. A IAP trata principalmente problemas de performance, preocupando-se em desenvolver linguagens e algoritmos de computação paralela. E a MAS caracteriza-se pelo estabelecimento de modelos, arquiteturas e implementações para que entidades autônomas (denominadas agentes) possam executar ações de modo coordenado em uma sociedade e, ao final, se possa obter um comportamento global coerente (GARCIA; SICHMAN, 2002).

Nos últimos anos a tecnologia de agentes (MAS) tem sido empregada no desenvolvimento de aplicações para as mais diversas áreas do conhecimento. Isso se deve, em parte, a fatores como a variedade de plataformas de desenvolvimento (BRADSHAW, 1997), modularidade (pequenos processos atuando de forma cooperativa), eficiência (FRANCESCHI; BARRETO ROISENBERG, 2000) e à gama de aplicabilidade para a solução de uma diversidade de problemas (FRANCESCHI; BARRETO ROISENBERG, 2000; NWANA, 1996).

No intuito de conhecer um pouco sobre a tecnologia de agentes de software, apresenta-se neste Capítulo uma visão geral dessa tecnologia, incluindo-se algumas definições, propriedades, classificações, arquiteturas e algumas áreas de aplicação. 


\subsection{Definição de Agentes de Software}

No contexto computacional, os agentes foram propostos para facilitar a criação de softwares capazes de interoperar, ou seja, trocar informações e serviços com outros programas e, dessa forma, resolver problemas complexos (MOREIRA; WALCZOWSKI, 1997).

Apesar da tecnologia de agentes de software ser amplamente utilizada, ainda existe uma certa dificuldade em se chegar a um consenso sobre sua definição. Uma destas dificuldades está no fato do termo ser amplamente utilizado por diversos grupos em áreas de pesquisa correlatas (WOOLDRIDGE; JENNINGS, 1995), sendo que cada um tem suas próprias interpretações e suas próprias idéias sobre quais são as questões realmente importantes nessa área (WOOLDRIDGE, 1997). O mesmo problema ocorre dentro da Inteligência Artificial quando se tenta encontrar definições para o termo "inteligência". Isso ocorre porque essas definiçõ̃es envolvem termos difíceis de mensurar, tais como autonomia, habilidade social, reatividade, racionalidade, dentre outros (NUNES, 2001).

Iniciando pela definição encontrada nos dicionários, agente é aquele que opera; ou, agente é aquele que é encarregado dos negócios de terceiros (FERREIRA, 1999). Tais definições consideram duas perspectivas diferentes: a primeira que associa um agente a uma entidade que é capaz de agir; e a segunda em que um agente é considerado como um ajudante, ou alguém que atua por intermédio de outra pessoa.

No contexto computacional, essa definição é muito imprecisa, pois, por não haver consenso no que é de fato um agente, cada autor cria sua própria definição ou utiliza aquela que melhor se adapta aos seus objetivos e contexto. Por causa dessa divergência de opiniões, pesquisadores que trabalham com agentes de software têm oferecido uma grande variedade de definições para o termo, cada um procurando explicar a sua própria utilização da palavra "agente". Por isso, definições para o mesmo termo podem ser diferentes. De acordo com o ponto de vista de alguns autores e pesquisadores da área, agentes podem ser definidos como:

- "Um agente é uma entidade - fisica ou abstrata - capaz de agir sobre si mesma e seu ambiente, e que dispõe de uma representação parcial de seu ambiente permitindo sua comunicação com outros agentes" (FERBER; GHALLAB, 1988).

- "Um agente é qualquer coisa que pode perceber seu ambiente mediante sensores $e$ que responde ou atua em tal ambiente por meio de executores" (RUSSEL; NORVIG, 1995). 
- "Agentes autônomos são sistemas computacionais que habitam algum ambiente complexo dinâmico, sentem e agem de maneira autônoma nesse ambiente e, assim, atingem objetivos ou cumprem tarefas para as quais foram designados" (MAES, 1995).

- "Um agente é um programa independente capaz de controlar suas prôprias ações e decisões, baseado na percepção do seu ambiente, em busca de um ou mais objetivos" (WOOLDRIDGE; JENNINGS, 1995).

Conforme observado, não existe uma definição única para o termo agente, pois diferentes definições são adotadas de acordo com o ponto de vista de cada um dos autores e pesquisadores. Em virtude dessa variedade de definições, os sistemas baseados em agentes são muitas vezes confundidos ou considerados como sendo sistemas orientados a objetos e vice-versa. De fato, existe uma grande proximidade entre essas duas tecnologias de desenvolvimento, porém, apesar das semelhanças, existem várias diferenças, tais como (ODELL, 2002):

- objetos agem apenas quando seus métodos são invocados e da forma como os métodos são implementados (ou seja, são previsíveis); agentes podem observar o ambiente e iniciar uma ação sem a intervenção de outras entidades, além de poder decidir qual ação deve ser realizada de acordo com o estado do ambiente (ou seja, podem ser imprevisíveis);

- objetos interagem normalmente através da invocação de métodos de outros objetos (um método tem um nome e um número fixo e determinado de parâmetros que são passados ao outro objeto); agentes possuem uma capacidade de interação maior e podem manter contato com vários outros agentes utilizando uma linguagem de comunicação específica, por exemplo, baseadas em atos de fala ${ }^{1}$.

Apesar de serem entidades diferentes, objetos e agentes podem conviver em um mesmo sistema computacional. Nas várias definições de agentes, é comum encontrar o trecho "agentes são objetos que...", o que significa que objetos podem ser utilizados para implementar agentes. Na concepção de Odell (2002), um agente nada mais é do que um objeto acrescido de características extras (que não fazem parte da tecnologia de objetos). Por

\footnotetext{
${ }^{1}$ De acordo com a Teoria dos Atos de Fala, a comunicação ocorre através de atos tais como: requisições, sugestões, promessas, ameaças, entre outros, que representam o tipo de mensagem trocada entre os agentes.
} 
outro lado, Odell enfatiza que agentes e objetos são entidades diferentes que funcionam de forma diferente e que, portanto, não podem ser consideradas iguais.

Pela dificuldade em se chegar a um consenso sobre a definição do termo agente de software, muitos pesquisadores relacionam algumas propriedades aos agentes para caracterizá-los. Essas características serão discutidas na próxima seção.

\subsection{Propriedades dos Agentes}

Atualmente, vários pesquisadores da área abordam o termo agente levando em consideração pelo menos algumas das propriedades encontradas na literatura para caracterizar agência. Tais propriedades estão relacionadas ao ambiente em que os agentes estão inseridos, sendo que esse ambiente constitui o meio do qual o agente obtém informação e sobre o qual o agente pode atuar. Algumas dessas propriedades são (WOOLDRIDGE; JENNINGS, 1995; RUSSELL; NORVIG, 1995; WOOLDRIDGE, 1997; FRANKLIN; GRAESSER, 1997; JAQUES; OLIVEIRA, 2000):

- Autonomia: agentes são capazes de operar e resolver problemas sem a intervenção humana ou outras entidades e mantêm um certo grau de controle sobre suas próprias ações e seus estados internos.

- Habilidade Social: agentes interagem ou cooperam com outros agentes (humanos ou outras entidades) usando uma linguagem de comunicação de agentes.

- Reatividade: agentes percebem e analisam seu ambiente, respondendo de maneira adequada às mudanças que nele ocorrem. Esse ambiente pode ser um mundo físico, uma interface gráfica, uma coleção de outros agentes, a Internet, ou uma combinação desses elementos.

- Pró-atividade: agentes não atuam apenas em resposta a alterações no seu ambiente, mas também são capazes de apresentar um comportamento dirigido por objetivos ao tomarem iniciativas. Tomar iniciativas pode significar, em um entendimento mais simples, tomar medidas preventivas para o bom funcionamento de um sistema.

- Continuidade Temporal: agentes são processos rodando continuamente e não somente scripts que mapeiam uma determinada entrada numa saída e finalizam sua execução. 
- Adaptação: capacidade do agente em adaptar-se às mudanças que ocorrem no meio em que está inserido.

- Mobilidade: é a habilidade de um agente mover-se através de uma rede.

- Veracidade: assume-se que um agente não transmitirá uma informação falsa conscientemente.

- Benevolência: assume-se que um agente não apresenta objetivos conflitantes e que sempre tentará realizar as tarefas que lhe forem solicitadas. Um agente deixará de realizar uma determinada tarefa se não possuir as condições necessárias para isso.

Apesar de existirem várias propriedades, isso não significa que todos os agentes computacionais tenham que, necessariamente, conter todas elas. A presença de uma ou mais propriedades permite classificar os agentes em diferentes tipos (NUNES, 2001).

Pelas definições e propriedades apresentadas e considerando o contexto deste projeto, adotouse uma definição estendida da definição dada por Shoham (1997) sobre agentes de software. Dessa maneira agente de software são programas que podem ter continuidade de execução dentro de seu ambiente, percebendo-o e reagindo sem a intervenção externa, podendo tomar iniciativas e comunicar-se com outros agentes para realização de tarefas.

\subsection{Classificação dos Agentes}

As propriedades dos agentes podem ser combinadas de modo a estabelecer condições necessárias (ou suficientes) para determinar diferentes tipos de agentes. Porém, assim como na definição do termo, a classificação dos tipos de agentes também possui diferenciações na literatura (NUNES, 2001).

Wooldrige \& Jennings (1995) classificam os agentes sob duas perspectivas, as quais permitem dizer o quanto um sistema computacional pode ser considerado como sendo baseado em agentes:

- Noção fraca de agente: identifica um sistema computacional que possui as propriedades de autonomia, capacidade social, reatividade e pró-atividade. Constitui uma das formas mais comuns de uso do termo agente e está baseada no desenvolvimento de programas independentes que executam em processos concorrentes, encapsulam estados e são capazes de comunicar-se uns com os outros. 
- Noção forte de agente: identifica um sistema computacional com as propriedades do item anterior acrescidas de estados mentais, crenças, desejos, intenções e, algumas vezes, estados emocionais (conceitos normalmente aplicados aos humanos). Constitui a forma de uso do termo adotada principalmente por especialistas da área de AI que visam a criação dos agentes human-like, ou seja, o mais próximo possível dos agentes humanos.

De acordo com Nwana (1996), existem outras dimensões diferentes para se classificar os agentes de software, por exemplo, os agentes podem ser classificados:

- quanto à mobilidade: podem ser móveis, quando eles têm a capacidade de se mover sobre a rede; ou estáticos, quando rodam em apenas um computador;

- quanto à presença de raciocínio simbólico: podem ser cognitivos, quando possuem um modelo de representação interna do ambiente e dos outros agentes e um modelo de planejamento e decisão; ou reativos, quando agem baseados em estímulos/respostas do ambiente;

- quanto aos atributos primários, tais como autonomia, cooperação e aprendizado: podem ser colaborativos, quando colaboram uns com os outros (autonomia e cooperação); de interface, quando colaboram com o usuário como se fosse um assistente pessoal (autonomia e aprendizado); e espertos (smart agents), quando envolvem os três atributos sendo capazes de aprender, cooperar e serem autônomos;

- quanto aos papéis: podem ser de informação (ou de Internet), quando gerenciam, manipulam e coletam informações em repositórios como a Internet e em ambientes distribuídos; ou de interface, quando estabelecem interação com os usuários;

- quanto às filosofias híbridas, quando combinam diferentes classificações em um mesmo agente (nesse caso há diferentes classificações);

- quanto aos atributos secundários, tais como versatilidade, benevolência, veracidade, continuidade temporal, qualidades emocionais e mentais (que também geram classificações variadas).

No desenvolvimento de um projeto de software baseado em agentes se faz necessário ter uma idéia precisa das metas e medidas de performance que devem ser consideradas, assim como 
do tipo de ambiente onde tal agente irá operar. Para tal, é importante o conhecimento de arquiteturas de agentes, assunto este tratado na próxima seção.

\subsection{Arquitetura de Agentes}

Uma arquitetura de agentes pode ser definida como sendo uma metodologia particular para a construção de agentes (MAES, 1991), isto é, ela mostra a maneira como o sistema será implementado em termos de propriedades e estruturas e como os agentes que o compõem podem interagir para garantir a funcionalidade do sistema. A arquitetura também especifica como o agente pode ser decomposto para a construção de um conjunto de componentes ou módulos e como esses módulos devem interagir (MAES, 1991).

Wooldridge \& Jennings (1995) dividem a arquitetura de agentes em três abordagens:

- Clássica ou Deliberativa: baseia-se no paradigma da IA simbólica, na qual os agentes têm um modelo simbólico do mundo para processar seus raciocínios e decidir as seqüências de ações (planos) apropriadas para a realização de tarefas.

- Alternativa ou Reativa: é a arquitetura mais simples de agentes, onde os agentes são capazes de reagir a estímulos do ambiente em que se encontram, mas não possuem modelos internos do mesmo. Os agentes desenvolvidos neste trabalho seguem a implementação desta arquitetura, que será discutida na seção 2.3.1.

- Híbrida: combina componentes das arquiteturas deliberativas e reativas com o objetivo de torná-los mais adequados e funcionais para a construção de agentes. Geralmente, a arquitetura híbrida divide o sistema de software em camadas, sendo uma para o planejamento de alto-nível (camada deliberativa) e outra para o tratamento de detalhes de interação com o mundo (camada reativa).

\subsubsection{Agentes Reativos}

A arquitetura de agentes reativos baseia-se em modelos de organização biológica como, por exemplo, as sociedades de abelhas ou formigas. Embora uma abelha sozinha não represente uma entidade inteligente, o enxame como um todo apresenta uma organização comportamental inteligente, por exemplo, para a busca de alimento para estocagem, a construção da colméia, a organização da reprodução com berçários etc. (MOREIRA; WALCZOWSKI, 1997). 
Essa arquitetura representa uma categoria especial de agentes que não possuem uma representação simbólica interna de seus ambientes, nem usam mecanismos de raciocínio simbólico. Ao contrário disso, estes agentes respondem aos estímulos dos ambientes onde se encontram a partir de uma quantidade limitada de informações. Os agentes reativos são relativamente simples e interagem com outros agentes de forma băsica. No entanto, padrões complexos de comportamentos surgem dessas interações quando se considera o grupo de agentes de forma global (NWANA, 1996).

Os agentes reativos, em geral, não apresentam memória, não planejam suas ações futuras e comunicam-se através de sinais, mensagens ou estímulos, sendo que seu comportamento é modelado como respostas das mensagens ou estímulos que recebem do meio. Os tipos de agentes reativos mais simples não mantêm histórico dos estímulos recebidos e simplesmente respondem aos estímulos através da execução de ações; enquanto que os mais complexos podem manter histórico dos estímulos recebidos para representar seus estados internos. A Figura 3.1 mostra um diagrama simples representando uma arquitetura de agentes reativos.

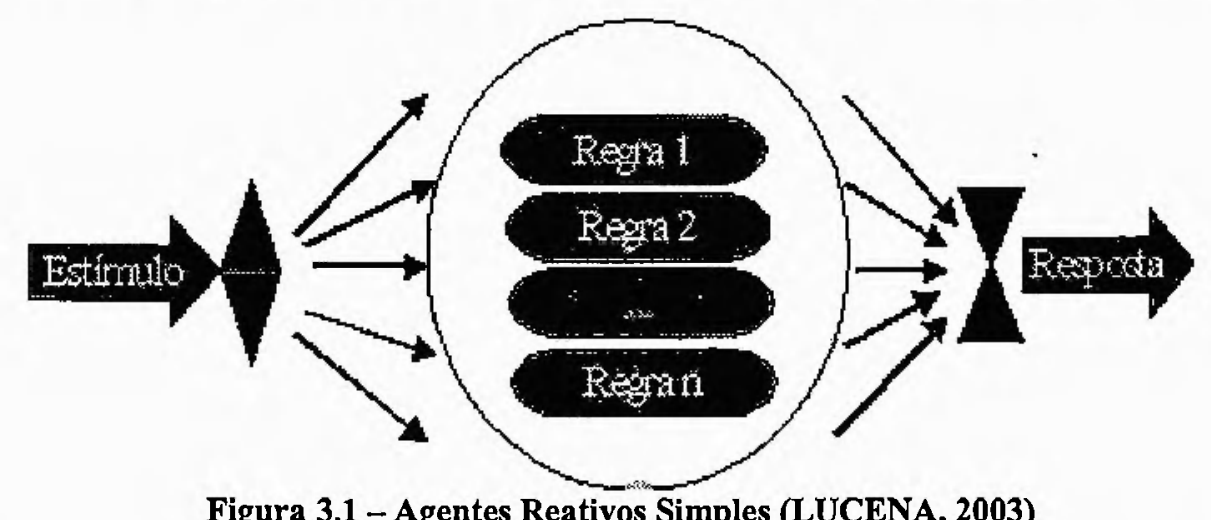

Figura 3.1 - Agentes Reativos Simples (LUCENA, 2003)

Então, pode-se dizer que os agentes reativos, que não possuem modelo simbólico interno, são inteligentes apenas na medida em que cada agente interage com os outros agentes.

Os agentes reativos apresentam algumas vantagens, tais como (NWANA, 1996):

- Não possuem uma representação simbólica explícita, evitando raciocínio simbólico explícito e assim tornando-se simples e fáceis de entender.

- Eles são situados, isto é, não planejam ou revisam qualquer modelo de mundo e suas ações dependem, tão somente, dos acontecimentos do momento.

- São mais robustos e tolerantes a falhas do que outros tipos de agentes, pois possuem uma estrutura descentralizada. 
- Eles possuem flexibilidade e adaptabilidade.

- A velocidade de resposta é maior que os outros tipos de arquitetura de agentes.

Na próxima seção são apresentadas as áreas de aplicação da tecnologia de agentes.

\section{6 Áreas de Aplicação}

A tendência atual no desenvolvimento de aplicações baseadas em agentes segue, cada vez mais, rumo a aplicações mais integradas e avançadas, capazes de executar tarefas de alto nível para os usuários. A seguir são mostradas algumas áreas de aplicação onde a tecnologia de agentes está sendo utilizada (COSTA Jr., 2002).

\section{- Acesso à informação e administração}

Com o advento da internet, grandes quantidades de dados e informações estão sendo disponibilizadas ao mundo, tornando a informação um "bem precioso" para indivíduos e organizações. Porém, muito mais importante que a quantidade é a qualidade das informações, o que pode ser traduzido em informações relevantes, íntegras e atualizadas. Nesse contexto, o acesso à informação e a sua administração tornam-se um trabalho árduo para os usuários da Internet. Neste caso, os agentes inteligentes podem ajudar os usuários com a procura, recuperação e filtragem de informação e com a categorização, prioridade, disseminação seletiva, anotação e compartilhamento de informação e documentos.

\section{- Comércio Eletrônico}

O Comércio eletrônico é uma área crescente onde os clientes fazem suas transaçỗes comerciais de forma cômoda, sem precisar se locomover. Consumidores precisam encontrar os vendedores de produtos e serviços, além de informações de produtos, incluindo especificações técnicas, configurações viáveis, dentre outras. Vendedores precisam encontrar consumidores e fornecer informações sobre seus produtos ou serviços, assim como atendimento e suporte ao consumidor. Consumidores e vendedores precisam automatizar o manuseio dos seus "negócios financeiros". Dessa forma, agentes inteligentes podem ajudar em comércio eletrônico de várias maneiras: agentes podem "ir às compras" para um usuário, levar especificações e devolver 
recomendações de compras; agentes podem agir como "ajudantes de compras" para vendedores, ajudando a localizar e reparar problemas de clientes.

\section{- Interfaces Adaptáveis}

Embora a interface com o usuário tenha melhorado com o advento das interfaces gráficas (Graphical User Interfaces - GUIs), para muitos, os computadores permanecem dificeis de aprender e de usar. Como as populações de usuários crescem e se diversificam, as interfaces precisam aprender hábitos e preferências dos usuários e se adaptar a cada usuário. Para isso, pode-se utilizar a tecnologia de agentes, e mais especificamente os chamados agentes de interface, para monitorar as ações do usuário.

\section{- Mail e Messaging}

Software para messaging, assim como um software para e-mail, existe há bastante tempo e também é uma área onde a função de agente inteligente está sendo atualmente utilizada. Atualmente, usuários querem a habilidade para priorizar e organizar automaticamente seus e-mails. Agentes inteligentes podem facilitar essas funções permitindo que regras de manuseio de correio sejam especificadas anteriormente para que os agentes inteligentes possam operar em nome do usuário de acordo com essas regras.

\section{- Administração de Redes}

A administração de redes é uma área que cada vez mais vem sendo explorada utilizando tecnologia de agentes. A evolução da computação para cliente/servidor intensificou a complexidade dos sistemas que são administrados, especialmente na área de LANs ${ }^{2}$. Usuários nesta área, principalmente os operadores e administradores de sistema, necessitam de gerenciamento simplificado em face à complexidade ascendente. Agentes inteligentes podem ser utilizados para automatizar a administração de sistemas.

\subsection{Considerações Finais}

Neste Capítulo apresentou-se uma visão geral sobre a tecnologia de agentes de software, de modo a ter um melhor entendimento sobre o assunto.

${ }^{2}$ LAN - é acrônimo de Local Area Network 
O termo agente tem sido empregado de diversas formas no mundo da computação e de modo especial, no contexto da inteligência artificial. Apesar de existirem diversas definições para este termo, e não se ter chegado a um consenso em relação a este fato, as definições estão convergindo para o conceito de que algumas características fundamentais são necessárias para se caracterizar um programa como um agente. Segundo Franklin \& Graesser (1997) as características de reatividade, autonomia, pró-atividade e continuidade temporal constituem elementos básicos para a definição de um agente.

É importante colocar que a extensão do assunto vai além da abordagem dada neste projeto, pois a cada dia novas abordagens estão sendo adicionadas e a viabilidade para novas áreas de aplicação estão sendo estudadas.

No contexto deste trabalho, foi utilizada a arquitetura de agentes do tipo reativo. Esse tipo de agente consegue ter um tempo bom de resposta, pois exige pouco processamento e é ideal para trabalhar em ambientes distribuídos. Os agentes implementados neste trabalho se comunicam uns com os outros requisitando informações ou informando determinadas proposições.

O próximo capítulo apresenta alguns conceitos relacionados a Sistemas de Computação Autônoma. 


\subsection{Considerações Iniciais}

Desde a duas décadas passadas até os dias de hoje, está havendo um crescimento a taxas exponenciais no desenvolvimento de computadores poderosos e na proliferação de equipamentos computacionais. Esse aumento na variedade de equipamentos computacionais tem direcionado o desenvolvimento de sistemas computacionais que integram múltiplos ambientes heterogéneos e que possuem grande interconectividade entre si (CONSTANTINESCU, 2003; WANT; PERING; TENNENHOUSE, 2003). Juntando-se a isso o crescimento da Internet, chegou-se a uma nova era de acessibilidade a pessoas, a outros sistemas e, principalmente, a informação.

Esta explosão simultânea de informação e integração de novas tecnologias está levando a um aumento da complexidade no gerenciamento de sistemas computacionais. A instalação, configuração e manutenção desses sistemas estão se tornando grandes desafios até mesmo para especialistas. Isto ocorre até mesmo nos sistemas mais simples, aumentando o risco na segurança e na geração de interrupções do sistema e, conseqüentemente podendo provocar um caos geral. Esse contexto levou os pesquisadores da IBM a considerarem técnicas de gerenciamento baseadas em estratégias usadas pelo sistema nervoso autonômico, isto é, sistemas que controlam ações involuntárias do corpo. Com base nessa idéia, a IBM, para tratar da complexidade e heterogeneidade dos sistemas, propôs uma nova visão de computação denominada sistema de computação autônoma ou sistemas autonômicos (KEPHART; CHESS, 2003).

\subsection{Origem da Computação Autônoma}

O termo computação autônoma foi cunhado pela IBM e oficialmente apresentado em 8 de Março de 2001 quando Paul Horn, vice-presidente sênior e diretor de pesquisa da IBM, introduziu o tema para a Academia de Engenharia da Universidade de Harvard. Um mês depois, Irving Wladawsky-Berger, vice-presidente de estratégia e tecnologia da IBM, 
introduziu o projeto de computação autônoma para grupos de servidores, denominada eLiza, que tinha como objetivo prover um sistema de auto gerenciamento (GANEK; CORBI, 2003).

A escolha da palavra "autônoma" pela IBM se deve à analogia com o sistema nervoso autônomo, pois o sistema nervoso autônomo libera o cérebro da carga de ter de tratar das funções vitais de baixo nível como o funcionamento do coração ou controle da temperatura do corpo. Na computação autônoma, o administrador é liberado do tratamento de uma grande parte das tarefas operacionais e rotinas de gerenciamento (GANEK; CORBI, 2003).

Apesar do termo computação autônoma ser recente, a idéia básica por trás dele não é inteiramente nova. Por exemplo, há anos existem sistemas que fazem gerenciamento de recursos como alocação e liberação de memôria, escalonamento de processos, alocação do espaço de swap etc, tudo de forma automática (RUSSELL; MORGAN; CHRON, 2003a).

\subsection{Porque Computação Autônoma?}

Há décadas a indústria da computação tem despendido esforços para criar sistemas que fazem milhões de coisas e resolvem milhões de problemas. Contudo, o aprimoramento desses sistemas está gerando uma complexidade maior no seu gerenciamento e, de certa forma, tornando o prôprio sistema em um problema.

Esse aumento da complexidade nos sistemas está conseqüentemente aumentando o custo do gerenciamento desses sistemas, e atualmente, mesmo com pessoas especializadas gerenciando-os existem tendências para geração de erros e consequentes paradas dos sistemas. Nesse contexto, algumas considerações são citadas em Ganek \& Corbi (2003):

- É estimado que $1 / 3$ (um terço) a $1 / 2$ (meio) do orçamento total em tecnologia da informação de uma empresa sejam gastos com prevenções e recuperações de paradas dos sistemas.

- Segundo Nick Tabellion, diretor de tecnologia da Fujitsu Softek: "Para cada dôlar gasto em armazenamento, gastam-se nove dôlares para ter alguém para gerenciá-lo".

- Um estudo da Aberdeen Group mostrou que o custo administrativo de uma base de dados pode ser de 60 a $75 \%$ de todo o custo de um banco de dados (isto inclui ferramentas administrativas, instalação, atualizações, desenvolvimento, treinamento, salário de administrador e serviços e suporte do fornecedor do banco de dados). 
- $40 \%$ das causas de paradas de sistemas é devido a erros do operador, mas não porque o operador é mal treinado e sim porque a complexidade dos sistemas atuais é tanta que fica difícil entendê-la.

Atualmente, uma grande parte das empresas dos mais variados ramos de atividade dependem dos sistemas computacionais para conduzir seus negócios, e uma parada em seus sistemas implica em prejuízos consideráveis. Além disso, a complexidade dos sistemas está exigindo pessoal mais capacitado, gerando um custo maior no gerenciamento desses sistemas.

Uma forma de minimizar essas paradas e automatizar uma parte do gerenciamento dos sistemas, e assim, evitar prejuízos e gastos excessivos às empresas é desenvolver ou adaptar as aplicações com funções, técnicas ou características de computação autônoma.

\subsection{Definição e Características}

Como visto na Seção 4.2 , a analogia chave da computação autônoma é a de um sistema nervoso autônomo, que cuida das muitas funções vitais de baixo nível em um animal. Embora o ser humano tenha consciência do funcionamento do sistema nervoso autônomo, as funções autônomas são, em sua maioria, inconscientes e auto-reguláveis. Essas funções autônomas são implementadas por um sistema separado de nervos e suas respostas podem variar conforme as condições do ambiente interno ou externo, por exemplo, a respiração e a tax a do batimento cardíaco são modulados pelos níveis de dióxido de carbono e outros elementos químicos no sangue (RUSSELL et al., 2003b).

Em analogia ao sistema nervoso autônomo, um sistema de computação autônoma é definido como um sistema computacional que tem a capacidade de se auto-gerenciar e que funciona de forma independente, respondendo conforme às variações do ambiente interno ou externo e sem ou com mínima intervenção humana (KEPHART; CHESS, 2003; RUSSELL et al., 2003b; APPAVOO et al., 2003).

O funcionamento do sistema autônomo leva a destacar o auto-gerencimento como sendo essencial para um sistema de computação autônoma. $O$ auto-gerenciamento libera os administradores de sistema de detalhes de operação e manutenção e provê às empresas e aos usuários sistemas de alta-disponibilidade.

Para que os sistemas de computação autônoma sejam auto-gerenciáveis é preciso que o projeto e a implementação desses sistemas de computação, bem como o armazenamento e o 
suporte exibam algumas das seguintes características básicas (GANEK; CORBI, 2003; CONSTANTINESCU, 2003):

- Autonomia: um sistema de computação autônoma precisa do conhecimento detalhado de seus componentes, estados correntes e todas as conecções com outros sistemas para se auto-configurar, trabalhar de forma otimizada, recuperar-se de eventos extraordinários e auto-proteger-se.

- Flexibilidade: um sistema de computação autônoma deverá ser capaz de filtrar dados para poder se configurar ou reconfigurar sob variadas condições.

- Acessibilidade: a natureza de um sistema de computação autônoma é estar sempre ligado e, para isso, deve-se recuperar de falhas que possam causar o seu mal funcionamento.

- Transparência: um sistema de computação autônoma realiza tarefas e se adapta às necessidades do usuário, enquanto mantém sua complexidade escondida.

- Otimização: um sistema de computação autônoma deve monitorar seus componentes e procurar otimizar suas tarefas, como alocação de recursos, balanceamento de carga etc.

- Segurança: um sistema de computação autônoma de ser capaz de detectar ataques e proteger os recursos a fim de manter a integridade do sistema.

Para incorporar todas essas características em um sistema de auto-gerenciamento, o sistema de computação autônoma deve possuir 4 (quatro) atributos fundamentais, que são (BANTZ et al., 2003; CONSTANTINESCU, 2003; GANEK; CORBI, 2003; KEPHART; CHESS, 2003):

- Auto configuração: é a capacidade do sistema para configurar-se dinamicamente e adaptar-se imediatamente às mudanças no ambiente de execução, com a mínima intervenção humana. Este aspecto do auto-gerenciamento significa que novos recursos, software e servidores podem ser adicionados dinamicamente à infraestrutura do sistema sem nenhum problema.

- Auto otimização: é a capacidade que o sistema tem para maximizar a alocação e utilização dos recursos de acordo com as necessidades dos usuários, com a mínima intervenção humana. Este aspecto do auto-gerenciamento pode ser extendido a vários sistemas heterogêneos para prover uma coleção única dos recursos computacionais. 
- Auto tratamento: é a capacidade que o sistema tem para recuperar operações ou componentes problemáticos. Primeiramente o componente problemático é detectado $\mathrm{e}$ isolado do sistema, depois é concertado e reintroduzido ao sistema ou é isolado e trocado por outro componente, sem a parada total do sistema.

- Auto proteção: é a capacidade do sistema em detectar comportamento hostil ou intrusivo assim que este ocorrer e tomar ações apropriadas para tornar o sistema computacional menos vulnerável a acessos não autorizados.

Para implementar um sistema de computação autônoma com todas essas características, a indústria de computação deve adotar uma abordagem evolucionária, isto é, a cada passo acrescentar melhoramentos ao sistema até atingir um auto-gerenciamento significativo, sem contudo, ter a necessidade de mudar totalmente o ambiente do sistema (GANEK; CORBI, 2003).

$\mathrm{Na}$ prôxima seção são apresentadas algumas aplicações que estão sendo desenvolvidas por empresas de tecnologia da informação e por instituições de pesquisa.

\subsection{Considerações de Arquitetura}

Em termos arquiteturais os sistemas de computação autônoma podem ser visto como interações entre um conjunto de elementos autônomos, isto é, pequenos módulos de programa que contêm recursos e oferecem serviços a usuários ou a outros elementos autônomos. Esses elementos autônomos gerenciam seus comportamentos internos e suas relações com outros elementos autônomos de acordo com uma política. Essa política pode ser estabelecida pelo administrador, por outros elementos autônomos ou podem ser funções pré-estabelecidas que realizam as mesmas atividades em concordância com outros elementos autônomos, por um longo período de tempo (KEPHART; CHESS, 2003; CHESS; PALMER; WHITE, 2003).

O auto-gerenciamento de um sistema de computação autônoma será maior quanto mais interações ocorrerem entre os elementos autônomos e mais elementos autônomos estiverem realizando pequenas tarefas. Isso pode ser comparado à inteligência social de uma colônia de formigas, onde as interações entre as formigas e a realização de pequenas tarefas por cada formiga fazem surgir uma organização auto-gerenciável.

A Figura 4.1 mostra um exemplo típico de estrutura de um elemento autônomo. Nessa estrutura, cada elemento autônomo tem um elemento gerenciado, embora se possa ter mais de 
um, e um gerenciador autônomo. O elemento gerenciado pode ser um recurso de hardware, tal como um disco rígido ou uma CPU ou uma impressora, ou pode ser um recurso de software como um banco de dados ou um servidor de aplicação. O gerenciador autônomo, nessa estrutura, confunde-se com o próprio elemento autônomo. A única diferença é a existência ou não de um elemento gerenciado. O gerenciador autônomo monitora o elemento gerenciado e executa planos baseado na análise das informações colhidas no monitoramento. O elemento autônomo interage com outros elementos autônomos ou com um humano através do gerenciador autônomo (KEPHART; CHESS, 2003).

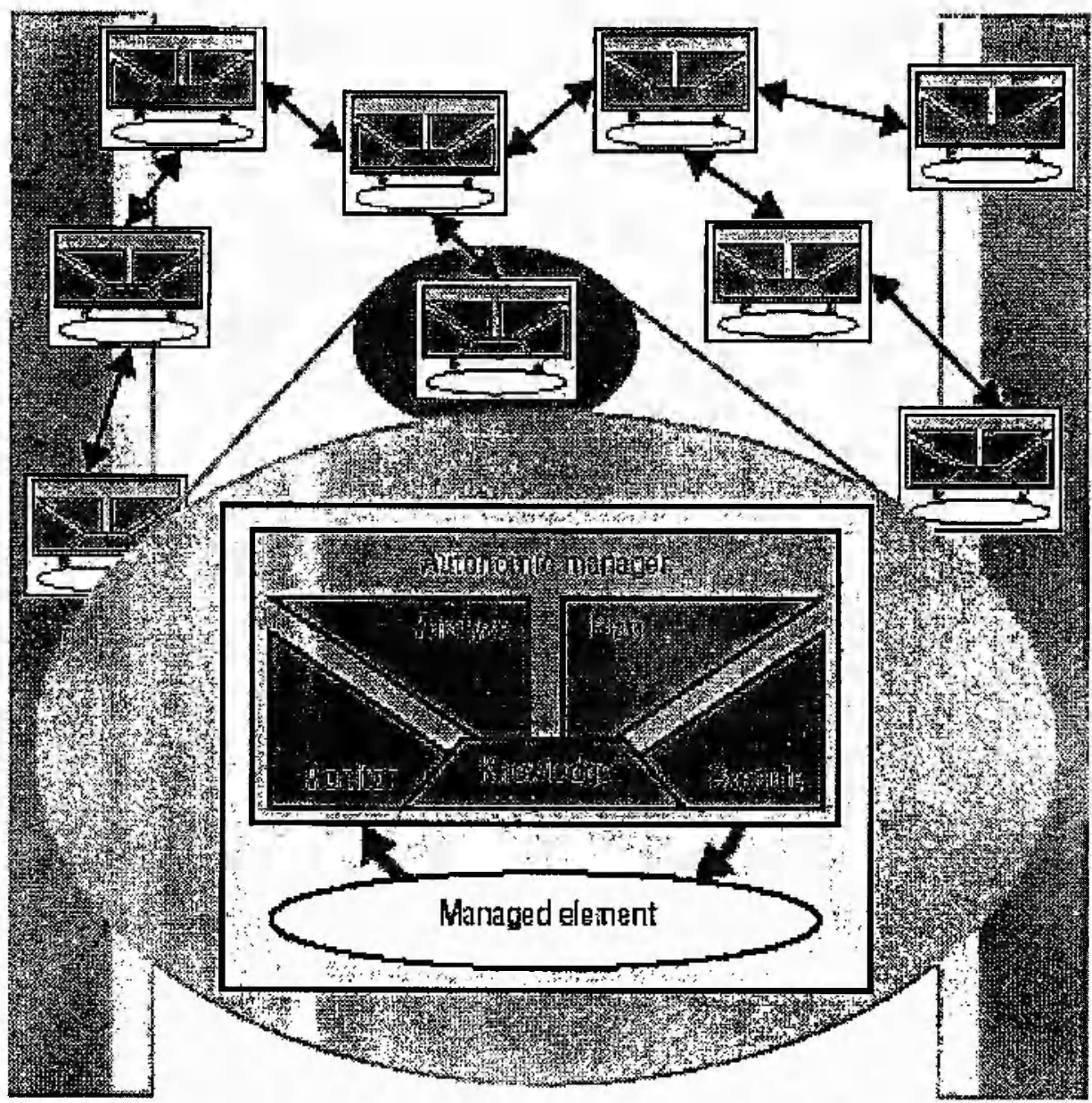

Figura 4.1 - Estrutura de um elemento autônomo e suas interações (KEPHART; CHESS, 2003)

Elementos autônomos podem funcionar em vários niveis de computação, desde componentes de computação simples como estações de trabalho ou servidores, passando por clusters de computadores e até em uma rede de grande escala como a rede mundial. Apesar dessa flexibilidade, um elemento autônomo tem um ciclo de vida complexo, pois ele continuamente executa atividades e continuamente monitora e responde ao ambiente onde ele se situa (KEPHART; CHESS, 2003). 
Esse monitoramento contínuo por parte de um elemento autônomo e os vários aspectos que caracterizam um sistema de computação autônoma como autonomia, flexibilidade, transparência etc. são características que podem ser encontradas em um agente de software. Dessa forma, é bastante atraente desenvolver um elemento autônomo utilizando a tecnologia de agentes de software.

\subsection{Aplicações - Pesquisas e Desenvolvimentos}

Atualmente, infra-estruturas computacionais heterogêneas e complexas compostas de dezenas de aplicações, centenas de componentes de sistema e milhares de parâmetros de configuração já são uma realidade. A dura tarefa de gerenciar toda essa infra-estrutura computacional complexa mais a necessidade que as empresas têm, no contexto da dinâmica da economia, de disponibilizar essas infra-estruturas computacionais 24 (vinte e quatro) horas por dia e 7 (sete) dias por semana, está exigindo cada vez mais especialistas altamente capacitados e disponíveis. Essa exigência está ocasionando um aumento nos custos de pessoal dentro da empresa e, em muitas delas, os custos com mãos-de-obra especializada já excedem os custos com equipamentos (GANEK; CORBI, 2003).

Uma possível solução para todo esse problema é o desenvolvimento de sistemas de computação autônoma contendo as características apresentadas na Seção 4.4, que são: auto configuração, auto otimização, auto tratamento e auto proteção.

Atualmente, ainda não existe um sistema de computação autônoma que contenha todas essas características (PEREIRA, 2002; SOLTIS, 2003). Mas, as pesquisas em sistemas de computação autônoma têm aumentado significativamente, ocorrendo em diversas áreas, tais como: redes de comunicação, banco de dados, computação ubíqua, e-business, computação grid e servidores de aplicações (balanceamento de carga, alocação de processos, monitoramento de energia, atualização automática de softwares e drivers, correção de erro de memôria, sistema de backup e recuperação).

Pode-se constatar esse aumento, pela quantidade substancial de empresas de tecnologia de informação e instituições de pesquisas que estão empenhadas no desenvolvimento de sistemas autônomos. A seguir têm-se alguns exemplos de iniciativas acadêmicas e industriais: 


\section{Acadêmicos:}

- OceanStore - UC Berkeley Computer Science Division:

OceanStore será um repositório global de dados persistentes projetado para suportar acessos continuos a dados por bilhões de usuários. Ele será autônomo, otimizará dinamicamente os acessos aos dados através de um algoritmo de roteamento probabilistico, fará o monitoramento e adaptação de roteamentos e realizará testes e reparos nos dados (RHEA et al., 2003).

- Kinesthetics eXtreme (KX) - Columbia University

KX será uma meta-arquitetura implementada como uma infraestrutura de middleware para adicionar as características de um sistema de computação autônoma aos sistemas computacionais existentes (KAISER et al., 2003).

- Anthill - University of:Bologna

Anthill será um framework que dará suporte para projeto, implementação e avaliação de aplicações peer-to-peer baseados nas idéias de um sistema multi-agentes e programação evolucionária (BABAOGLU; MELING; MONTRESOR, 2002).

- Software Rejuvenation - Duke University

Software Rejuvenation é um conjunto de técnicas que serão utilizadas para o gerenciamento pró-ativo de falhas, reduzindo assim, a probabilidade de futuras quedas, paradas e degradação de performance em sistemas (CASTELLI et al., 2001).

- eBiquity - University of:Maryland Baltimore County

eBiquity é projeto que explora as interações entre Computação Pervasiva, Sistemas Multi-agentes e Inteligência Artificial, e serviços web (HARIRI; PARASHAR, 2003).

- Recovery Oriented Computing - UC Berkeley/Stanford

Recovery Oriented Computing é um projeto que investiga novas técnicas para a construção de serviços para Internet, enfatizando a abordagem de recuperação de falhas em vez de prevenção de falhas (PATTERSON et al., 2002). 
- Autonomia - University of Arizona

Autonomia será um ambiente que proverá aos desenvolvedores ferramentas apropriadas para o controle e gerenciamento de sistemas, bem como serviços de middleware para suporte a computação autônoma (HARIRI et al., 2003).

\section{Industriais:}

- eLiza - IBM

É um dos primeiros projetos rumo a um sistema de computação autônoma e consistirá em um conjunto de ferramentas para auto gerenciamento de tecnologia da informação, principalmente em relação a negócios na Internet (e-business) (SUTTON, 2001).

- $\quad$ 1 1 - Sun Microsystems

N1 será um conjunto de aplicativos para a otimização de serviços e utilização de recursos de rede com o intuito de facilitar o gerenciamento da rede (TURNER et al., 2004).

- AutoAdmin - Microsoft

AutoAdmin será um sistema que fará o auto tratamento e auto administração de base de dados (HARIRI; PARASHAR, 2003).

Apesar de existirem vários projetos de computação autônoma sendo desenvolvidos, é interessante destacar que já existem sistemas que possuem componentes de hardware ou software com algum comportamento autônomo. Como exemplos, têm-se (GANEK; CORBI, 2003):

- Gerenciamento de dados: componentes de banco de dados que utilizam cálculos estatísticos para localizar potenciais gargalos e ajudar a melhorar o acesso a base de dados.

- Software e servidores web: servidores web que provêm informações de diagnôstico de problemas em tempo real.

- Gerenciamento de sistemas: software de gerenciamento de sistemas que podem detectar problemas, oferecer o diagnóstico e as possíveis soluções para o problema. 
Apesar de todos esses avanços, existem ainda alguns desafios e dificuldades a serem considerados com relação ao desenvolvimento de um sistema de computação autônoma, que são (BANTZ et al., 2003):

- Segurança: a falta de facilidade de uso dos esquemas de segurança ainda causa um retardo na sua utilização, principalmente em tecnologias recentes como o wireless.

- Conectividade: a mobilidade adiciona complexidade em um sistema e cada localização tem seus prôprios atributos de conectividade.

- Armazenamento: dados são frequentemente armazenados em muitos lugares e em múltiplas versões.

- Colaboração entre grupos e membros de grupos: as dificuldades em formar os grupos, identificar um tipo específico de colaboração entre os grupos e membros de grupos e determinar os privilégios de cada grupo e de cada membro do grupo.

- Serviços baseados em rede: questóes de segurança e escalabilidade da infraestrutura.

A maioria dessas questões não necessita ser aplicada a todos os ambientes computacionais, senão em ambientes mais complexos. De fato, a computação autônoma é uma idéia que surgiu para ser aplicada e desenvolvida em infraestruturas e sistemas complexos. Um bom candidato para desenvolver um sistema de computação autônoma é um cluster de computadores.

\subsubsection{Computação Autônoma aplicada a Cluster de Computadores}

Como visto no Capítulo 3, um cluster de computadores é um conjunto de servidores conectados por uma rede de alta velocidade que fornecem recursos e diferentes serviços aos usuários. Um cluster de computadores é um tipo de sistema computacional que traz muitas vantagens para uma empresa, sendo que as principais são o baixo custo dos equipamentos, performance, escalabilidade e alta disponibilidade. Apesar dessas vantagens, um cluster de computadores nã̃o é tão simples de gerenciar, pois envolve várias máquinas e cada máquina possue vários serviços. Dessa forma, uma opção para o gerenciamento de clusters é contratar um especialista que tenha disponibilidade para tratar dos problemas que eventualmente venham a surgir. Uma outra opção seria o gerenciamento através de um sistema autônomo. 
Para aplicações web, um cluster de computadores, denominado Web Farm Cluster, tem seus serviços fornecidos por diferentes componentes de software, tais como o balanceador de carga, servidores web, servidores de aplicações e servidores de banco de dados.

$\mathrm{Na}$ literatura, ainda existem poucos sistemas, que possuam alguma característica de computação autônoma, aplicados especificamente para cluster de computadores. Entre os sistemas existentes, podem-se citar os seguintes (ABBONDANZIO et al., 2003):

- Raquarium - IBM

O Raquarium é uma solução fechada que é integrada ao IBM Director, que é um produto de gerenciamento de sistemas xSeries e é aplicado especificamente em Web Farm Clusters. Ele possui componentes que simplificam o ciclo de vida do gerenciamento de serviços e da capacidade sob demanda.

- BladeForce Suite, OpForce Suite e Elemental Server - Jareva Technologies, Inc.

Suporta o desenvolvimento de software de aplicação, do sistema operacional e ainda da configuração de redes utilizando VLAN (Virtual Local Area Network).

- ThinkControl Suite - ThinkDynamics Inc.

Automatiza a alocação de servidores e recursos de rede.

- Control Center - Terraspring Inc.

É uma interface de usuário que disponibiliza ao operador o gerenciamento de um conjunto de servidores, compreendendo a rede e os recursos de armazenamento.

Na próxima seção são apresentados alguns benefícios que os sistemas autonômicos podem trazer às empresas e usuários.

\subsection{Benefícios}

A IBM fez um estudo e constatou que o custo de se treinar o pessoal para gerenciar sistemas é aproximadamente equivalente ao custo dos equipamentos e estimou-se que o custo de pessoal dobrará o de equipamentos nos próximos cinco ou seis anos (GANEK; CORBI, 2003). 
Logo, no contexto acima descrito, a tecnologia de auto-gerenciamento dos sistemas autônomos fornecerá diversos benefícios, tanto para empresas quanto para usuários. Dentre os benefícios, podem ser destacados:

- Redução substancial dos custos de operação e de pessoal especializado.

- Redução da dependência da intervenção humana para manter sistemas complexos.

- Redução da complexidade computacional para usuários finais.

- Redução na manutenção do sistema.

- Alta disponibilidade dos serviços.

- Produtividade.

- Redução do tempo de desenvolvimento de novos sistemas.

Outros beneficios podem ser obtidos, mas com relação a capacidades técnicas dos sistemas autônomos, como:

- Eficiência operacional.

- Colapso menos frequente do sistema.

- Aumento da estabilidade do sistema.

- Utilização balanceada dos processadores, de forma a evitar processadores ociosos.

- No longo prazo, indivíduos, organizações e negôcios poderão contar com soluções mais simples (de operar) para a resolução de problemas complexos.

\subsection{Considerações Finais}

Neste Capítulo foi apresentada uma visão geral sobre a computação autônoma. Nele foram descritos um histốrico e os conceitos relacionados, bem como as características que a concebem como tal, além de algumas considerações de arquitetura, aplicações existentes e os beneficios que ela pode proporcionar.

Neste Capítulo, mostrou-se que as características que envolvem um sistema de computação autônoma se tornam interessantes e vantajosas quando aplicadas no desenvolvimento de sistemas de gerenciamento que atuam em ambientes complexos. Isso se deve, dentre outros fatores, ao custo em se obter pessoas especializadas e pela grande probabilidade de erros humanos quando estes lidam com sistemas complexos.

Foi destacado que um ambiente bastante interessante e complexo que se beneficiaria com o desenvolvimento de um sistema de computação autônoma é o de clusters de computadores. 
Este trabalho utilizou características dos sistemas de computação autônoma para desenvolver um sistema, utilizando agentes de software, para monitorar e controlar os principais serviços e estados de um Web Farm Cluster. 


\subsection{Considerações Iniciais}

O cluster de computadores montado no Laboratório Intermídia, ICMC-USP, faz parte de um projeto de pesquisa financiado pela Fapesp. O projeto é intitulado "Gerenciamento de Atividades de Ensino via Internet usando Agentes de Software e Clusters de Computadores" (processo 01/10203-9).

Esse projeto tem como objetivo a criação de um ambiente, usando o modelo de agentes de software, para o gerenciamento de atividades de Ensino via Internet, podendo ser usado tanto como ferramenta de apoio para o ensino presencial como a distância.

Esse ambiente deve rodar em clusters de computadores baseados no sistema operacional Linux. Para essa finalidade seria montado um cluster com 8 nós (cada nó com duas CPUs Pentium III $1 \mathrm{GHz}$ com $256 \mathrm{MB}$ de memória e 20 GB de disco), interconectados por uma rede Gigabit Ethernet e montados num rack. Mas, como a Fapesp, em parecer de sua assessoria, avaliou que a importância do projeto era mais tecnológica e de engenharia do que de inovação, houve uma redução dos recursos financeiros concedidos. Juntando-se a isso a alta do dólar com consequente alta nos preços dos computadores, teve-se que alterar a idéia original, que era a montagem de um cluster com computadores de maior confiabilidade em um rack. Essa alteração consistiu na aquisição de máquinas desktop, mais baratas, para tentar manter o poder de processamento dos nós do cluster em detrimento da qualidade das máquinas dos mesmos.

Essa alteração mudou o tipo de software de gerenciamento que deveria rodar no cluster. Como essas máquinas mais baratas oferecem uma menor confiabilidade, o cluster teve de incluir programas e topologia (serviços redundantes) para se tornar um cluster de alta disponibilidade, além de alta performance. Isso resultou num projeto de cluster melhor: mais barato (com o uso de máquinas mais baratas), mas com a mesma performance de um cluster mais caro. Mas, infelizmente, também significou um maior tempo de montagem com a adição 
de serviços redundantes e o desenvolvimento de programas de gerenciamento, que agora têm de levar em consideração a possibilidade de falhas nos nós do cluster.

Este Capítulo tem como objetivo mostrar e descrever as várias etapas que foram necessárias para a implementação do cluster do Laboratório Intermídia.

\subsection{Arquitetura do Cluster do Laboratório Intermídia}

O Cluster montado no Laboratório Intermídia do ICMC-USP é do tipo Web Farm e é formado por 8 computadores: 6 nós, um director mestre e um director escravo, como visto na Figura 5.1.

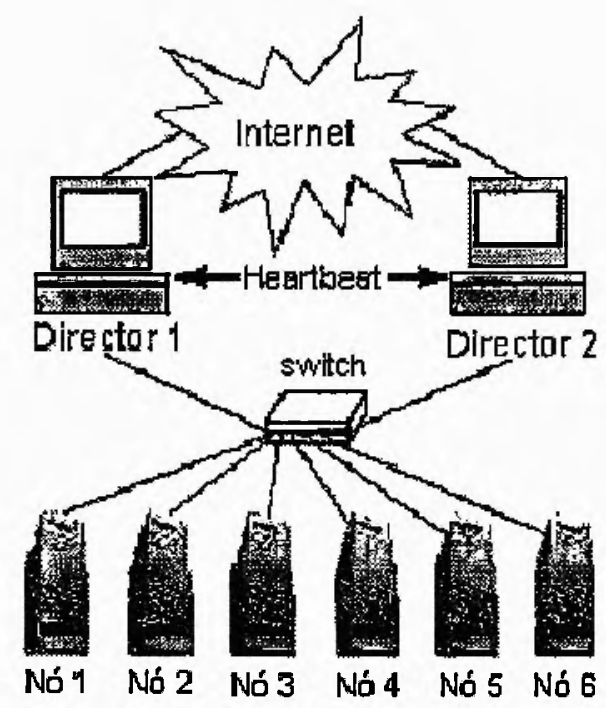

Figura 5.1 - Arquitetura física do Cluster do Laboratório Intermídia

Como na maioria dos clusters de computadores, os nós e os directors do Cluster do Laboratório Intermídia são interligados por um switch utilizando o protocolo TCP/IP. A tecnologia de hardware de rede utilizado é do tipo Fast Ethernet. Atualmente existem redes mais rápidas, dentre as mais utilizadas estão a Gigabit Ethernet e a Myrinet (BAKER, 2000), mas, pelos motivos apresentados na Seção 5.1, teve-se que optar pela Fast Ethernet, que embora não seja a mais rápida, supriu as necessidades do projeto.

Para a implementaçã̃o do cluster foi utilizada uma arquitetura centralizada em relação à distribuição de requisições, através do uso de um director. Um director, como visto no Capítulo 2 é uma máquina que atua como interface entre os nós servidores de um cluster e a Internet e que, especificamente, faz a tradução dos endereços internos do cluster para a Internet e vice-versa, além do balanceamento de carga entre os nós do cluster. $\mathrm{O}$ 
balanceamento de carga ocorre através da distribuição das requisições dos clientes aos nós servidores do cluster, de acordo com um algoritmo de escalonamento.

A tradução de endereços e o balanceamento de carga são feitos através do programa LVS (Linux Virtual Server), que já foi discutido no Capítulo 2, Seção 2.7.3.

O tipo de arquitetura do Web Farm Cluster (WFC) do Laboratório Intermídia, mostrada na Figura 5.1, além de centralizada, é uma arquitetura bidirecional baseada na camada 4 do protocolo OSI (Open Systems Interconnection), visto no Capítulo 2, Seção 2.7.2.

Essa arquitetura é baseada no NAT. A arquitetura NAT foi escolhida para o WFC do Laboratório Intermídia principalmente pela sua característica de utilizar apenas um endereço IP externo e pela segurança que ele propicia com relação a invasões externas. Nesse tipo de arquitetura, as requisições dos clientes e as respostas a essas requisições passam pelo director, tornando-o dessa forma, um ponto único de falha. Para evitar que o cluster pare de funcionar devido à falha do director, foi adicionado ao cluster um segundo director, conhecido como director secundário. $\mathrm{O}$ director secundário serve para substituir o director principal ou director primário, quando este parar de funcionar.

O director secundário assume as funções exercidas pelo director primário utilizando o programa Heartbeat (MAROWSKY-BRÉE, 2003).

\subsection{Infra-estrutura de hardware do Web Farm Cluster}

A infra-estrutura do WFC teve que se ajustar às mudanças ocorridas com a redução de recursos financeiros do projeto. Essa redução, como visto na Seção 53, levou à aquisição de máquinas desktop de menores custos. Como essas máquinas não foram feitas para ficarem ligadas 24 horas por dia durante os 7 dias da semana (operação $24 \times 7$ ), pois elas apresentam uma alta taxa de pequenos defeitos (ventoinhas, fontes etc), foi necessário incluir programas e serviços redundantes, além de pequenas modificações na topologia do WFC, para que o cluster conseguisse a característica de alta disponibilidade.

Como foram utilizadas máquinas desktop na montagem do WFC, foi possível a criação de um cluster de uso misto, distribuído da seguinte maneira: 
- Três máquinas são usadas exclusivamente para serviços do cluster: aplicações web, serviços $E J B$ (Enterprise Java Beans) etc. Elas não têm monitor, teclado ou mouse, como mostrado na Figura 5.2.

- Três máquinas são usadas para serviços do cluster e para desenvolvimento. Elas têm monitor de 17', teclados e mouse (Figura 5.3), além de interface gráfica, programas de desenvolvimento, como os ambientes Websphere Studio Application Developper, Eclipse e Netbeans (para o desenvolvimento de aplicações Java), e aplicativos comuns, como editores de texto (Staroffice), navegadores web (Netscape, Nautilus) etc.

Esta opção permite um uso mais racional do poder de computação dos nós do cluster. Raramente todo o poder computacional das 6 máquinas do cluster estará sendo usado para atender requisições. Assim pode-se usar esse recurso computacional extra para outros usos, como desenvolvimento.

Cada uma das 6 máquinas que formam os nós do cluster é um microcomputador que tem as seguintes características de hardware:

- Dual Athlon XP 1.6GHz.

- $512 \mathrm{MB}$ de memória.

- $256 \mathrm{~KB}$ de cache.

- 1 disco rígido de 40GB IDE ATA 100 de alta performance

- 1 Placa de rede Fast Ethernet.

Os directors não participam do processamento das requisições feitas ao cluster, por isso foram colocadas máquinas menos potentes para desempenhar esse papel, como se pode observar na Tabela 5.1 - Configuração de hardware dos directors:

\begin{tabular}{|l|l|}
\hline \multicolumn{1}{|c|}{ Primário } & \multicolumn{1}{c|}{ Secundário } \\
\hline Pentium III $866 \mathrm{MHz}$. & Pentium II 266MHz. \\
$256 \mathrm{MB}$ de memória. & 64MB de memória. \\
$256 \mathrm{~KB}$ de cache. & $512 \mathrm{~KB}$ de cache. \\
1 disco rígido de 4GB. & 1 disco rígido de 3GB. \\
2 placas de rede Fast Ethernet. & 2 placas de rede Fast Ethernet. \\
\hline
\end{tabular}

Tabela 5.1 - Configuração de hardware dos directors 


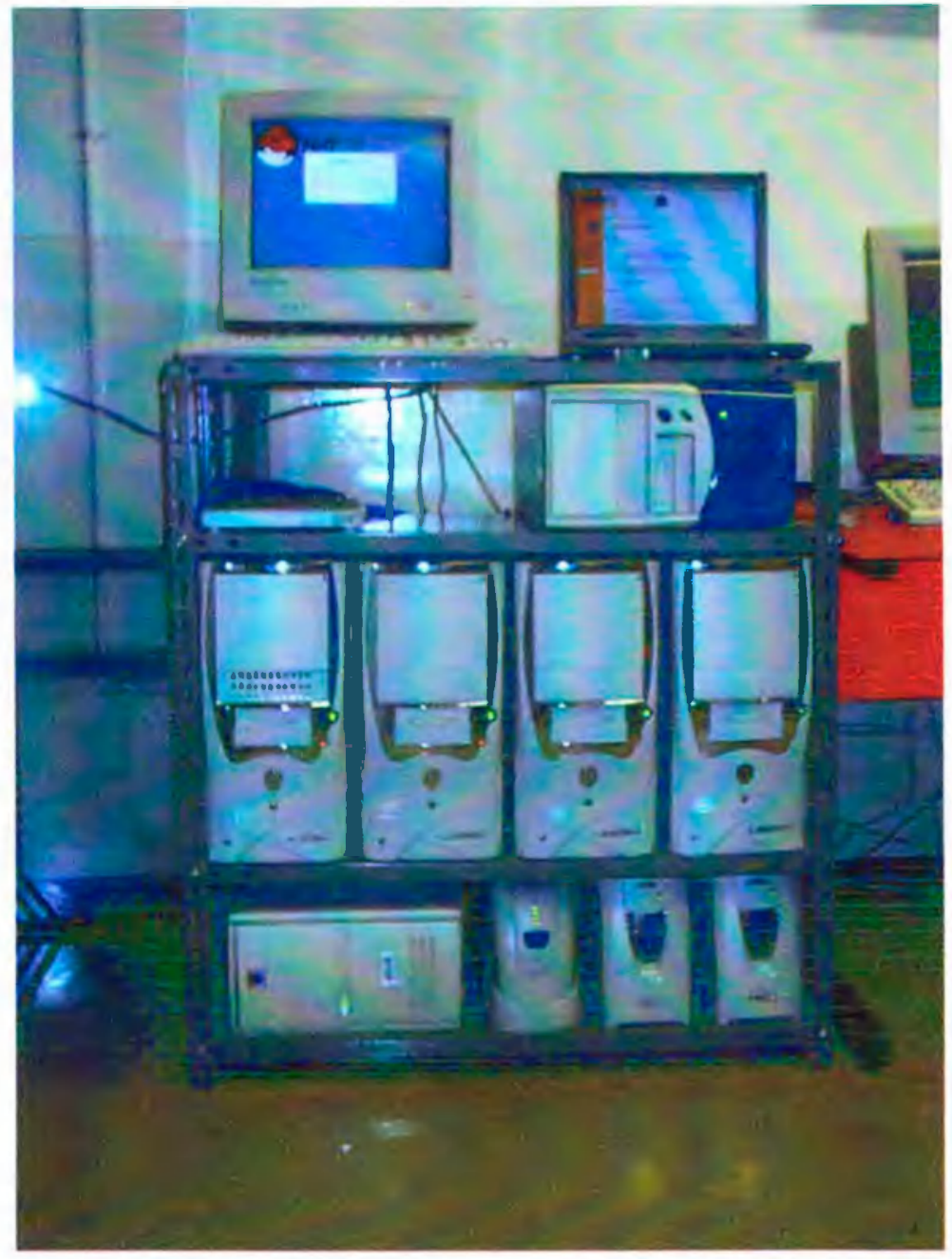

Figura 5.2 - Estante com as máquinas do cluster

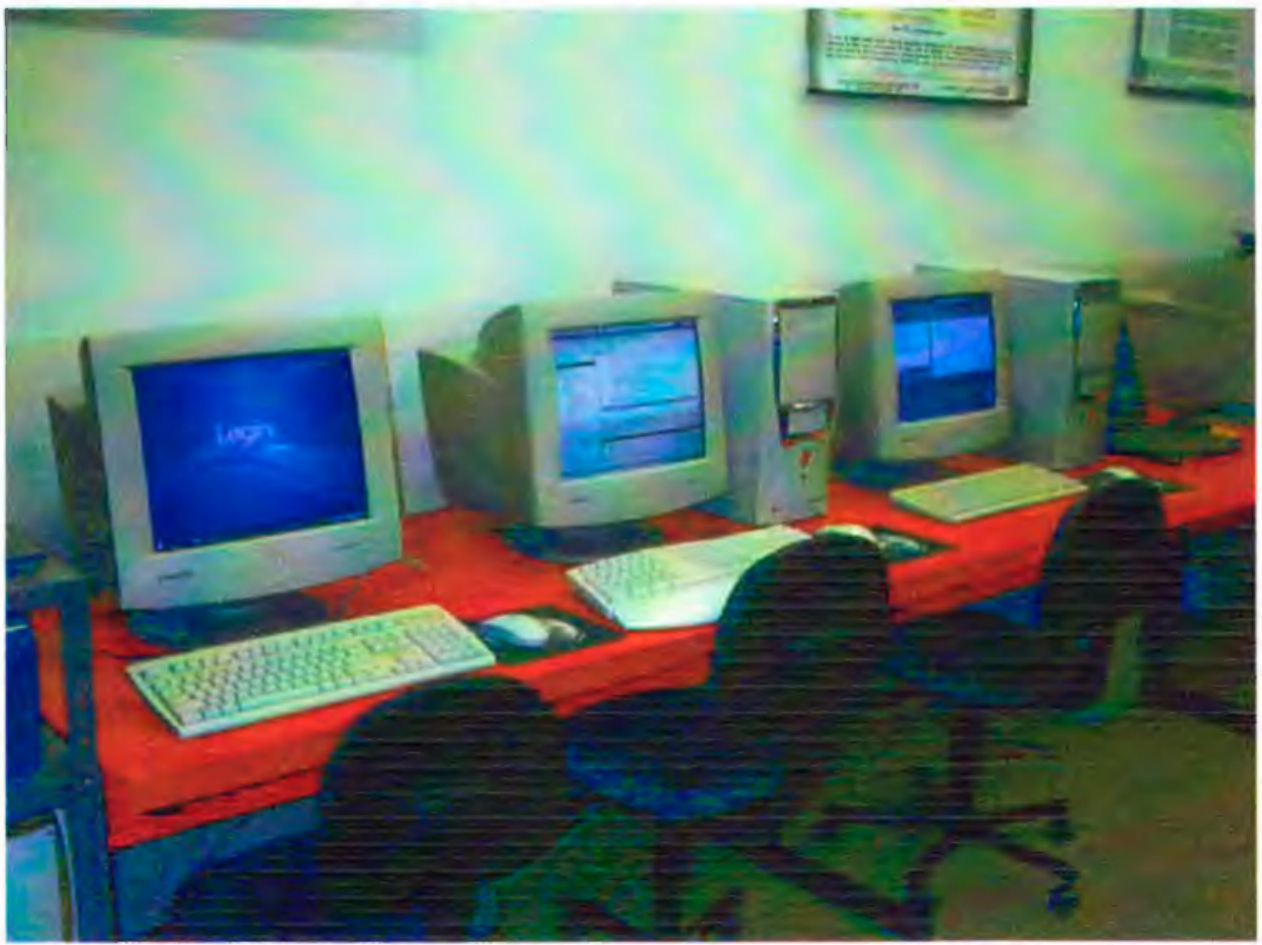

Figura 5.3 - Os 3 nós de uso misto 
Como visto na Seção 54, o director secundário é um recurso utilizado para prover a alta disponibilidade dos serviços do WFC. Um outro recurso utilizado, que também ajuda a manter disponibilidade dos serviços, são os nobreaks. No WFC são utilizados 3 nobreaks, que podem ser vistos na Figura 5.2 - Estante com as máquinas do cluster, sendo que um deles tem um sistema inteligente de desligamento dos computadores.

Os nós do cluster e os directors são conectados por um switch, como visto na Seção 54 . O switch utilizado é do tipo store-and-forward dual speed de 8 portas. Esse tipo de switch tem uma pequena desvantagem em relação a um switch do tipo cut-through no aspecto de performance. Porém, um switch store-and-forward tem a vantagem de garantir a integridade dos quadros de dados (STALLINGS, 2000).

A conexão dos nós e directors ao switch é feita por cabos de par trançado de categoria 5E sem blindagem. Os cabos de par trançado sem blindagem têm um custo bem menor que outros tipos de cabeamento, além disso, são mais flexíveis, mais utilizados e mais fáceis de serem manipulados. A categoria $5 \mathrm{E}$ pode atingir uma largura de banda acima de $100 \mathrm{MHz}$, o que é ideal para tecnologias Fast Ethernet, e é menos suscetível a interferências de fontes externas (STALLINGS, 2000; TANENBAUM, 2003).

\subsection{Infra-estrutura de Software do WFC do Laboratório Intermídia}

Para que o WFC do Laboratório Intermídia seja do tipo web-farm é necessário que ele possua uma certa infra-estrutura de software. A idéia é que essa infra-estrutura de software, juntamente com a infra-estrutura de hardware, garanta a disponibilização de serviços web.

Um software básico para um funcionamento estável de um cluster de computadores é o sistema operacional. O sistema operacional utilizado no WFC é o Linux. A escolha do sistema operacional Linux deveu-se pelos motivos já comentados no Capítulo 2, Seção 13.

Um WFC de arquitetura centralizada necessita também de um programa que gerencie as requisições, isto é, um software que faça a distribuição das requisições aos nós servidores. O Linux Virtual Server (LVS) foi a escolha feita. Essa escolha deveu-se pelas seguintes razões:

- É implementado em software.

- $\dot{E}$ livre e de código aberto. 
- Suporta tanto a arquitetura unidirecional (NAT - Network Address Translation) quanto a arquitetura bidirecional (Tunelamento de Pacotes ou Direcionamento de Pacotes), discutidas no Capítulo 2, Seção 18.

- Disponibiliza 8 tipos de algoritmo de escalonamento (Round-Robin, Weighted Round-Robin, Least Connection, Weighted Least-Connection, Localy-Based LeastConnection, Localy-Based Least-Connection with Replication, Destination Hashing e Source Hashing).

Para que as requisições sejam atendidas igualmente por qualquer um dos nós devidamente registrados na lista de distribuição de um software de gerenciamento de requisições é necessário que todos esses nós tenham acesso aos dados necessitados pelos seus serviços.

Uma das formas de prover o acesso a esses dados seria utilizando um sistema de arquivos distribuído. Uma outra forma seria replicando esses dados em todos os nós servidores de serviços web.

Como o WFC do Laboratório Intermídia é de utilização mista, como visto na Seção 55, o ideal seria a utilização de um sistema de arquivos que disponibilizasse os arquivos em quaisquer nós para que os desenvolvedores tivessem um controle melhor de seus arquivos e, também, para que determinados arquivos fossem replicados em vários nós, a fim de se ter uma disponibilidade maior de serviços.

\subsubsection{Sistema de Arquivos: AFS}

Após alguns estudos, determinou-se que um sistema maduro o suficiente e capaz de oferecer essas características seria o AFS (Andrew File System). Entăo, ele foi instalado e utilizado por alguns meses. Contudo, quando foi determinado que o AFS seria uma boa solução, pensava-se em um cluster com máquinas bastante confiảveis (năo haveria a necessidade de recursos extra para se ter alta disponibilidade). Infelizmente, apenas com ventoinhas, ocorreram mais de 12 falhas em um curto periodo de tempo, o problema, alegado pelo fornecedor, é que as máquinas desktops (mais baratas) não tinham sido feitas para operar 24 horas por dia durante os 7 dias da semana (operação $24 \times 7$ ).

A tolerância do AFS a falhas infelizmente não é muito alta, falta um sistema de failover do servidor de arquivos para o processo de escrita de dados: o AFS faz replicação de dados e 
com isso tem-se uma disponibilidade maior com relação à leitura de dados, mas ele não disponibiliza um sistema de substituição do servidor de arquivos para escrita.

Além disso, outros problemas foram encontrados com o AFS durante o seu uso no WFC:

- Complexidade no seu gerenciamento: existem muitos detalhes na configuração e gerenciamento do AFS. Para configurar e gerenciar o AFS são necessários vários passos, com modificações em diversos arquivos e execuções de comandos com diversos parâmetros.

- Incompatibilidades encontradas no sistema de permissões do AFS com o sistema de permissões do Linux: como no AFS existem 7 permissões e aproximadamente 20 grupos e no Linux só existem 3 permissões e 3 grupos, não raro acontecia de usuários dos serviços web do WFC do Laboratório Intermídia não conseguirem fazer uploads de arquivos ou até mesmo visualizar certas páginas ou itens de páginas web.

A pouca tolerância a falhas do AFS aliada a falta de confiabilidade das máquinas desktaps do WFC fizeram com que esse sistema de arquivos distribuído fosse substituído por outra alternativa.

\subsubsection{Sistema de Arquivos: Sistema misto}

A nova solução para o sistema de arquivos do WFC adotou o uso do servidor de arquivos NFS, da ferramenta rsync e do servidor de aplicações JBoss, sendo que cada um deles tem uma função específica, como mostrado a seguir:

- Para os arquivos de aplicações não críticas, como, por exemplo, das áreas dos usuários de desenvolvimento, um servidor NFS é usado. A máquina servidora NFS tem dois discos em configuração RAID-1. Além disso, como seu conteúdo tem backup diário em outro nó, caso ela sofra um dano permanente, o nó de backup pode ser ativado como servidor NFS.

- Para os arquivos que são enviados ao WFC pelos usuários das aplicações web, adotou-se a replicação desses arquivos usando a ferramenta rsync. Quando um desses arquivos é modificado ou excluído, o rsync é periodicamente usado para fazer a atualização em todos os outros nós.

- Para os arquivos de aplicações $w e b$ que devem continuar rodando mesmo com a falha de múltiplos nós do cluster, adotou-se a replicação de todos esses arquivos via servidor de aplicações JBoss. 


\subsubsection{Servidor de aplicações Web: JBoss}

O JBoss é um servidor de aplicações Java que inclui um conjunto de componentes que implementam a especificação J2EE: servidor Web, Servlets, JSP (Java Server Pages), EJB (Enterprise Java Beans) etc. O micro-kernel do JBoss é baseado na especificação JMX (Java Management Extension), que define uma arquitetura para gerenciamento dinâmico de recursos (aplicações, sistemas ou equipamentos de rede) distribuídos através de uma rede (FLEURY; REVERBEL, 2003).

Gerenciamento dinâmico significa que a aplicação é capaz de carregar, descarregar e executar componentes, sem interromper ou parar as aplicações, sistemas ou equipamentos.

Além do gerenciamento dinâmico o JBoss suporta várias outras características como (FRICKE, 2004):

- Escalabilidade: o JBoss suporta rodar em cluster.

- Performance: oferece performance melhor que outros servidores de aplicações.

- Arquitetura modular e elegante: o JBoss oferece uma arquitetura única construída em um micro-kernel que resulta em modelos de componentes mais leves.

- Arquitetura orientada a serviços: serviços podem facilmente ser adicionados ou removidos, dependendo das necessidades específicas.

- Características adicionais no nível de aplicação: tem integração com JAAS (Java Authentication and Authorization Service) e outra implementações de segurança.

- Suporta padrões: o JBoss oferece suporte completo para o J2EE 1.4.

\subsubsection{Base de Dados: Servidor MySQL Redundante}

O armazenamento e disponibilização da base de dados são feitos através do sistema MySQL. O MySQL na sua versão 4.0, que é atualmente a última versão estável e é a versão que está sendo utilizada no WFC do Laboratório Intermídia, possibilita a replicação de dados em conjunto de computadores. Isso gera redundância de dados garantindo uma maior segurança contra falhas. Porém, o MySQL, nessa versão, não disponibiliza a replicação de dados juntamente com a redundância do serviço de escrita na base de dados, isto é, num conjunto de computadores, cada um com um servidor MySQL, existirá apenas um servidor MySQL com direito de escrita (servidor mestre) e a replicação de dados será feita a partir da base de dados 
desse servidor para os outros (servidores escravos). Isso gera um problema do ponto único de falha para os serviços de escrita e replicação.

Para solucionar esse problema, foi implementado um programa (mysqlmonitor) que faz o monitoramento do funcionamento do servidor mestre. O mysqlmonitor, quando detecta o mau funcionamento do servidor mestre, converte o servidor escravo em servidor mestre e lança instruções aos outros servidores escravos para que reconheçam essa mudança de servidor mestre. Quando o servidor mestre original voltar a funcionar, o mysqlmonitor detecta esse retomo e faz com que esse servidor vire um servidor escravo. A partir desse ponto, o mysqlmonitor passa a monitorar o novo servidor mestre e segue o mesmo processo anterior. Desse modo, o mysqlmonitor fornece uma maior disponibilidade do serviço de escrita na base de dados MySQL.

No contexto específico de clusters, o MySQL não fornece o balanceamento das requisições sobre a base de dados replicada entre os vários servidores MySQL. Isso acaba gerando uma performance menor no atendimento de várias requisições que precisam de acesso a base de dados. Atualmente, uma possível solução para esse problema seria a utilização do C-JDBC.

O C-JDBC é um cluster middleware para base de dados que permite a qualquer aplicação Java acessar transparentemente um cluster de bases de dados através do JDBC. Com ele, não é necessária nenhuma modificação nas aplicações cliente, ou nos servidores de aplicação ou ainda nos servidores de base de dados. A única condição é assegurar que todo acesso à base de dados seja realizado via driver C-JDBC e C-JDBC controller. A Figura 5.4 mostra o princípio de funcionamento do C-JDBC.

O driver C-JDBC encaminha as requisições SQL para o controlador C-JDBC, que então, as balanceia no cluster de bases de dados (uma requisição de leitura é encaminhada para um dos nós e uma requisição de escrita é encaminhada para todos os nós) (CECCHET et al., 2004).

O C-JDBC foi lançado em Outubro de 2002, porém ele não foi utilizado no WFC do Laboratório Intermídia porque uma versão estável não estava disponível na época da implementação do mesmo. 


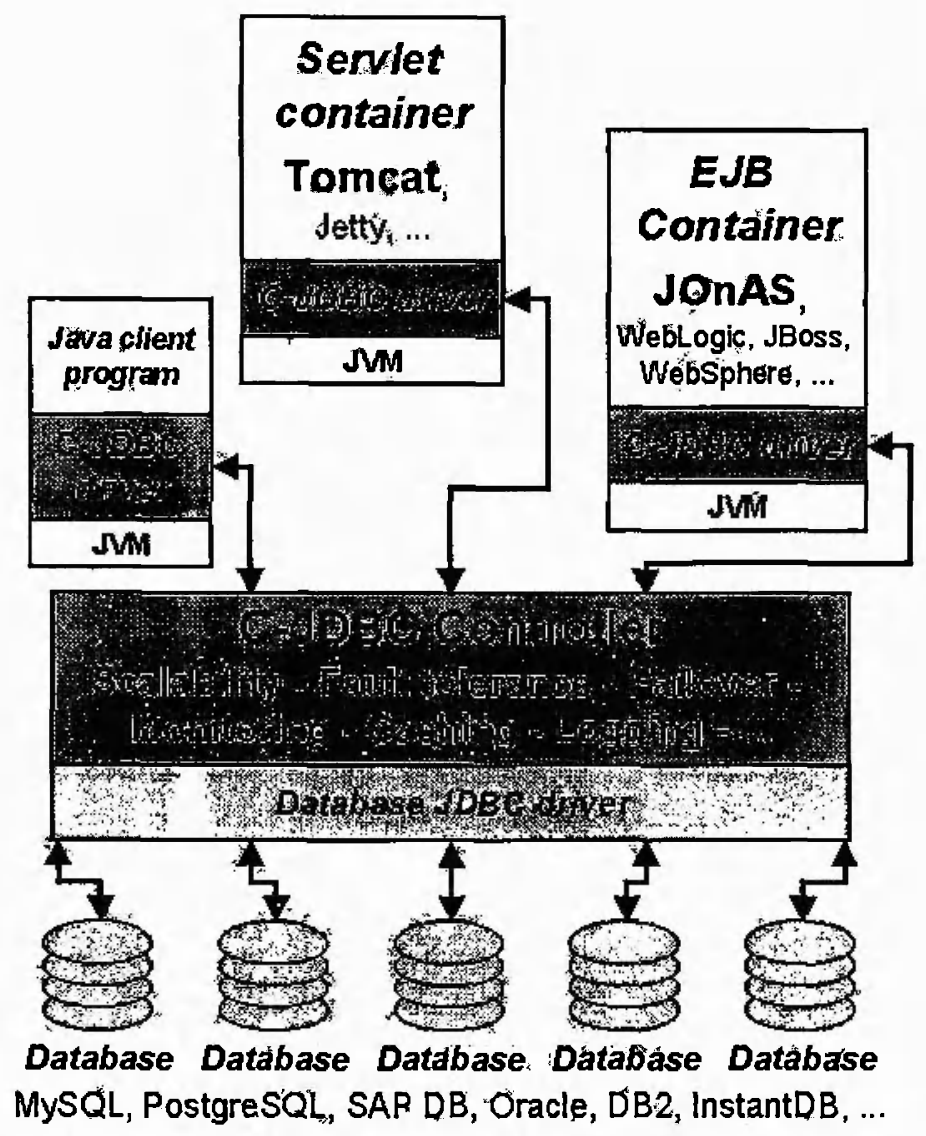

Figura 5.4 - Princípio de funcionamento do C-JDBC (CECCHET et al., 2004)

\subsection{Testes de Escalabilidade e Performance}

Testes de escalabilidade e performance no WFC do Laboratório Intermídia foram realizados com a utilização da ferramenta JMeter. O JMeter é uma ferramenta desenvolvida pelo Apache Group (http://www.apache.org) para testes de carga em servidores web. Ela é escrita em Java e permite o uso de um grupo de máquinas para gerar requisições para testar servidores web (ou FTP, ou Bancos de Dados). Ela utiliza threads para simular a geração de requisições por vários usuários (THE APACHE JAKARTA PROJECT, 2004).

A topologia para os testes foi composta pelo WFC do Laboratório Intermídia e 5 computadores, para gerar requisições ao cluster. A qualidade e a quantidade desses computadores (apenas cinco) foi determinada pelo número de máquinas livres no Laboratório Intermídia (durante o período de testes) e por problemas de baixa capacidade da conexão do laboratório com o resto da rede do ICMC-USP (o que impedia o uso de computadores de fora do laboratório). Tanto o WFC como as 5 máquinas foram ligados ao mesmo switch, para garantir uma maior capacidade de comunicação e não prejudicar a precisão nos resultados. Uma porta do switch estava ligada ao hub do laboratório (para resolução de nomes etc). No 
período de testes, o computador directorl (Pentium III) do cluster não estava disponível, então os testes foram realizados com o director2 (Pentium II). Essa troca não afetou a performance do cluster, já que o uso de CPU do director2 foi monitorado e ficou sempre bem abaixo de $20 \%$. Contudo, a quantidade e capacidade de processamento das máquinas usadas para geração de requisições prejudicou bastante os testes, já que o volume de requisições ficou muito abaixo do necessário para atingir a capacidade máxima do cluster (daí o uso da CPU do director2 ficar tão baixo).

Apesar dos problemas citados, os testes serviram para demonstrar o funcionamento do WFC (hardware e software) mesmo com nós fora do ar e para dar alguma idéia do tipo de carga mínima que ele pode suportar. Foram feitos 3 tipos de teste:

1. Acesso a uma página HTML estática.

2. Acesso a 2 páginas HTML estáticas e 2 dinâmicas (JSP com acesso a banco de dados MySQL).

3. Acesso a uma servlet Java que calculava a sequência de Fibonacci para cada acesso (não havia caching).

O teste do tipo 1 simula uma carga simples e deveria demonstrar (caso houvessem máquinas de teste suficientes) o throughput máximo do cluster, já que as páginas estáticas não exigem grande quantidade de processamento dos nós do cluster. $O$ teste do tipo 2 simula um uso mais normal do cluster, com chamadas estáticas e dinâmicas. $O$ teste do tipo 3 exige mais processamento dos nós do cluster e deveria mostrar escalabilidade, isto é, um aumento de performance com a adição de novos nós ao cluster.

Cada tipo de teste foi repetido com o cluster rodando com 6 nós, 3 nós e 1 nó, com $o$ intuito de demonstrar a tolerância do cluster a perda de nós, isto é, para demonstrar que mesmo que se alguns nós parem de funcionar o cluster continuará a fornecer os seus serviços, e também a escalabilidade. Cada repetição durou cerca de 10 minutos. Uma máquina de teste rodou o console JMeter e outras 4 rodaram como escravas gerando as requisições. A Figura 5.5 mostra a interface do JMeter em funcionamento. O gráfico mostrado nessa figura apresenta a evolução do tempo de resposta (em milisegundos), dos desvios (em milisegundos) e da quantidade de requisições por minuto. 


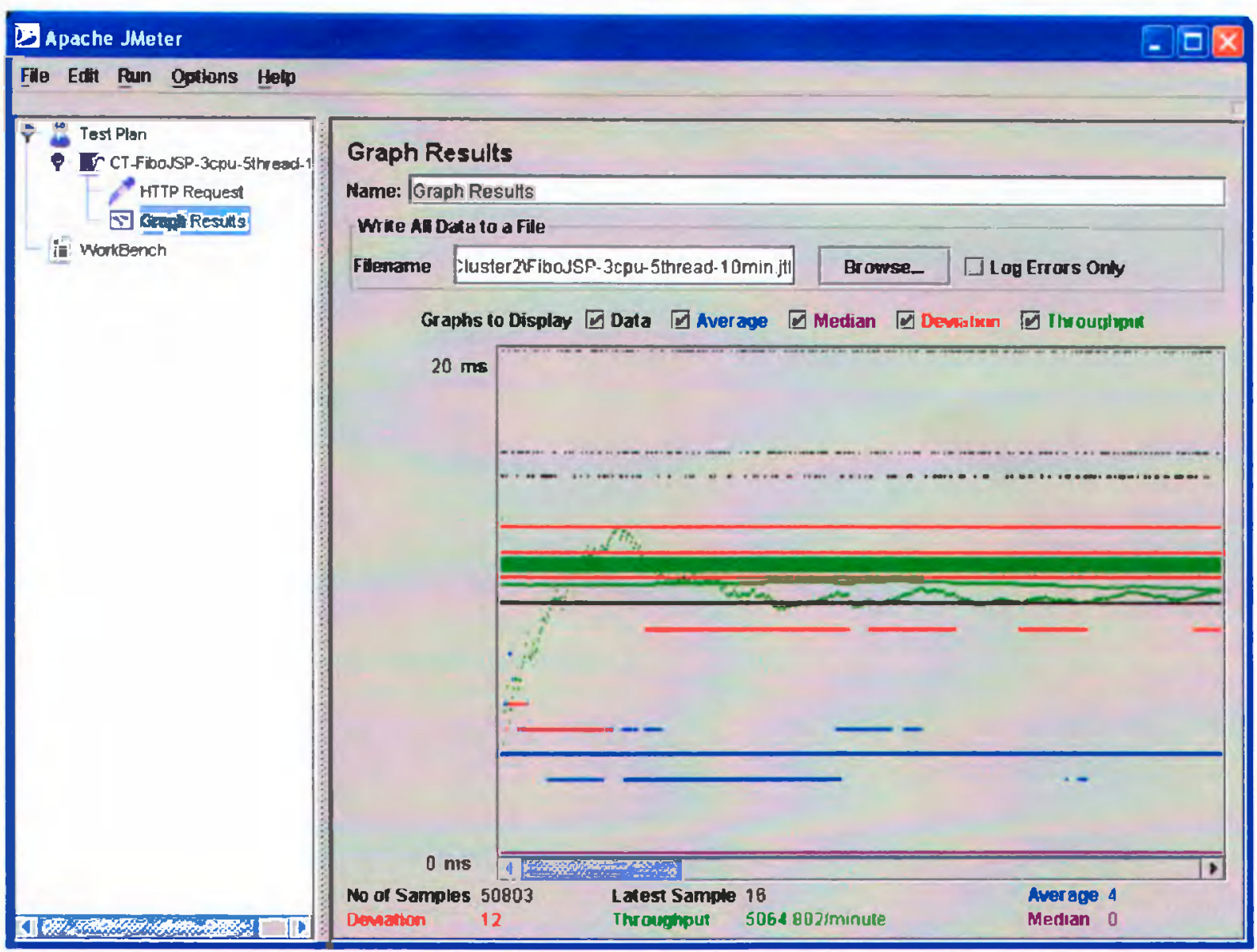

Fiqura 5.5 - Tela do JMeter mostrando os gráficos do teste 3 com 3 nós

A Tabela 5.2 mostra os resultados dos testes feitos com o JMeter. Como já tinha sido comentado, os computadores de teste foram incapazes de gerar requisições suficientes para afetar significativamente a performance do c/uster. Em todos os 3 testes, os resultados para as 3 configurações (6, 3 e 1 nós) foram muito próximos, indicando que o cluster poderia atender a muito mais requisições por minuto. O valor do throughpuı (requisições por minuto) dos testes (sendo teste $3>$ teste $1>$ teste2) é praticamente proporcional ao tamanho das páginas que o chlıster retorna em cada caso, isso sugere fortemente que esses valores estão sendo determinados pela capacidade dos computadores de teste processarem as requisições e não pela capacidade do c/lıs/er de atendê-las. Contudo, nessa tabela pode-se verificar que o clıss/er pode continuar em funcionamento mesmo com apenas um nó. Desse modo, o clıster poderá manter o funcionamento dos seus serviços com apenas 2 computadores: um direc/or (directorl ou director2) e um nó. Ou seja, no pior caso, 2 computadores (os dois directors) têm de falhar para o cluster parar, e no melhor caso, até 6 computadores ( 5 nós e um director) podem falhar e o cluster ainda continuará em funcionamento. Os valores de Ihroughpul medidos servem para se ter alguma estimativa, baseada em testes, da capacidade mínima do cluster, mas, infelizmente, não dizem nada sobre sua possível capacidade máxima 


\begin{tabular}{|c|l|c|c|c|}
\hline \multicolumn{2}{|l|}{} & 6 nós & 3 nós & 1 nó \\
\hline \multirow{3}{*}{ Teste 1 } & número de amostras & 39925 & 37923 & 38803 \\
\cline { 2 - 5 } & média (ms) & 4 & 4 & 4 \\
\cline { 2 - 5 } & desvio (ms) & 11 & 10 & 11 \\
\cline { 2 - 5 } & Throughput(req./min) & 3967.26 & 3770.32 & 3856.72 \\
\hline \multirow{5}{*}{ Teste2 } & número de amostras & 24991 & 24949 & 25355 \\
\cline { 2 - 5 } & média (ms) & 170 & 170 & 173 \\
\cline { 2 - 5 } & desvio (ms) & 215 & 215 & 217 \\
\cline { 2 - 5 } & throughput(req./min) & 2484.61 & 2482.75 & 2518.76 \\
\hline \multirow{3}{*}{ Teste 3 } & número de amostras & 49460 & 50803 & 51731 \\
\cline { 2 - 5 } & média (ms) & 4 & 4 & 4 \\
\cline { 2 - 5 } & desvio (ms) & 23 & 12 & 12 \\
\cline { 2 - 5 } & throughput(req./min) & 4920.03 & 5064.80 & 5151.41 \\
\hline
\end{tabular}

Tabela 5.2 - Testes de carga usando o JMeter

\subsection{Considerações Finais}

Neste Capítulo foi apresentada uma descrição da implementação do Web Farm Cluster do Laboratório Intermídia. Mostrou-se quais tecnologias e programas foram utilizados para essa implementação, bem como algumas dificuldades encontradas.

Como esse cluster foi montado com máquinas desktop de pouca confiabilidade, necessitou-se de programas adicionais (heartbeat, rsync, MySQL com replicação, JBoss etc) e também da implementação de um programa (mysqlmonitor) para garantir a redundância do serviço de escrita na base de dados. Essas soluções foram necessárias para garantir uma maior disponibilidade dos serviços oferecidos pelo WFC do Laboratório Intermídia.

No intuito de ter um controle melhor dos serviços e dos estados de um WFC, no próximo Capítulo é apresentado o sistema de gerenciamento desenvolvido para o WFC do Laboratório Intermídia. 


\section{6iCluster-Sistema de Gerenciamento
de Web Farm Cluster}

\subsection{Considerações Iniciais}

A crescente utilização de clusters de computadores nas mais diversas áreas de aplicação da computação tem aumentado a necessidade de profissionais com maior capacitação técnica e maior disponibilidade para gerenciar esses tipos de sistemas. Uma maneira de auxiliar o gerenciamento de clusters de computadores é utilizar sistemas de computação autônoma que monitoram os serviços e os recursos disponibilizados pelo cluster.

Pelas propriedades inerentes aos sistemas autônomos, apresentadas no Capítulo 4, clusters de computadores são candidatos ideais para implementação de sistemas computacionais autônomos, pois como apresentado no Capítulo 2, um cluster é formado por diversos computadores interligados (formando um sistema grande e complexo) que idealmente devem trabalhar de maneira harmoniosa, sem muita intervenção humana. Além disso, com todas as características apresentadas no Capítulo 3, os agentes de software têm muito a oferecer à computação autônoma.

Os agentes de software podem ser implementados de diversas maneiras, sendo que neste projeto, foi utilizado o conceito de agentes baseados em comportamento. Nesse tipo de agentes, comportamentos são as unidades fundamentais que compõem o programa que os controlam. $\mathrm{O}$ comportamento é definido como uma regularidade na dinâmica de interação do agente com seu ambiente.

Diferentes tipos de agentes podem trabalhar juntos no mesmo problema e ter suas próprias "personalidades". Essas personalidades são determinadas pelo conjunto de comportamentos que um agente pode ter. Mudanças de comportamento podem ser disparadas pela percepção pelo agente de mudanças em seu meio ambiente ou diretamente através de outros agentes (MOREIRA, 1995). 
Essa técnica de implementação de agentes, parecida com o modo como comportamentos se expressam em muitos animais (como insetos), dá características quase "orgânicas" aos agentes, o que idealmente é esperado de um sistema computacional autónomo, ou seja, que o sistema computacional se comporte como um sistema biológico. Assim, utilizou-se essa técnica para a implementação dos vários agentes que formam o sistema autónomo para controle de clusters.

O iCluster, apresentado neste capítulo, é um sistema para gerenciamento de Web Farm Clusters (WFCs), desenvolvido com a tecnologia de agentes de software, que tem por objetivo manter a alta disponibilidade dos serviços oferecidos por esse tipo de cluster.

\subsection{Visão Geral do iCluster}

Atualmente a utilização de clusters de computadores para fornecer serviços, aplicações e dados web tem aumentado significativamente. Esse aumento se deve, principalmente, à disponibilidade de serviços oferecidos pela própria natureza distribuída e redundante de um cluster de computadores. Apesar de ser naturalmente distribuído e redundante, a parada de serviços em um nó ou a parada de um nó do cluster pode degradar significativamente a performance do cluster como um todo, principalmente em clusters que possuam um fluxo alto de requisições. Além disso, pode haver, dependendo do balanceador de carga, uma continuidade na distribuição de requisições para um nó ou serviço fora de operação. $O$ objetivo do iCluster é assegurar uma maior disponibilidade de serviços e recursos oferecidos por um WFC, de modo que o administrador de um WFC possa se concentrar na parte estrutural e organizacional do gerenciamento.

Para atingir esse objetivo, o iCluster utiliza um conjunto de agentes para monitorar as principais variáveis que possibilitam a parada do fornecimento de serviços de um WFC e, ainda, disponibiliza ao administrador alguns recursos de gerenciamento.

Depois de analisar os principais problemas que podem ocorrer em um WFC e que possibilitariam a algum nó ou serviço tornar-se indisponivel, um conjunto de variảveis foi identificado para o monitoramento base dos agentes:

- Serviços: requisições podem deixar de ser atendidas devido a um serviço fora de operação. 
- Rotação das ventoinhas: as ventoinhas, que refrigeram os processadores, são fundamentais para o bom funcionamento dos nós. O mau funcionamento das ventoinhas, que pode ser detectado pela redução de sua rotação, ocasiona o superaquecimento dos processadores podendo gerar comportamentos impróprios.

- Temperatura dos processadores: os processadores podem operar até uma temperatura máxima. Se essa temperatura for ultrapassada, podem ocorrer danos aos mesmos.

- Voltagem dos componentes de uma placa mãe: os componentes de uma "placa mãe" operam em uma determinada voltagem com uma taxa de tolerância. Se a voltagem tiver uma oscilação fora do valor de tolerância, os componentes da "placa mãe" podem ser danificados e causar problemas de funcionamento.

- Espaço em discos rígidos: serviços podem deixar de completar suas operações por falta de espaço em disco.

- Memória: serviços podem deixar de completar suas operações por falta de memória disponível ou ficarem lentos com o uso demasiado de swap.

- Nós: o próprio nó é uma variável que deve ser monitorada por um agente a fim de se obter consistência na distribuição de requisições, e para que, remotamente, um nó fora de operação possa ser adequadamente reinicializado.

Os agentes do iCluster foram projetados para monitorarem essas variáveis, observando o comportamento delas em cada nó de um WFC, e tomarem medidas resolutivas, preventivas e informativas. A medida resolutiva está relacionada com a execução de ações para tentar solucionar um problema ocorrido. A medida preventiva está relacionada com o envio de mensagens ao administrador avisando sobre problemas iminentes. A medida informativa está relacionada com o envio de mensagens ao administrador no intuito de informá-lo de um problema ocorrido e não solucionado.

O principal conceito relacionado aos agentes do iCluster é a simplicidade. Cada agente é uma entidade única que desempenha uma atividade específica e coopera ou não com outros agentes. Quando o comportamento de uma variável sofre alteração e atinge um valor limite, o agente encarregado dessa variável toma as providências cabiveis de acorđo com suas capacidades. 
Além de monitorar os serviços do cluster, o iCluster disponibiliza ao administrador, recursos de visualização (via web) dos estados das variáveis (descritas anteriormente) e recursos de adição e remoção de serviços a serem monitorados e de serviços relacionados à lista de distribuição do director.

De modo geral, as seguintes características podem ser encontradas no iCluster:

- Facilidade na visualização dos estados das variáveis: os estados das variáveis são disponibilizados e visualizados através de páginas web.

- Facilidade no gerenciamento dos serviços, tanto de monitoramento quanto da lista de distribuição do director: os serviços de monitoramento e da lista de distribuição do director são gerenciados por meio de páginas web.

- Rodar somente em clusters baseados em Linux: o iCluster, apesar de escrito em Java, é dependente de um módulo de kernel do linux denominado lm_sensors, que é discutido brevemente na Seção 6.7.

- Permitir escalabilidade e extensibilidade: o iCluster pode ser facilmente adaptado a novos nós do WFC, e novas funcionalidades ou agentes podem ser adicionados ao sistema sem maiores dificuldades.

- Envio de mensagens à caixa de correio eletrônico do administrador: os problemas ocorridos e não solucionados são imediatamente informados ao administrador por meio do envio de emails.

Com base nas características e no conjunto de variáveis de monitoramento apresentados, o iCluster foi proposto com vistas a adicionar um alto grau de disponibilidade de serviços e recursos a um WFC, com a mínima intervenção humana.

O iCluster focaliza o controle, monitoramento, obtenção e divulgação das variáveis apresentadas, de maneira simplificada e distribuída, utilizando o ambiente WWW.

\subsection{Arquitetura do iCluster}

O iCluster foi projetado segundo os conceitos de agentes apresentados no Capítulo 3 . No contexto deste trabalho, o conceito de agentes reativos é o que apresenta melhores características para esse tipo de sistema. 
O iCluster é composto por um conjunto de pequenos agentes, desenvolvidos em Java, que são capazes de executar ações reativas e que podem cooperar entre si por meio da passagem de mensagens, notificando outros agentes sobre problemas em um nó do WFC. Especificamente, existem três categorias de agentes em cada nó do cluster: Agente de Controle (AC), Agente de Notificação (AN) e Agentes Monitores(AM).

A Figura 6.1 apresenta o modelo em camadas dos agentes que compõem o iCluster.

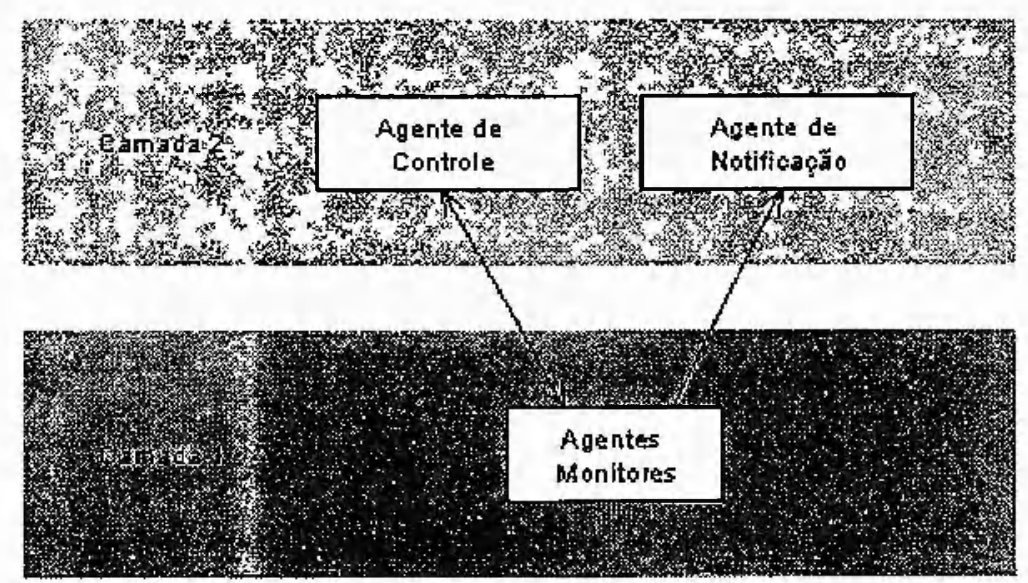

Figura 6.1 - Modelo em camadas dos agentes do iCluster

Agentes Monitores representam o primeiro nível de agentes do iCluster. Esse nível é composto por um conjunto de agentes especializados em monitorar determinadas variáveis de um nó de um WFC. Os Agentes Monitores podem se comunicar com um Agente de Controle ou com um Agente de Notificação. Fazem parte dessa categoria de agentes: Agente Monitor de Serviços (Service Monitor Agent - SMAg), Agente Monitor de Nós (Nodes Monitor Agent - NMAg), Agente Monitor de Disco Rígido (Hard Disk Monitor Agent - HDMAg), Agente Monitor de Memória (Memory Monitor Agent - MMAg), Agente Monitor de Temperatura (Temperature Monitor Agent - TMAg), Agente Monitor de Ventoinha (Fan Monitor Agent FMAg) e Agente Monitor de Voltagem (Voltage Monitor Agent - VMAg).

Os Agentes de Controle e de Notificação representam o segundo nível do modelo de camadas do iCluster. Um Agente de Controle é responsável pelo gerenciamento de requisições de controle (e dos resultados dessas requisições) feitas por um usuário do iCluster ou por outros agentes. Essas requisições podem ser enviadas de uma Servlet na máquina local ou numa remota, como pode ser visto na Figura 6.2. O Agente Gerenciador (Manager Agent - ManAg) é um agente que faz parte dessa categoria. 
Os Agentes de Notificação são responsáveis por enviar mensagens ao administrador a pedido de um agente monitor. O Agente Correio (Mail Agent - MailAg) faz parte dessa categoria de agentes. A Figura 6.2 apresenta uma visão geral da arquitetura do iCluster.

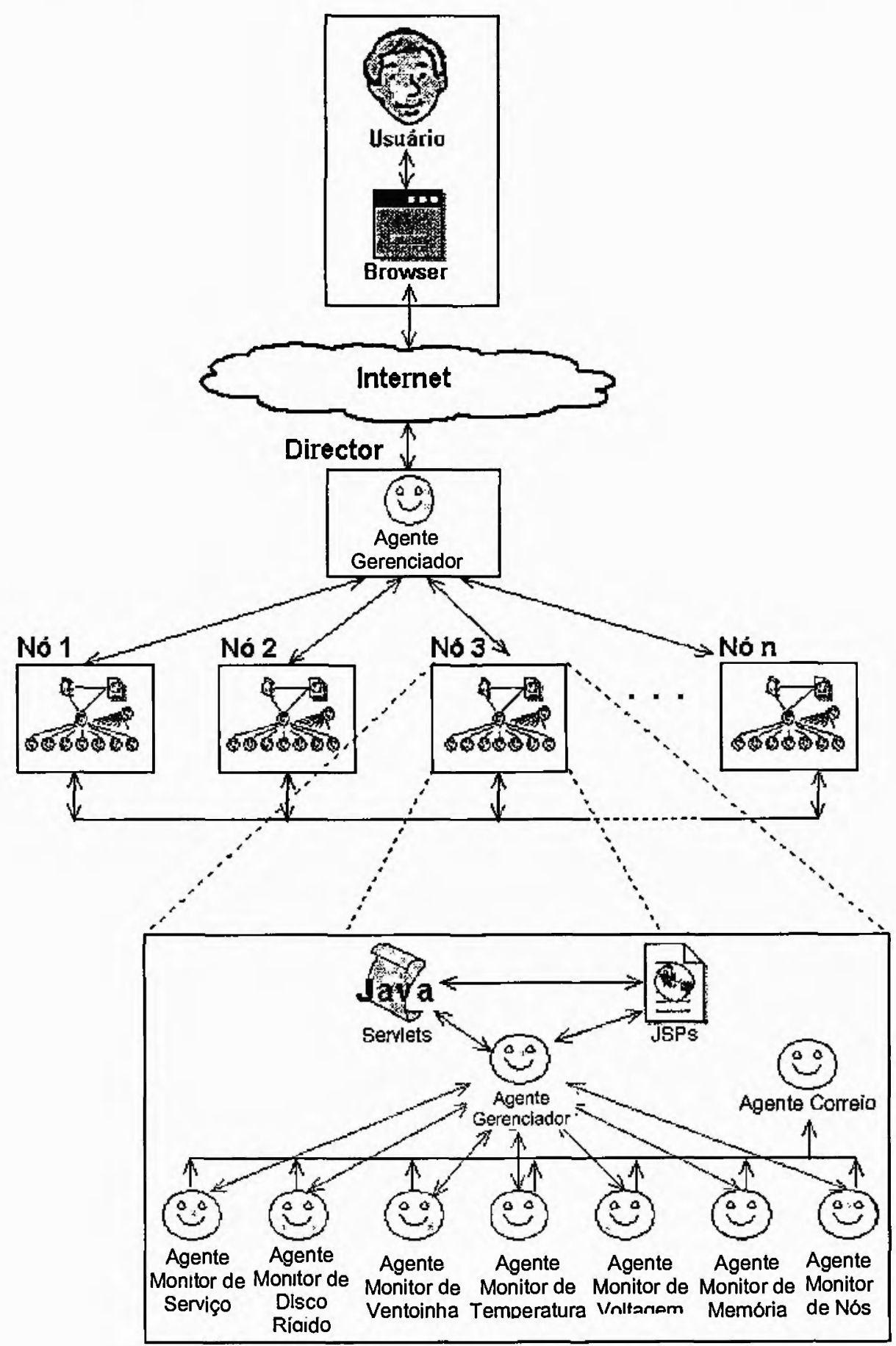

Figura 6.2 - Arquitetura Genérica do iCluster

Para fins organizacionais, a arquitetura do iCluster foi dividida em 4 niveis, de acordo com sua funcionalidade no sistema: 
- Nivel de apresentação: é composto por páginas JSPs que permitem a um usuário interagir com o iCluster, tanto na parte de visualização dos estados das variáveis, quanto no controle e gerenciamento de recursos do WFC.

- Nivel de controle: é composto por um conjunto de Servlets que gerenciam as requisições realizadas pelo administrador.

- Nivel de organização: é composto pelo ManAg e pelo MailAg, e é responsável pela organização das mensagens.

- Nivel de monitoramento (base do iCluster): é composto pelos vários agentes monitores e é responsável por monitorar as variáveis de um WFC e manter um alto grau de disponibilidade dos serviços oferecidos.

A Figura 6.3 ilustra os níveis da arquitetura do iCluster em um nó de um WFC. Como pode se observar, a interação de um usuário, geralmente um administrador, com o iCluster é feita por meio do ambiente WWW (um browser). Desse modo, o usuário pode visualizar ou gerenciar as variáveis de um WFC de qualquer lugar, bastando para isso, ter um computador conectado à Internet e um web browser.

A comunicação entre agentes de um mesmo nó de um WFC é realizada entre um agente do nível de organização (ManAg ou MailAg) e um agente do nível de monitoramento (os vários agentes monitores). Não houve necessidade de implementar a comunicação entre os agentes monitores, pois as variáveis monitoradas são independentes, ou seja, a leitura de seus valores é conseguida sem a necessidade de informações de outras variáveis. O ManAg, por sua vez, não necessita de interação com o MailAg, porque ele não tem a função de relatar nenhum problema ao administrador do iCluster.

A comunicação entre agentes de nós diferentes é realizada apenas entre os agentes SMAg e NMAg de cada nó com os ManAgs dos directors. Isso ocorre quando algum serviço ou nó pára de funcionar (os NMAgs monitoram se os outros nós do cluster estão no ar), nesse caso os ManAgs dos directors atualizam as suas listas de serviços e nós ativos (usadas na distribuição de requisições), retirando esses serviços ou nós.

Para um melhor entendimento do sistema, uma descrição mais detalhada das funcionalidades do iCluster é apresentada na Seção 6.5. No apêndice B, encontra-se os diagramas de classes UML de todos os agentes do iCluster. 


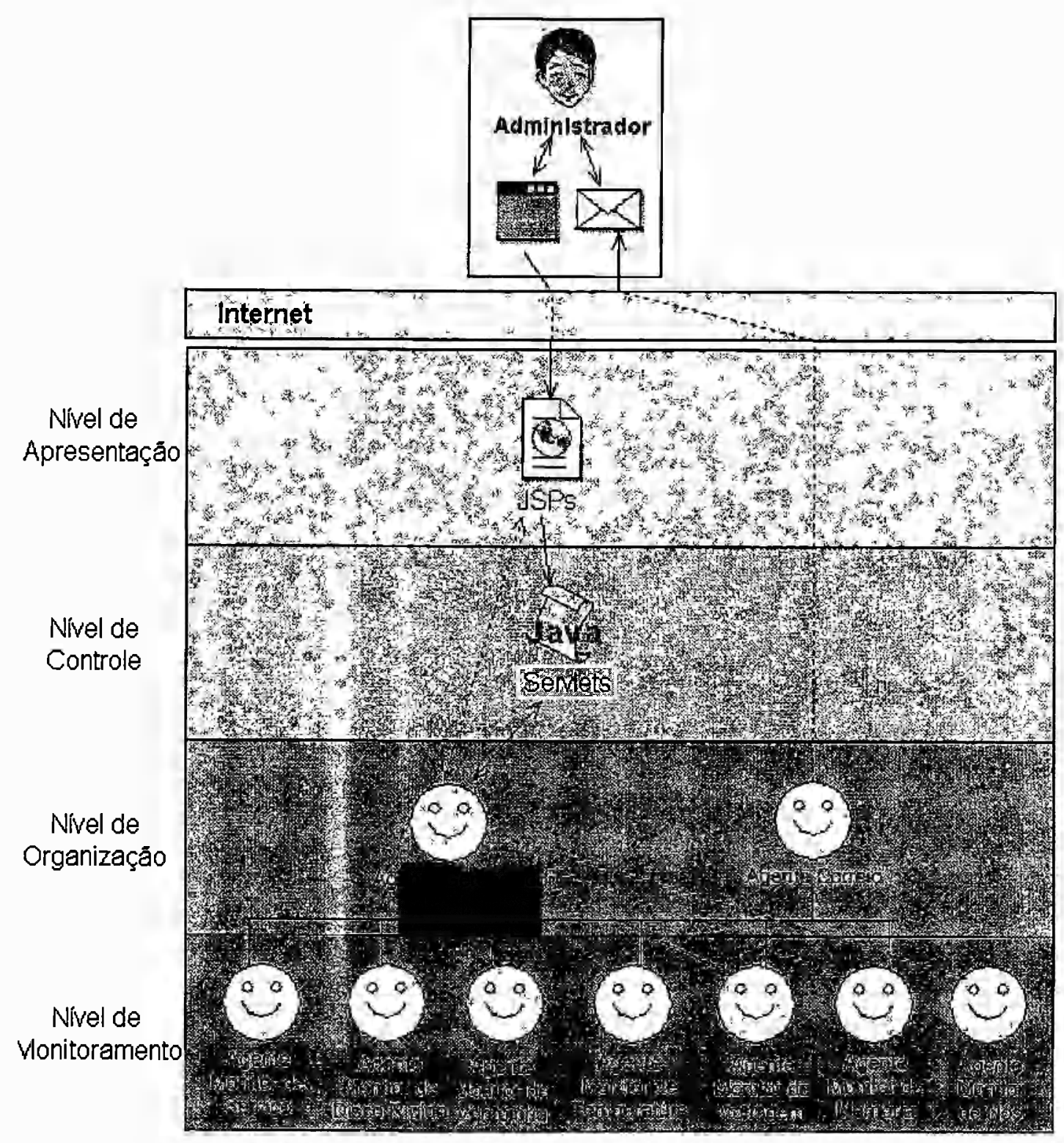

Figura 6.3 - Arquitetura em níveis do iCluster

\subsection{Comunicação dos agentes}

A comunicação entre os agentes do iCluster é feita via passagem de mensagens simples, sendo que a codificação dessas mensagens utiliza o formato binário através da serialização de objetos. As mensagens são enviadas na forma de objetos serializados por Sockets TCP. As mensagens trocadas pelos agentes são compostas de uma performativa (utilizou-se um subconjunto das performativas da FIPA-ACL (FIPA, 2004), um objeto e um conteúdo.

A Figura 6.4 mostra a estrutura das mensagens utilizadas para a comunicação entre os agentes no iCluster. 


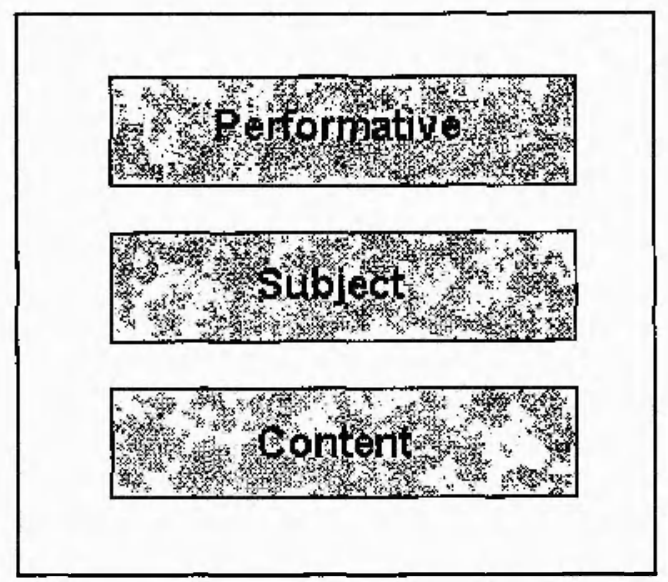

Figura 6.4 - Estrutura das mensagens utilizadas para a comunicação entre os agentes no iCluster As performativas definem os tipos de operações possíveis entre os agentes. As performativas utilizadas na comunicação entre os agentes do iCluster são mostradas na Tabela 6.1.

\begin{tabular}{|l|l|}
\hline Performativa & Uso \\
\hline Request & Requisição de alguma tarefa \\
\hline Propagate & Retransmissão de algum objeto \\
\hline Inform & Transmissão de alguma informação \\
\hline
\end{tabular}

Tabela 6.1 - Performativas utilizadas na comunicação entre os agentes do iCluster

A performativa Request é utilizada quando um agente remetente quer que um agente destinatário execute alguma ação. A Propagate é utilizada quando um agente remetente quer que o agente destinatário retransmita alguma informação. E, por fim, a performativa Inform é utilizada quando um agente quer transmitir algum conteúdo informativo a outro agente.

Para um agente realizar uma operação é necessário que ele saiba o tipo de ação. Por exemplo, quando um agente requisita (Request) alguma tarefa a outro agente, ele tem que especificar que tipo de ação deve ser realizada: uma remoção por exemplo. O elemento Subject, na estrutura da mensagem, é utilizado para atender essa necessidade, isto é, para indicar a um agente o tipo de ação a ser realizada. As Tabela 6.2, Tabela 6.3 e Tabela 6.4 mostram os tipos de Subjects possíveis para cada performativa: 


\begin{tabular}{|l|l|}
\hline \multicolumn{2}{|c|}{ Performativa - Request } \\
\hline Subject & Descrição \\
\hline Add & Adição de uma informação \\
\hline Remove & Remoção de uma informação \\
\hline Execute & Execução de uma instrução \\
\hline Get & Obtenção de um elemento \\
\hline Comment & Inserção de comentário \\
\hline Uncomment & Remoção de comentário \\
\hline
\end{tabular}

Tabela 6.2 - Subjects para a performativa Request

\begin{tabular}{|l|l|}
\hline \multicolumn{2}{|c|}{ Performativa - Propagate } \\
\hline Subject & Descrição \\
\hline Warning & Mensagem de aviso \\
\hline
\end{tabular}

Tabela 6.3 - Subjects para a performativa Propagate

\begin{tabular}{|l|l|}
\hline \multicolumn{2}{|c|}{ Performativa - Inform } \\
\hline Subject & Descrição \\
\hline Fail & Falha de algum recurso \\
\hline
\end{tabular}

Tabela 6.4 - Subjects para a performativa Inform

Para a execução de uma operação, além da identificação da performativa e Subject, é necessário que exista um conteúdo de execução da ação. Por exemplo, quando um agente receber uma requisição de remoção, isto é, um Request e um Remove, o agente não saberá o que remover. $\mathrm{O}$ elemento Content, na estrutura da mensagem, é utilizado para resolver esse problema, isto é, para focalizar a ação em alguma estrutura. A Tabela 6.5 lista o foco de ação dos agentes do iCluster.

\begin{tabular}{|l|l|}
\hline Content & Descrição \\
\hline Services & Serviços em monitoramento \\
\hline Services-off & Serviços em monitoramento que estão fora de operação \\
\hline Pooling-service & Serviços da lista de distribuição do director \\
\hline $\mathrm{Cpu}$ & CPU de um nó de um WFC \\
\hline Fans & Ventoinhas de um nó de um WFC \\
\hline Hard-disk & Disco rígido de um nó de um WFC \\
\hline
\end{tabular}




\begin{tabular}{|l|l|}
\hline Memory & Memória de um nó de um WFC \\
\hline Temperature & Temperatura das CPUs de um nó de um WFC \\
\hline Voltage & Voltagem dos componentes de um nó de um WFC \\
\hline Nodes-off & Nós de um WFC que estão desativados \\
\hline Command & Comando de um sistema operacional \\
\hline
\end{tabular}

Tabela 6.5 - Conteúdos focalizados pelos agentes do iCluster

Com estes três elementos da estrutura de uma mensagem, os agentes do iCluster são capazes de realizar uma comunicação simples e eficiente.

\subsection{Funcionalidades do iCluster}

Conforme mencionado, o iCluster tem como objetivo assegurar maior disponibilidade de serviços e recursos oferecidos por um WFC. Para isso, foi implementado um conjunto de agentes autônomos, listados na Seção 6.3, que realizam tarefas específicas. Esses agentes são desprovidos de inteligência, mas utilizando o princípio da cooperação, no qual cada agente executa ações específicas, eles completam uma operação complexa.

O iCluster permite a interação do sistema com dois atores: usuário e administrador. A Figura 6.5 mostra alguns casos de uso desses atores.

Como se pode observar, o ator usuário só tem permissão para visualizar os estados das variáveis de um WFC. Já o ator administrador tem permissão tanto para visualizar os estados das variáveis monitoradas pelos agentes quanto para fazer o controle de algumas variáveis.

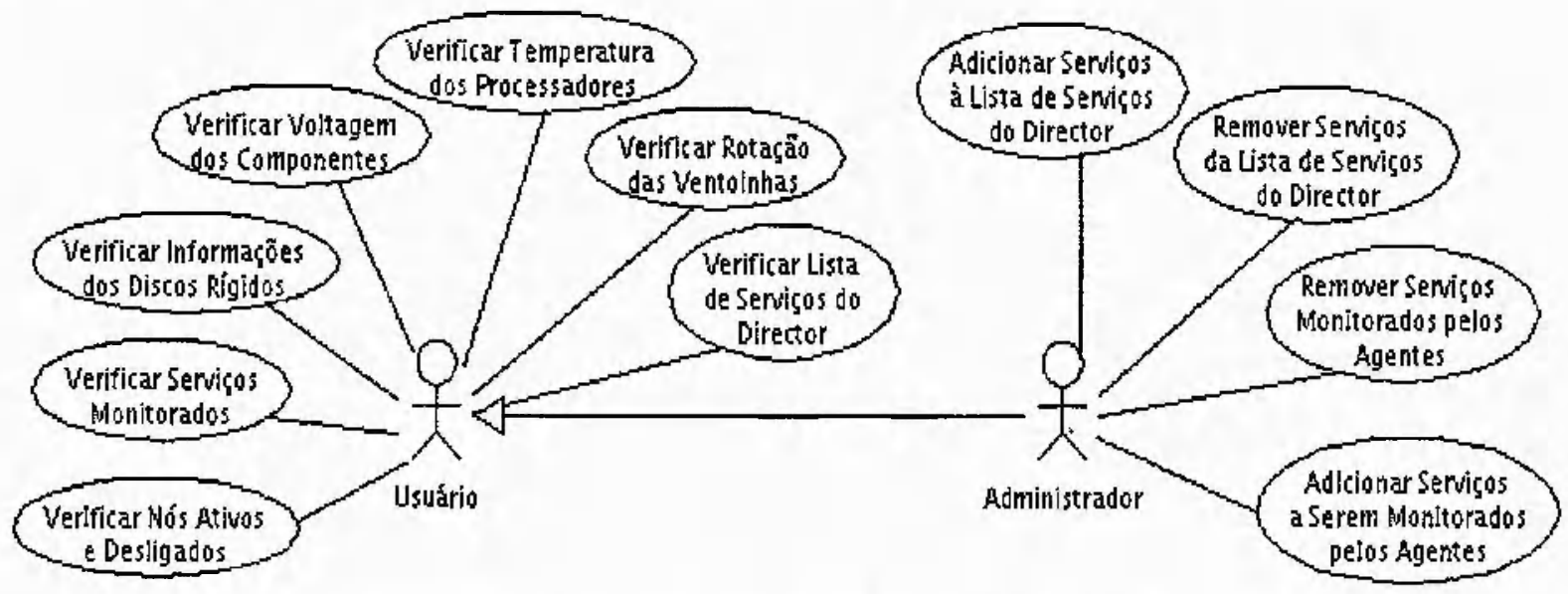

Figura 6.5 - Diagrama de casos de uso dos atores do iCluster 


\subsubsection{Visualização dos Estados das Variáveis do WFC}

Os estados das variáveis podem ser visualizados por um usuário do iCluster em qualquer web browser. No entanto, o usuário deverá estar cadastrado no sistema de autenticação para que ele possa ter acesso às páginas do iCluster. A autenticação é realizada pelo próprio servidor de aplicações web. No caso dos testes realizados, utilizou-se o JBoss.

Depois de autenticado, o usuário tem acesso à página principal do iCluster, mostrada na Figura 6.6. Como pode ser visto nessa figura, um usuário pode visualizar os estados de todas as variáveis monitoradas pelo iCluster e o administrador poderá efetuar operações de controle nos serviços monitorados ou na lista de distribuição de requisições dos director. As Figura 6.7 e Figura 6.8 mostram, como exemplo, as telas de duas variáveis: a rotação das ventoinhas e o estado dos discos rígidos.

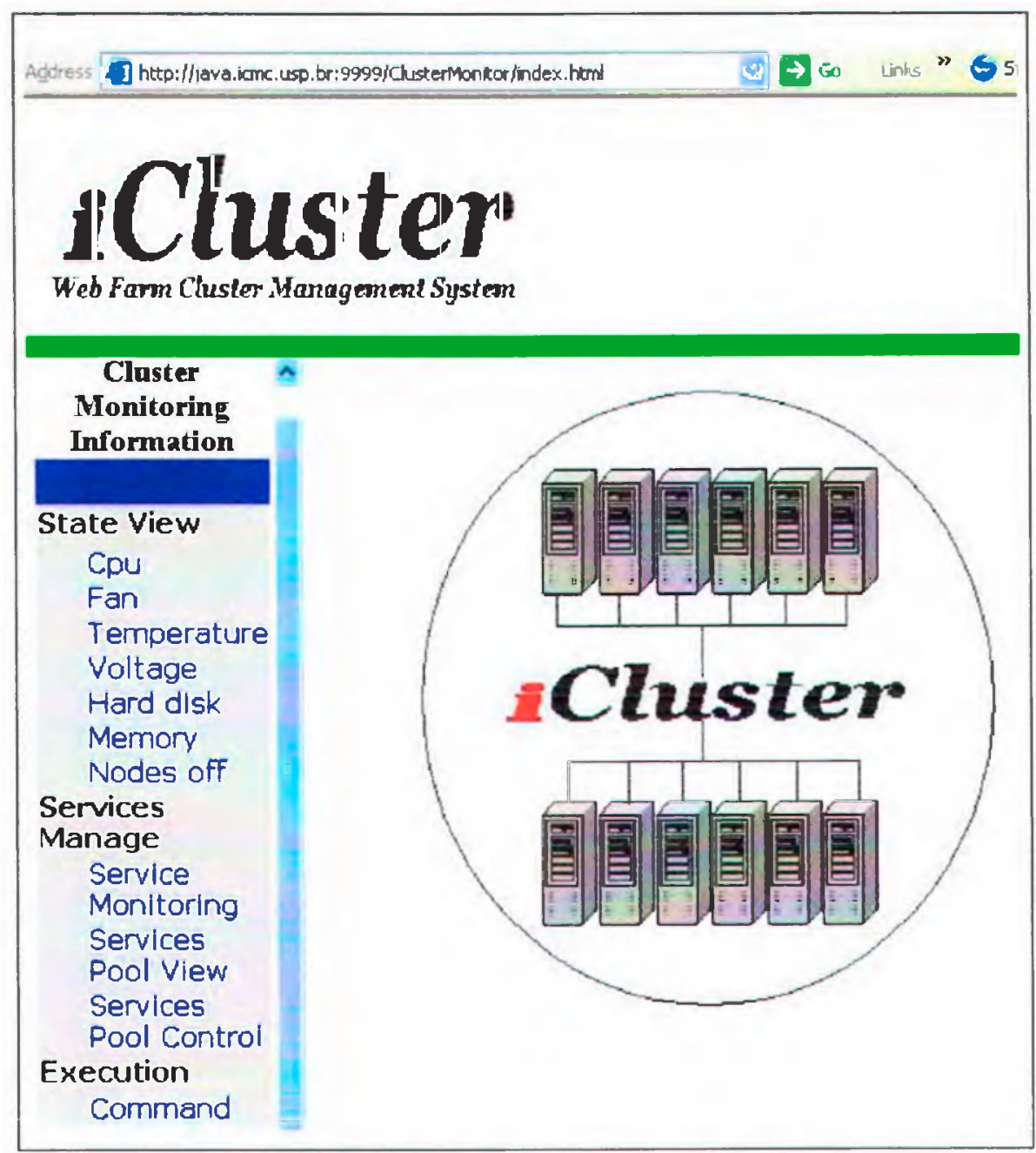

Figura 6.6 - Página principal de acesso ao iCluster 


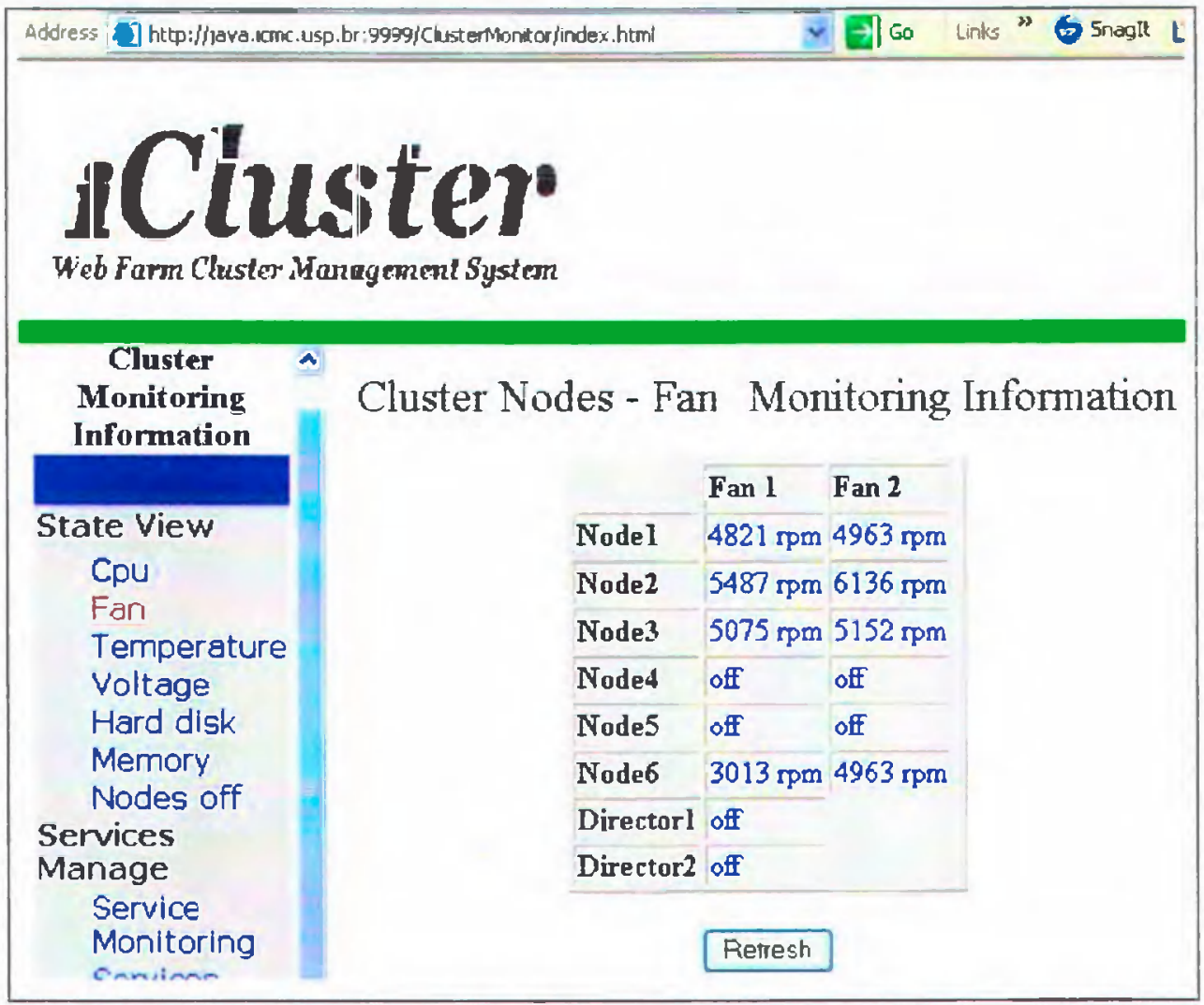

Figura 6.7 - Visualização da rotação das ventoinhas

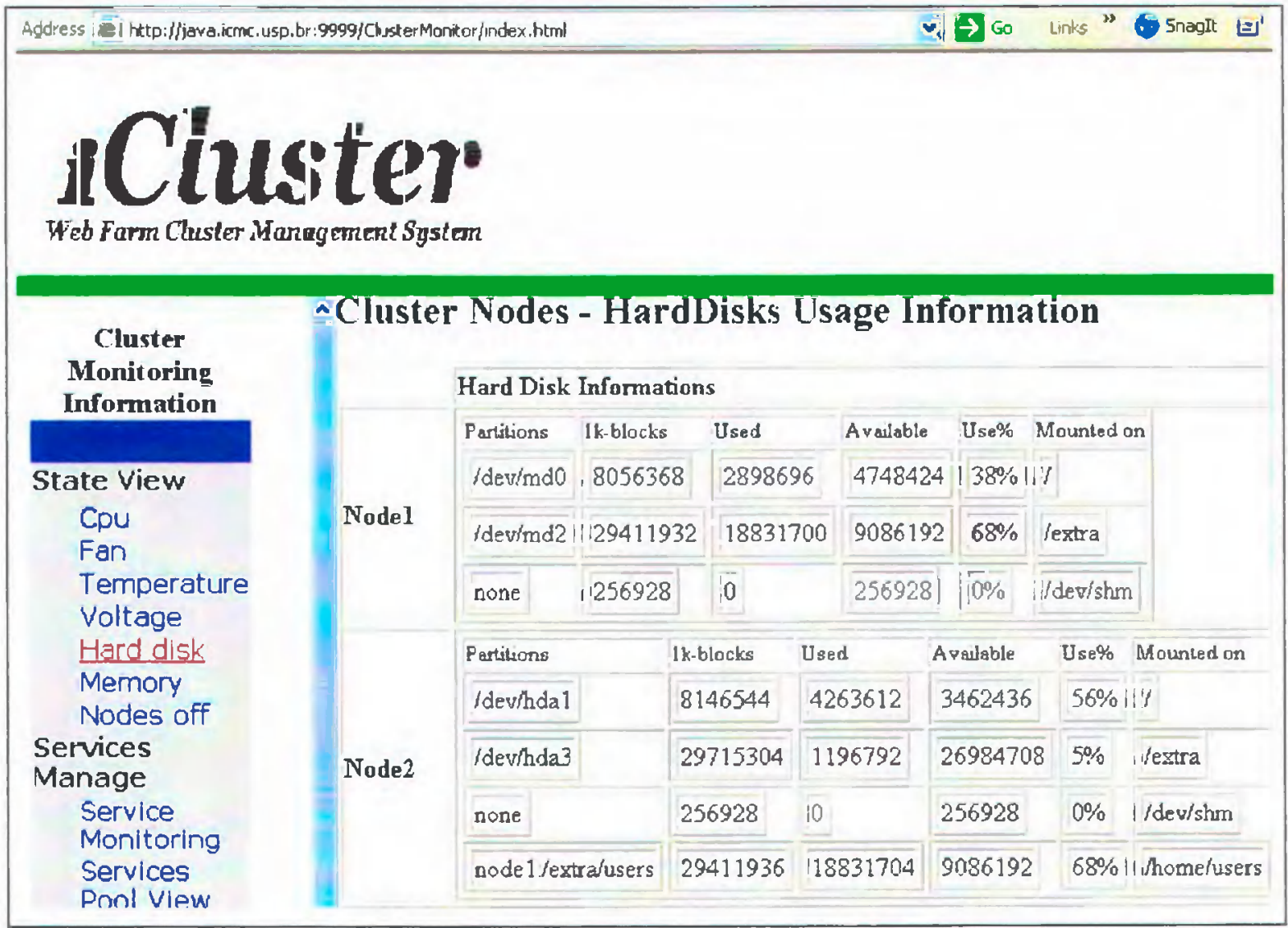

Figura 6.8 - Visualização da utilização dos discos rigidos 
O processo de visualização do estado de uma variável (ilustrado na Figura 6.9) ocorre da seguinte forma:

1. Quando o usuário clica no link relativo ao estado da variável que deseja visualizar, uma requisição é encaminhada para uma página JSP (de qualquer um dos nós do WFC). Essa página JSP envia uma requisição para cada ManAg de cada nó do WFC.

2. O ManAg de cada nó recebe e identifica a requisição. Depois, ele comunica-se com o agente monitor local, responsável pelo monitoramento da variável em questão, e requisita o estado da mesma.

3. O agente monitor faz a leitura do estado da variável, empacota-o e envia-o ao ManAg local.

4. O ManAg recebe o pacote e o envia de volta à página JSP que fez a requisição.

5. Por fim, a página JSP coleta as respostas dos ManAgs e apresenta ao usuário o estado da variável em cada nó do WFC.

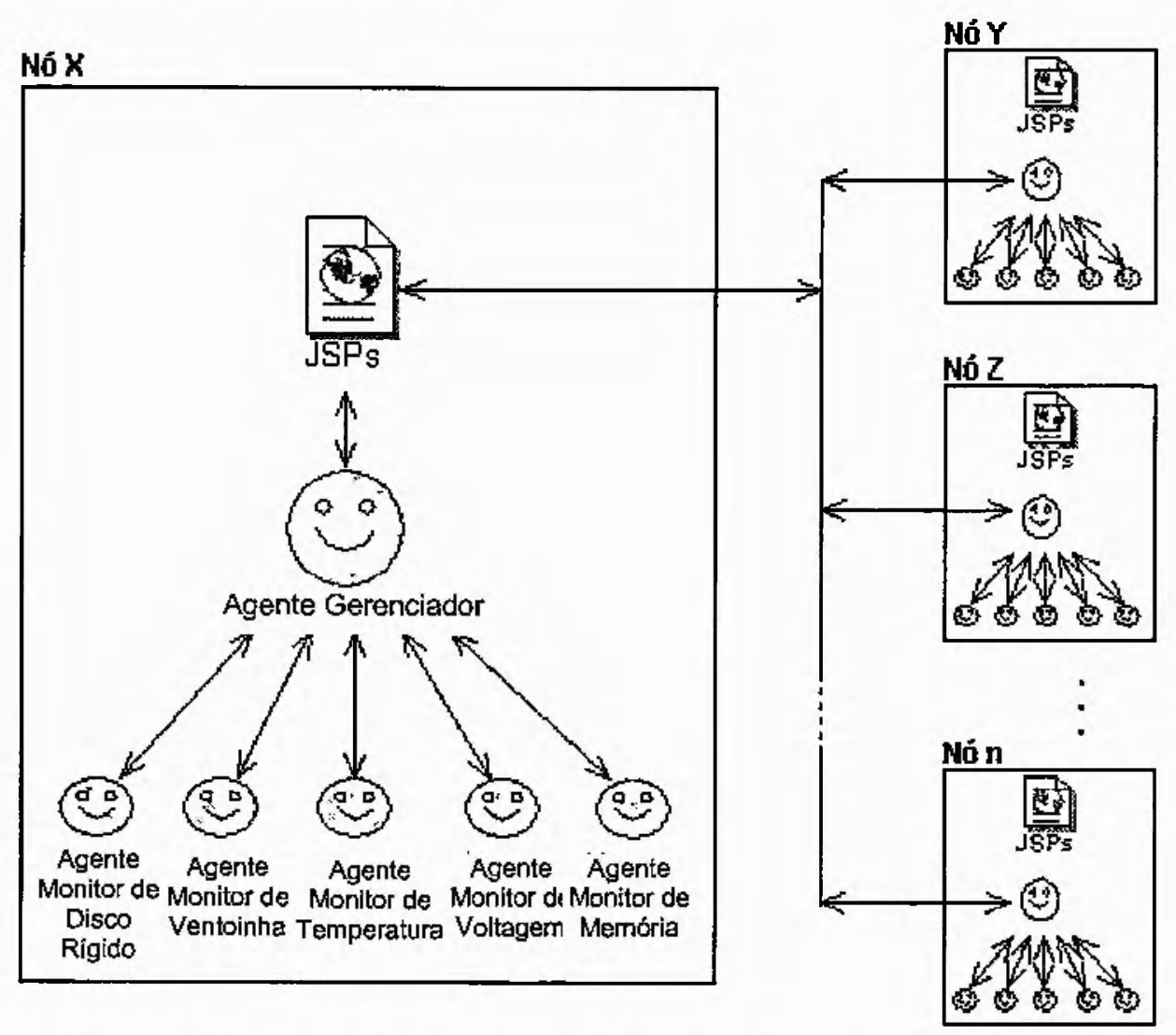

Figura 6.9 - Processo de visualização dos estados das variáveis monitoradas 
O processo descrito anteriormente não se aplica aos serviços monitorados pelos SMAgs, aos nós ligados e desligados e aos detalhes da lista de serviços para distribuição de requisições (http, ftp, ssh etc) dos directors. O processo para a visualização dos serviços monitorados (ilustrado na Figura 6.10) ocorre da seguinte maneira:

1. Este passo é o mesmo da visualização de variáveis.

2. O ManAg de cada nó recebe e identifica a requisição da página JSP. Após identificar que a requisição se trata de um serviço monitorado, o ManAg acessa os arquivos "services.cluster" e "services-off.cluster" que se localizam no "/etc/" e que identificam, respectivamente, todos os serviços que estão sendo monitorados e, entre estes, os serviços que estão parados com problemas. O arquivo "services.cluster" pode ser atualizado pelo administrador do iCluster através da página web de adição de serviços monitorados, e o arquivo "services-off.cluster" é atualizado pelo SMAg do nó. Após a leitura desses arquivos, o ManAg de cada nó empacota as informações e as envia para a página JSP que as requisitou.

3. A página JSP formata a informação recebida e apresenta ao usuário os serviços monitorados e os serviços que estão parados (com problemas) em cada nó do WFC.

Nó X

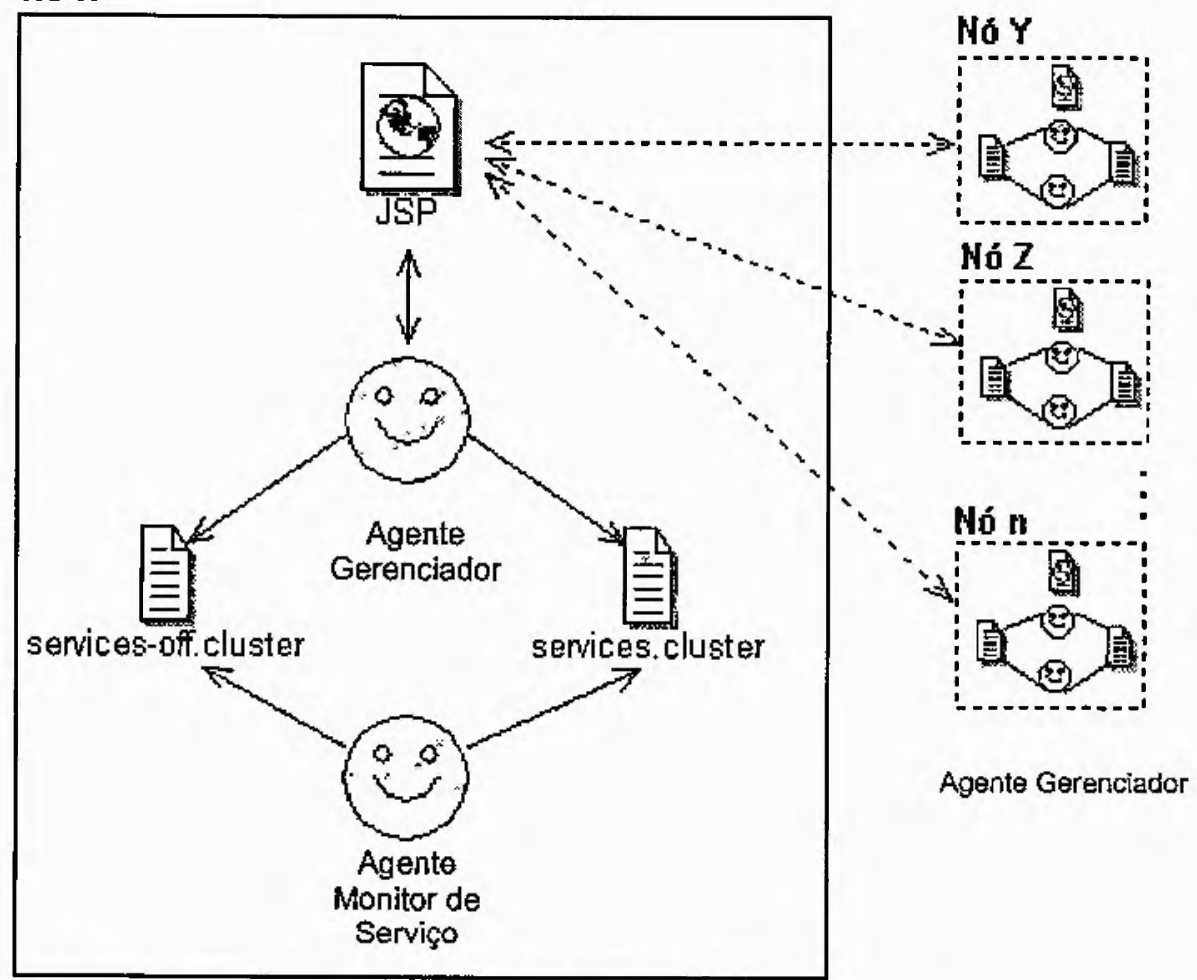

Figura 6.10 - Processo de visualização dos serviços monitorados 
A Figura 6.11 mostra a página de visualização e controle dos serviços que estão sendo monitorados

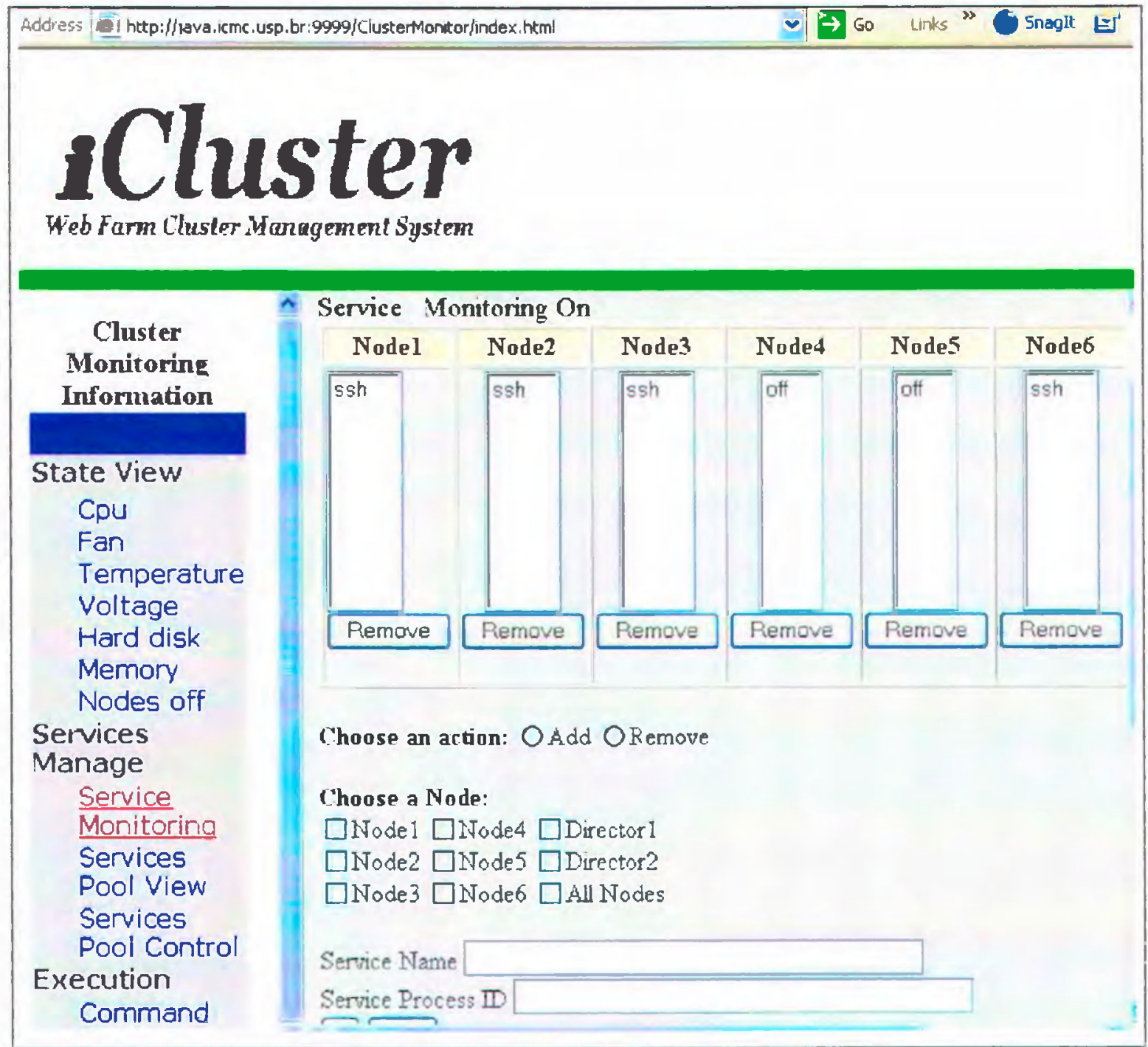

Figura 6.11 - Visualização c controle dos serviços monitorados

O processo para a visualização dos nós monitorados e os nós parados (devido a problemas) se dá de maneira semelhante à visualização de serviços monitorados. A diferença é que neste processo, quando a página especifica para esta operação é acessada pelo usuário, ela não encaminha a requisição para o ManAg dos outros nós. mas somente para o ManAgg local. Isso porque o NIVAg de cada nó monitora sempre a mesma lista de nós. Então, os nós fora de operação serão identificados pelos NMAg de todos os outros nós. Este processo é ilustrado na Figura 6.12. 


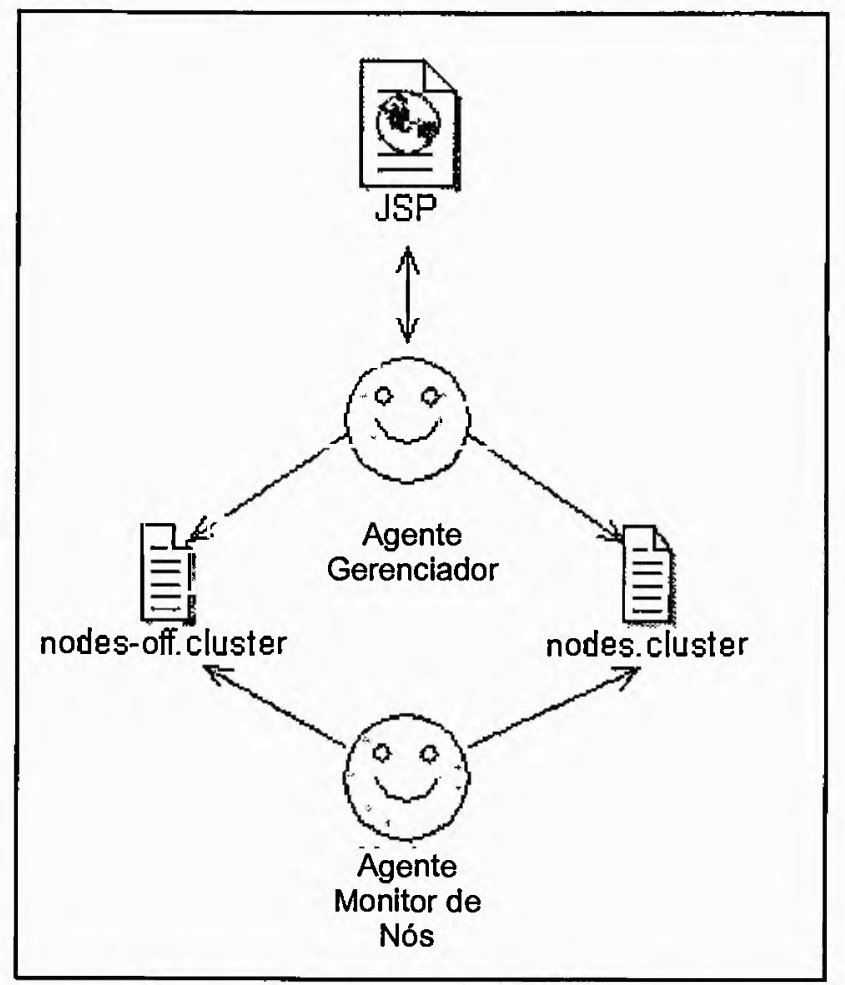

Figura 6.12 - Processo de visualização dos nós monitorados

Já o processo de visualização da lista de serviços para distribuição de requisições (http, ftp, ssh etc) do director ocorre como ilustrado na Figura 6.13:

1. Após um usuário clicar no link relativo a lista de serviços para distribuição de requisições dos directors (ver Figura 6.14), uma requisição é encaminhada para uma página JSP, num dos nós do WFC, que faz uma requisição ao ManAg desse nó.

2. O ManAg do nó comunica-se com o ManAg do director ativo e requisita os detalhes da lista de serviços.

3. O ManAg do director verifica a requisição; identifica o que está sendo pedido; lề o arquivo com a lista dos serviços para distribuição de requisições; empacota essa informação e a envia ao ManAg do nó que fez a requisição.

4. O ManAg do nó recebe a informação $\mathrm{e} a$ envia à página JSP que realizou a requisição inicial.

5. A página JSP, por fim, formata e mostra os dados ao usuário. 


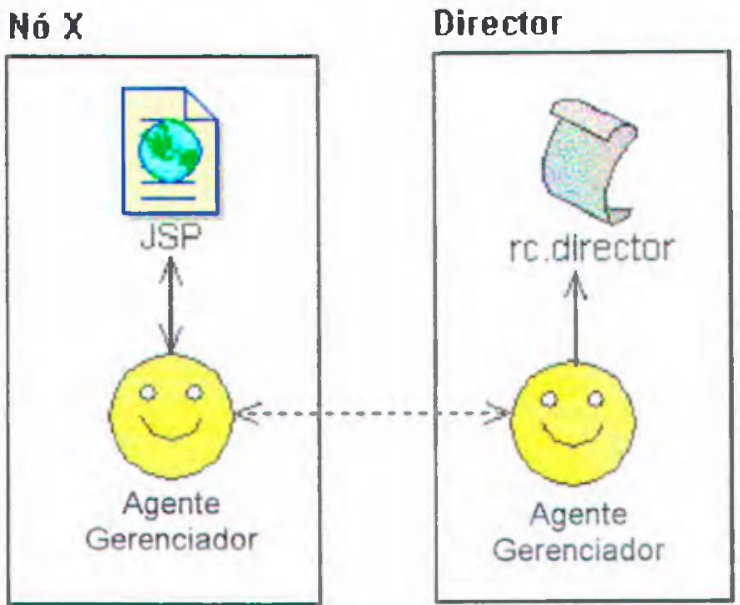

Figura 6.13 - Processo de visualização da lista de serviços para distribuição de requisições do director

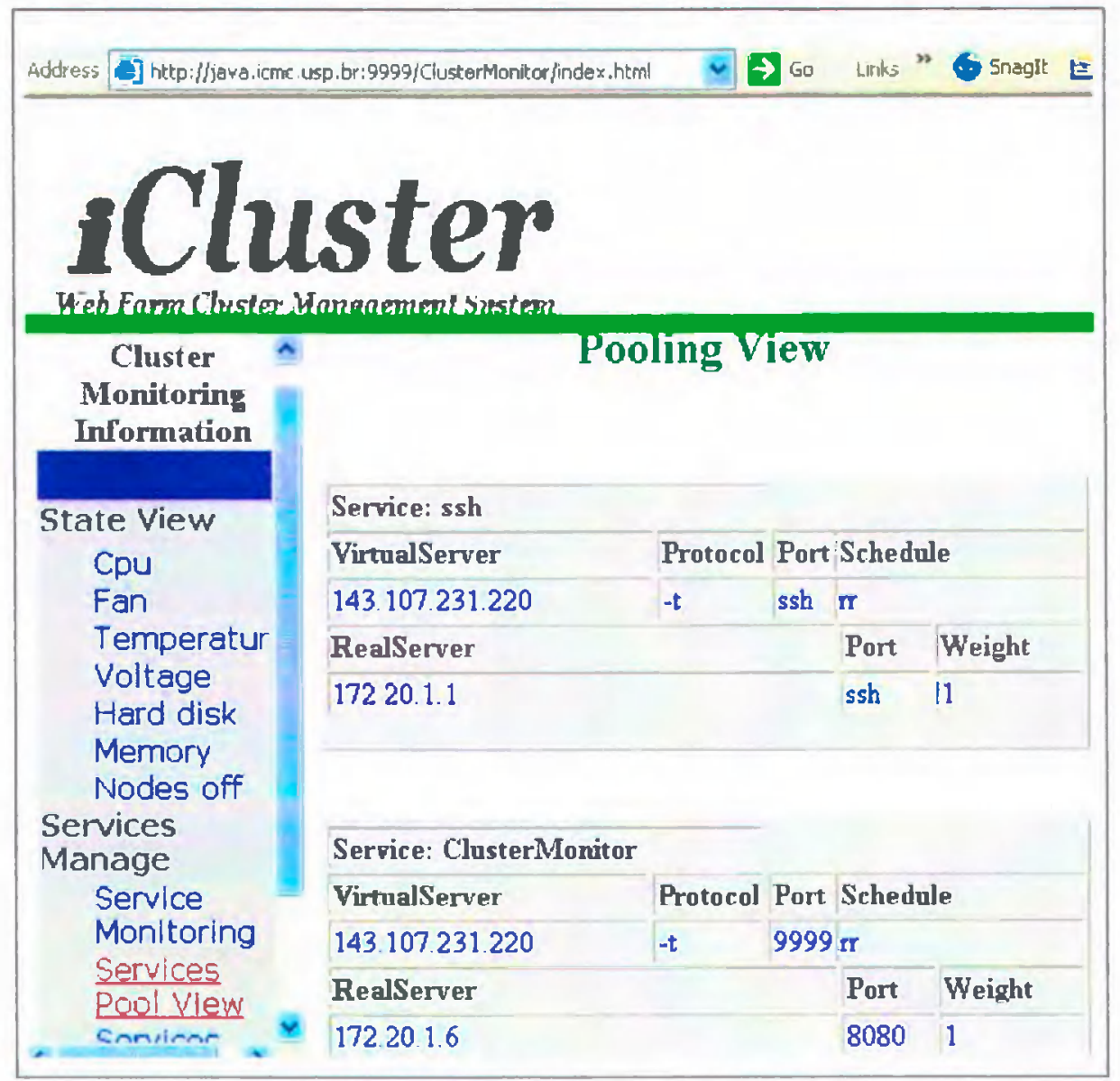

Figura 6.14 - Visualizaçăo da lista de serviços para distribuiçào de requisiçōes do director

\subsection{Controle das variáveis pelo Administrador do iCluster}

O administrador do iCluster pode. alem de visualizar os estados das variáveis do WFC, fazer alteraçòes na organizaçào do sistema. Isso inclui: adicionar/remover serviços monitorados pelo SMAg de um no especifico ou de todos os nós; adicionar/remover serviços da lista de serviços para distribuição de requisições do director. 
O processo de adição ou remoção de serviços monitorados pelo SMAg ocorre da seguinte maneira, como ilustrado na Figura 6.15:

1. Após o administrador clicar no link relativo aos serviços monitorados pelos SMAgs (ver Figura 6.11 - Visualização e controle dos serviços monitorados), uma página JSP mostra os serviços monitorados e os serviços que estão parados para que o administrador tenha conhecimento de quais serviços já estão sendo monitorados em quais nós do WFC. Nessa página o administrador escolhe uma ação a ser realizada (adição ou remoção), um ou vários nós para os quais os serviços serão monitorados, o nome do serviço e o nome do processo do serviço. Após a confirmação dos dados pelo administrador, essa página JSP envia esses dados para uma Servlet.

2. Essa Servlet organiza os dados e faz uma requisição de adição ou remoção, dependendo da opção escolhida pelo administrador, para o ManAg de cada nó escolhido pelo administrador.

3. O ManAg de cada nó recebe e identifica a requisição. Após identificar que a requisição se trata de adição ou remoção de serviço monitorado, ele acessa o arquivo "services.cluster", que identifica os serviços que estão sendo monitorados, e adiciona ou remove um serviço. Após o término desta operação, o ManAg envia para a Servlet uma confirmação da realização da operação requisitada.

4. A Servlet, por fim, apresenta ao administrador uma mensagem de operação bem sucedida.

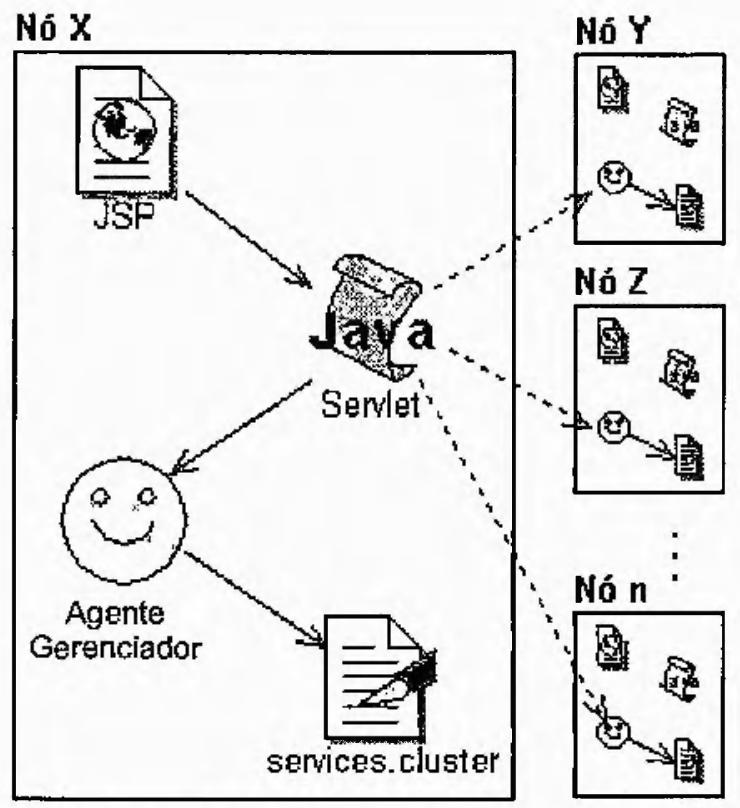

Figura 6.15 - Processo de adiç̧̃̃o ou remoção de serviços monitorados pelos SMAgs 
Já o processo de adição ou remoção de serviços da lista de serviços para distribuição de requisições do director ocorre como ilustrado na Figura 6.16:

1. Após o administrador clicar no link relativo aos serviços monitorados pelo SMAg (ver Figura 6.17), ele é levado a uma página JSP que contém os dados necessários para adição ou remoção de serviços da lista de serviços para distribuição de requisições (http, ftp, ssh etc) do director. Após a entrada de todos os dados e a confirmação pelo administrador, os dados são enviados para uma Servlet.

2. A Servlet organiza os dados e os envia para o ManAg de cada director (director mestre e director escravo).

3. O ManAg de cada director recebe e identifica a requisição. Após identificar que a requisição se trata de adição ou remoção de serviço da lista de serviços, ele acessa o arquivo "/root/rc.d/rc.director", que é um script do LVS com as informações necessárias para a distribuição de requisições do director, e adiciona ou remove serviços. Após a atualização desse arquivo, o ManAg executa o script para que a alteração realizada seja efetivada. Após o término desta operação, o ManAg envia para a Servlet uma confirmação de realização da operação requisitada.

4. A Servlet, por fim, apresenta uma mensagem de operação bem sucedida ao administrador.

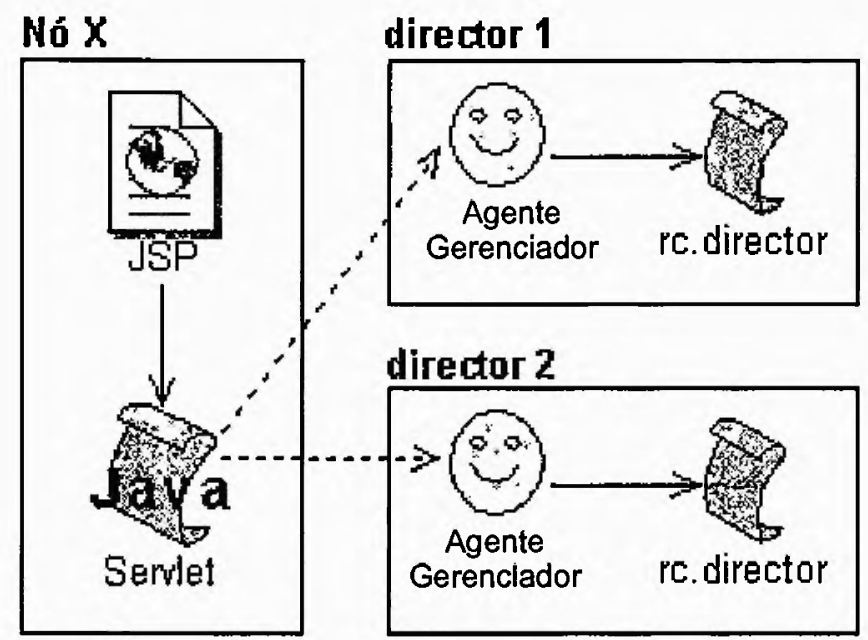

Figura 6.16 - Processo de adição ou remoção de serviços da lista de serviços para distribuição de requisiçōes do director 


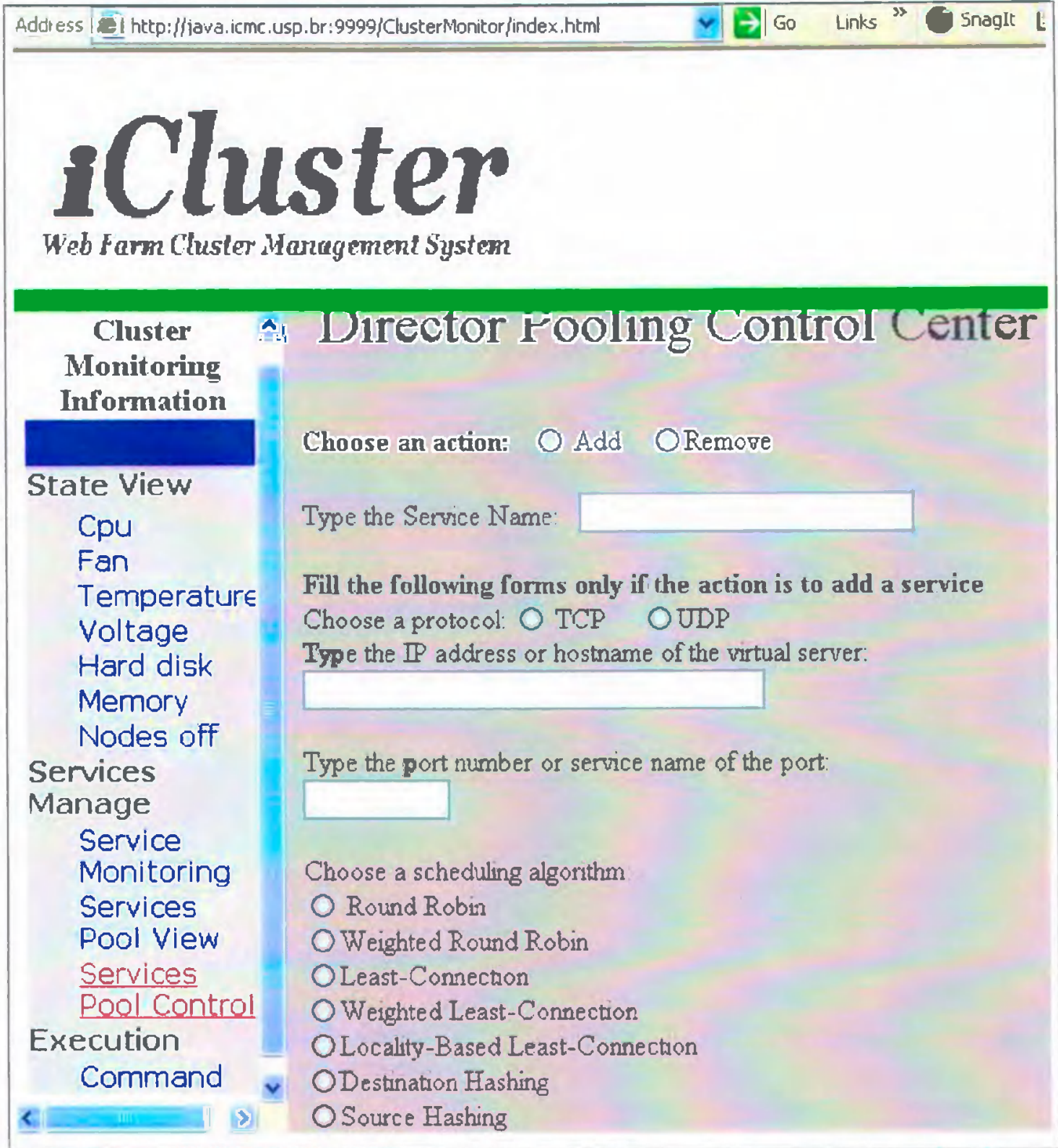

Figura 6.17 - Página de adlição e remoção de serviços da lista de serviços para distrihuição de requisiçōes to director

\subsection{Agentes Monitores}

A base do iCluster é formada pelo conjunto de agentes monitores. Esses agentes monitoram os estados das variaveis, já discutidos na Seção 6.2, no intuito de manter. com o auxilio do administrador, as condições necessárias para o bom funcionamento do WFC. A Tabela 6.6 mostra os agentes monitores e a função de cada um no WFC. Para mais detalhes sobre cada agente monitor, consultar apèndice $\mathrm{A}$.

Para os agentes que monitoram o estado dos recursos fisicos, o monitoramento das respectivas variáveis foi baseado na leitura e organização de arquivos disponibilizados no diretório 
"/proc/". Porém, como nem todos os recursos tinham seus estados disponibilizados nesse diretório, tais como temperatura das CPUs, rotação das ventoinhas e voltagem dos componentes, foi necessário pesquisar formas de conseguir o estado desses recursos.

\begin{tabular}{|c|l|}
\hline $\begin{array}{c}\text { Agente Monitor } \\
\text { Agente Monitor de Serviços } \\
\text { (SMAg) }\end{array}$ & $\begin{array}{l}\text { Realizar o monitoramento dos serviços especificados pelo } \\
\text { administrador de um WFC }\end{array}$ \\
\hline $\begin{array}{c}\text { Agente Monitor de Nós } \\
\text { (NMAg) }\end{array}$ & Realizar o monitoramento dos nós de um WFC \\
\hline $\begin{array}{c}\text { Agente Monitor de } \\
\text { Ventoinha } \\
\text { (FMAg) }\end{array}$ & $\begin{array}{l}\text { Realizar o monitoramento da rotação das ventoinhas dos } \\
\text { processadores existentes no nó de um WFC }\end{array}$ \\
\hline $\begin{array}{c}\text { Agente Monitor de Disco } \\
\text { Rígido } \\
\text { (HDMAg) }\end{array}$ & $\begin{array}{l}\text { Realizar o monitoramento de espaço em discos rígidos } \\
\text { existentes no nó de um WFC }\end{array}$ \\
\hline $\begin{array}{c}\text { Agente Monitor de } \\
\text { Memória } \\
\text { (MMAg) }\end{array}$ & $\begin{array}{l}\text { Realizar o monitoramento do uso de memória no nó de um } \\
\text { WFC }\end{array}$ \\
\hline $\begin{array}{c}\text { Agente Monitor de } \\
\text { Temperatura } \\
\text { (TMAg) }\end{array}$ & $\begin{array}{l}\text { Realizar o monitoramento da temperatura dos processadores } \\
\text { existentes no nó de um WFC }\end{array}$ \\
\hline $\begin{array}{c}\text { Agente Monitor de } \\
\text { Voltagem }\end{array}$ & $\begin{array}{l}\text { Realizar o monitoramento da voltagem dos componentes } \\
\text { fisicos do nó de um WFC }\end{array}$ \\
\hline
\end{tabular}

Tabela 6.6 - Agentes monitores e suas funções

Uma maneira encontrada para disponibilizar o estado desses recursos foi a utilização de um módulo do kernel do Linux denominado lm_sensors desenvolvido por Lm_sensors Group (2004).

O lm_sensors é um software desenvolvido para Linux que disponibiliza dados, em forma de arquivos texto, das condições comportamentais de alguns componentes encontrados em uma "placa mãe". Ele é um conjunto de programas que atua nos níveis de hardware, kernel e também de usuário. Foge ao escopo deste trabalho uma descrição detalhada da arquitetura desse software. Para um melhor entendimento deste software cosultar (LM_SENSORS GROUP, 2004). 


\subsection{Considerações Finais}

Conforme citado, o uso de cluster de computadores está se tornando cada vez mais popular em diversas áreas de aplicação. Contudo, ainda se tem uma deficiência no que diz respeito a programas que realizam o gerenciamento desses tipos de sistemas.

O iCluster, apresentado neste Capítulo, constitui um sistema que gerencia um Web Farm Cluster (WFC) com o intuito de manter os recursos e os principais serviços oferecidos por esse tipo de cluster com o mínimo de intervenção humana. 


\section{Conclusões}

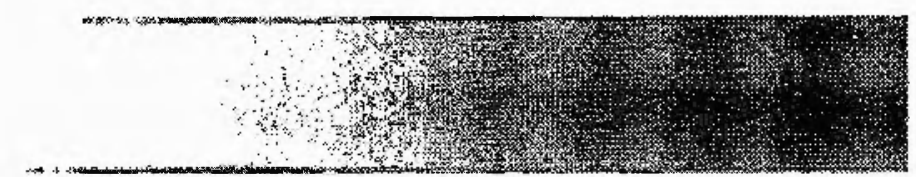

\subsection{Considerações Iniciais}

No presente trabalho foram apresentados a implementação de um Web Farm Cluster e o desenvolvimento de seu sistema de gerenciamento, o iCluster.

A implementação do cluster do Laboratório Intermídia, que teve como objetivo suportar um ambiente de gerenciamento de atividades de ensino via Internet, foi realizada em um cluster formado por máquinas desktop de pouca confiabilidade, de modo que, incluiu-se serviços para a Web em cluster, providos pelos programas JBoss e MySQL, serviços que realizam redundância, providos pelos programas heartbeat e rsync, e foi desenvolvido um programa que faz o monitoramento de servidores MySQL, para prover redundância ao serviço de base de dados. A arquitetura do cluster é baseada no NAT, o balanceador de carga utilizado é o LVS e como sistema de arquivos utilizou-se o rsync, juntamente com o NFS. Essas soluções foram implementadas para que o cluster tivesse as características de alta disponibilidade e tolerância a falhas.

O iCluster, que é um sistema que monitora e controla os serviços e estados das principais variáveis de um Web Farm Cluster com o propósito de manter a alta disponibilidade dos serviços oferecidos por esse tipo de cluster, foi desenvolvido em Java e é constituído por um conjunto de agentes de software que implementam as principais funcionalidades do sistema, por um conjunto de Servlets que interpretam as requisições do usuário e distribui essas requisições para os devidos agentes, e por um conjunto de páginas JSP que mostram os resultados das consultas feitas pelo usuário. $\mathrm{O}$ iCluster possibilita a visualizaçăo dos estados das variáveis monitoradas, o envio de mensagens de aviso, a execução de reinicíalização em serviços desativados por falha, e o controle de consistência dos serviços oferecidos (com o controle dos nós ativos e inativos. 


\subsection{Resultados e Contribuições}

Dentre os principais resultados e contribuições resultantes do trabalho estão:

- Implementação e validação de um web farm cluster tolerante a falhas e de alta performance, permitindo a hospedagem de um sistema de cursos via Internet e da ferramenta WebCoM, ambos desenvolvidos pelo grupo de pesquisa do Laboratório Intermídia do ICMC-USP.

- Disponibilização do cluster para o grupo de pesquisa com finalidade de desenvolvimento. Três nós do cluster estão sendo utilizados pelo grupo para o desenvolvimento de pesquisas sobre o uso de agentes em programas de apoio a educação (à distância ou presencial), sendo que esses nós podem ser utilizados também para $o$ atendimento de requisições.

- Redação de um relatório técnico sobre a implantação de um cluster. Esse relatório contém os passos básicos para a instalação e configuração de um web farm cluster tolerante a falhas.

- Desenvolvimento de um sistema baseado em agentes de software que permite a visualização dos estado e serviços de um Web Farm Cluster, através de páginas web, e realiza automaticamente tarefas simples que permitem que o cluster continue funcionando adequadamente mesmo que partes dele falhem. O sistema apresenta características de computação autỏnoma, permitindo a diminuição da intervenção humana para a manutenção do cluster, reduzindo o seu TCO (Total Cost of Ownership) e aumentando a robustez do mesmo (TANAKA; MOREIRA, 2004).

\subsection{Limitações}

O iCluster foi desenvolvido em Java e pode operar em qualquer plataforma Unix. Ele porém apresenta algumas limitações:

- O iCluster atualmente opera apenas em sistemas Linux, isto porque o iCluster é dependente de um módulo de kernel do Linux, o lm_sensors, que disponibiliza os arquivos relacionados a temperatura dos processadores, voltagem dos componentes e rotação das ventoinhas, e além disso, o sistema faz a leitura de vários outros arquivos disponibilizados no sistema de arquivos /proc. 
- Em sua primeira versão, o iCluster faz o controle de consistência de serviços em director apenas em conjunto com o programa LVS (Linux Virtual Server).

- O lm_sensors carrega drivers específicos para cada tipo de chip - dependendo do fabricante e do modelo - disponibilizando, desse modo, arquivos diferentes para cada chip. Desse modo, o iCluster, na atual versão, faz a leitura apenas de arquivos disponibilizados pelo driver i2c-amd756, que é carregado para chips AMD 756, $766 \mathrm{e}$ 768.

\subsection{Trabalhos Futuros}

A atual implementação do iCluster está em sua primeira versão, ele pode ser melhorado em diversos pontos.

Como o lm_sensors gera arquivos diferentes para cada tipo de chip, uma melhoria que pode ser adicionada ao iCluster é com relação à implementação de um parser que gere formatos de arquivos padrão a partir dos arquivos disponibilizados pelo $1 \mathrm{~m} \_$sensors. Essa melhoria tornaria o iCluster independente de arquivos disponibilizados pelo $1 \mathrm{~m}$ _sensors. Esse parser poderia ser implementado utilizando ferramentas como $\operatorname{Lex}^{3} \mathrm{e} \mathrm{YACC}^{4}$.

A arquitetura pode ainda ser adequada para outros tipos de balanceadores de carga. Para isso, é necessário implementar classes para outros tipos de balanceadores além do LVS.

Uma funcionalidade que pode ser adicionada ao iCluster é com relação à wake up on lan, isto é, quando um nó sair de operação ele poderá ser reinicializado remotamente de outro nó, através de um agente. Para implementar essa funcionalidade é necessário que as máquinas do cluster tenham suporte ao wake up on lan.

Como idealmente um Web Farm Cluster deve disponibilizar seus serviços continuamente, uma melhoria que pode ser acrescentada ao iCluster, para dar um melhor suporte a esse aspecto, é com relação a envios de mensagens ao administrador para dispositivos móveis, como celular, pager etc.

\footnotetext{
${ }^{3}$ http://dinosaur.compilertools.net/lex/index.html

${ }^{4}$ http://dinosaur.compilertools.net/yacc/index.html
} 


\subsection{Considerações Finais}

A implementação do Web Farm Cluster do Laboratório Intermídia vem propiciando um ambiente estável para a hospedagem do sistema de cursos e da ferramenta WebCoM e para o desenvolvimento de pesquisas do grupo.

O iCluster surge como uma alternativa a outras implementações existentes para o monitoramento e controle de serviços e estados de um cluster, com a vantagem de ser facilmente portável para outros sistemas operacionais, por ser escrito em Java, e usar conceitos como computação autônoma e agentes. A computação autônoma é um campo ainda muito novo e grandes possibilidades de inovações e, apesar do iCluster não implementar totalmente um sistema autônomo, ele fornece uma base para trabalhos futuros muito relevantes dentro do grupo de pesquisa. 


\section{Referências Biblogrin ficas}

ABBONDANZIO, A.; ARIDOR, Y.; BIRAN, O.; FONG, L. L.; GOLDSZMIDT, G. S.; HARPER, R. E.; KRISHNAKUMAR, S. M.; PRUETT, G.; YASSUR, B. A. Technical forum: management of application complexes in multitier clustered systems. IBM System Journal, v. 42, n. 1, p. 189-195, março 2003.

ANDERSON, E.; PERTERSON, D.; BREWER, E. The Magicrouter: an application of fast packet interposing. Computer Science Department, University of:Berkeley, California, USA, 12 p. Maio 1996. Relatório técnico não publicado.

ANDREOLINI, M.; CASALICCHIO, E.; COLAJANNI, M.; MAMBELLI, M. A clusterbased web system providing differentiated and guaranteed services. Cluster Computing, Kluwer Academic Publishers, Hingham, Massachusetts, USA, v. 7, n. 1, January 2004, p. 7-19.

APON, A.; BAKER, M. Network Technologies: in a white paper on cluster computing. The International Journal of High-Performance Computing Applications, v. 15, n. 2, p. 102-114, Summer 2001.

APOSTOLOPOULOS, G.; PERIS, V.; PRASHANT, P.; SAHA, D. L5: a self-learning layer-5 switch. Yorktown, NY, USA: IBM, IBM ResearchReport, RC 21461, April 1999. $20 \mathrm{p}$.

APPAVOO, J.; HUI, K.; SOULES, C. A. N.; Wisniewski, R. W.; SILVA, D. M. da; KRIEGER, O.; AUSLANDER, M. A.; EDELSOHN, D. J.; GAMSA, B.; GANGER, G. R.; Mckenney, P.; OSTROWSKI, M.; ROSENBURG, B.; STUMM, M.; XENIDIS, J. Enabling autonomic behavior in systems software with hot swapping. IBM Systems Journal, v. 42, n. 1, p. 60-76, março 2003.

ARON, M.; SANDERS, D.; DRUSCHEL, P.; ZWAENEPOEL, W. Scalable content-aware request distribution in cluster-based network servers. In: USENIX Annual Technical Conference, 25., 2000, San Diego, California, USA. Proceedings. San Diego, California, USA: USENIX Assoc., junho 2000. p. 65-74.

BABAOGLU, O.; MELING, H.; MONTRESOR, A. Anthill: a framework for the development of agent-based peer-to-peer systems. In: International Conference on Distributed Computing Systems, 22., 2002, Vienna, Austria. Proceedings. Vienna, Austria: IEEE, julho 2002. p. 15-22.

BAKER, M. Cluster computing white paper. University of Portsmouth, UK: Mark Baker, dezembro 2000. 
BAKER, M.; APON, A.; BUYYA, R.; JIN, H. Cluster computing and applications. Encyclopedia of:Computer Science and Technology, v. 45, (A. Kent and J. Williams, Editors), Marcel Dekker, Inc., Agosto 2001.

BANTZ, D. F.: BISDIKIAN, C.; CHALLENER, C.; KARIDIS, J. P.; MASTRIANNI, S.; MOHINDRA, A.; SHEA, D. G.; VANOVER, M. Autonomic personal computing. IBM Systems Journal, v. 42, n. 1, p. 165-176, março 2003.

BASU, A.; BUCH, V.; VOGELS, W.; EICKEN, T. von. U-Net: a user-level network interface for parallel and distributed computing. In: ACM Symposium on Operating Systems Principles, 15., 1995, Copper Mountain, Colorado, USA. Proceedings. Copper Mountain, Colorado, USA: ACM Press, dezembro 1995. p. 40-53.

BECKER, D. Beowulf Project. Disponível em: <http://www.beowulf:org>. Acesso em: 13 agosto 2003.

BRAAM, P. J. The Coda distributed file system. School of Computer Science, Carnegie Mellon University. Disponível em: <http://www.coda.cs.cmu.edu/ljpaper/lj.html >. Acesso em: 03 outubro 2004.

BRADSHAW, J. M. Software Agents. 1. ed. Menlo Park, CA, USA: The MIT Press, 1997. $480 \mathrm{p}$.

BUYYA, R. High performance cluster computing: architectures and systems. 1. ed. Upper Saddle River, NJ, USA: Prentice Hall, 1999. v. 1, 849 p.

BUYYA, R.; PAPRZYCKI, M. Special issue on clustering in search for scalable commodity supercomputing. Slovenia, v. 23, n. 1, p. 97-105, abril 1999.

CARDELLINI, V.; CASALICCHIO, E.; COLAJANNI, M.; MAMBELLI, M. Web switch support for differentiated services. ACM SIGMETRICS Performance Evaluation Review. ACM Press, New York, NY, USA, v. 29, n. 2, p.14-19, setembro 2001.

CARDELLINI, V.; COLAJANNI, M.; YU, P. S. The state of the art in locally distributed web-server systems. ACM Computing Surveys (CSUR). ACM Press, New York, NY, USA, v. 34, n. 2, p.263-311, junho 2002.

CASALICCHIO, E.; CARDELLINI, V.; COLAJANNI, M. Content-aware dispatching algorithms for cluster-based web servers. Cluster Computing, Kluwer Academic Publishers, Hingham, Massachusetts, USA, v. 5, n. 1, January 2002, p.65-74.

CASALICCHIO, E.; COLAJANNI, M. A client aware dispatching algorithm for web clusters providing multiple services. In: International World Wide Web Conference, 10., 2001, Hong Kong. Proceedings. New York: ACM Press, maio 2001. p. 535-544.

CASSEN, A. Keepalived for LVS. Guia do Usuário. 2002. 23 p. Disponível em: $<$ http://www.keepalived.org/pdf/UserGuide.pdf>. Acesso em: 13 setembro 2004.

CASTELLI, V.; HARPER, R. E.; HEIDELBERGER, P.; HUNTER, S. W.; TRIVEDI, K. S.; VAIDYANATHAN, K.; ZEGGERT, W. P. Proactive management of software aging. 
IBM Journal of Research and Development, v. 45, n. 2, p. 311-332, março 2001.

CECCHET, E.; MARGUERITE, J.; PELTIER, M.; MODRZYK, N. C-JDBC User's guide. France. 2004. 70 p.

CHESS, D. M.; PALMER, C. C.; WHITE, S. R. Security in an autonomic computing environment. IBM Systems Journal, v. 42, n. 1, p. 107-118, março 2003.

CHIEN, A. A.; PAKIN, S.; LAURIA, M.; BUCHANAN, M.; HANE, K.; GIANNINI, L.; PRUSAKOVA, J. High performance virtual machines (HPVM): clusters with supercomputing APIs and performance. In: SIAM Conference Parallel Processing for Scientific Computing, 8., 1997. Proceedings. Março 1997.

CHIEN, A. A.; PADUA, D. R. D. High performance virtual machine. Disponível em: $<$ http://www.csag.ucsd.edu/projects/hpvm.html $>$. Acesso em 15 agosto 2003.

CISCO SYSTEMS. Cisco CSS: 11500 series content services switches. Disponivel em: $<$ http://www.cisco.com/en/US/products/hw/contnetw/ps792/>. Acesso em: 03 outubro 2004.

CISCO SYSTEMS. Cisco LocalDirector: 400 Series. Disponível em:

<http://www.cisco.com/warp/public/cc/pd/cxsr/400/index.shtml>. Acesso em: 03 outubro 2004.

CONSTANTINESCU, Z. Towards an autonomic distributed computing system. In: International Workshop on Database and Expert Systems Applications, 14., 2003, Praga, República Tcheca. Proceedings. Praga, República Tcheca: IEEE, setembro 2003, p. 694698.

COSTA JR., H. L. Aplicações de Agentes Inteligentes. Disponível em:

$<$ http://www.helionet.varginha.br/files/agentes.htm>. Acesso em: 11 fevereiro 2003.

CULLER, D. E.; ARPACI-DUSSEAU, A.; ARPACI-DUSSEAU, R.; CHUN, B.; LUMETTA, S.; MARTIN, R.; YOSHIKAWA, C.; WONG, F. Parallel computing on the Berkeley NOW. In: Joint Symposium on Parallel Processing, 9., 1997, Kobe, Japan. Proceedings. Kobe, Japan, maio 1997. p. 237-247.

DAMANI, O. P.; CHUNG, P. E.; HUANG, Y.; KINTALA,C.; WANG, Y.-M. ONE-IP: techniques for hosting a service on a cluster of machines. Computer Networks, Elsevier Science Publishers Ltd., Essex, UK, v. 29, n. 8-13, 1997. p. 1019-1027.

DIAS, D. M.; KISH, W.; MUKHERJEE, R.; TEWARI, R. A scalable and highly available web server. In: IEEE Computer Society International Conference, 41., 1996, Los Alamitos, California, USA. Proceedings. Los Alamitos, California, USA: IEEE Computer Society, 1996. p. 85-92.

DUNNING, D.; REGNIER, G.; McALPINE, G.; CAMERON, D.; SHUBERT, B.; BERRY, F.; MERRITT, A. M.; GRONKE, E.; DODD, C. The virtual interface architecture. IEEE Micro, USA, v. 18, n. 2, p. 66-76, março/abril 1998. 
EICKEN, T. von; CULLER, D. E.; GOLDSTAIN, S. C.; SCHAUSER, KLAUS E. Active messages: a mechanism for integrated communication and computation. In: International Symposium on Computer Architecture, 19., 1992, Gold Coast, Australia. Proceedings. Gold Coast, Australia: ACM Press, maio 1992. p. 256-266.

FERBER, J.; GHALLAB, M. Problématiques des univers multi-agents intelligents. Actes des Journées Nationeles du PRC-GRECO Intelligence Artificialle, Taknea, p. 295-320, 1988.

FERREIRA, A. B. H. Novo Aurélio Século XXI - O dicionário da Língua Portuguesa. Rio de Janeiro, Nova Fronteira, 1999.

FLEURY, M.; REVERBEL, F. The JBoss extensible server. In: ACM/IFIP/USENIX International Middleware Conference M. Endler and D. Schmidt, editors, 4., 2003, Rio de Janeiro, RJ. Proceedings. Rio de Janeiro, RJ, Lecture Notes in Computer Science, v. 2672, Junho 2003. p. 344-373.

FOUNDATION FOR INTELLIGENT PHYSICAL AGENTS, FIPA ACL Message Structure Specification - RFC. Disponível em: $<\mathrm{http}: / / \mathrm{www}$.fipa.org/rfcs $>$. Acesso em: 15 Março 2004.

FOUNDRY NETWORKS. ServerIron. Disponível em: $<$ http://www.foundrynet.com/products/webswitches/serveriron/>. Acesso em: 03 outubro 2004.

FOX, A.; GRIBBLE, S. D.; CHAWATHE, Y.; BREWER, E. A.; GAUTHIER, P. Clusterbased scalable network services. In: ACM SYMPOSIUM ON OPERATING SYSTEMS PRINCIPLES, 16., 1997, Saint Malo, France. Proceedings. Saint Malo, France, Outubro 1997. p. 78-91.

FLANKLIN, S.; GRAESSER, A. Is it an agent, or just a program?: A taxonomy for autonomous agents. Intelligent Agents III, Lecture Notes on Artificial Intelligence, Springer-Verlag, Berlin, p. 21-35, 1997.

FRANCESCHI, A. S. M.; BARRETO, J. M.; ROISENBERG, M. Desenvolvimento de agentes de software autônomo para gerência de redes de computadores. In: Simpósio Brasileiro de Redes Neurais, 6., 2000, Rio de Janeiro, RJ. Proceedings. Rio de Janeiro, RJ, novembro 2000.

FRICKE, P.; BROWN, D. H. Report on JBoss and Professional Open Source Model. Port Chester, NY, USA: JBoss in Press. 13 Julho, 2004. 7 p.

GALSTAD, E. Nagios: version 1.0 documentation. 2002. 199 p. Disponível em: $<$ http://www.nagios.org/docs/>. Acesso em: 13 setembro 2004.

GANEK, A. G.; CORBI, T. A. The Dawning of the autonomic computing era. IBM Systems Journal, v. 42, n. 1, p. 5-18, março 2003.

GARCIA, A. C. B; SICHMAN, J. S. Agentes e Sistemas Multiagentes In: REZENDE, S. O. Sistemas Inteligentes - Fundamentos e Aplicações. Barueri, SP, 2002, Editora Manole, p. 
HARIRI, S.; PARASHAR, M. Autonomic computing landscape. In: ACS/IEEE International Conference on Computer Systems and Applications, AICCSA: Autonomic Computing Tutorial, 2003, Tunis, Tunisia. Proceedings. Tunis, Tunisia: IEEE, Julho, 2003.

HARIRI, S.; XUE, L.; CHEN, H.; ZHANG, M.; PAVULURI, S.; RAO, S. Autonomia: an autonomic computing environment. In: International Performance Computing and Communications Conference, 2003, Tucson, Arizona, USA. Proceedings. Tucson, Arizona, USA: IEEE, abril 2003. p. 61-68.

HAUKELAND, J. II.; PALA, M.; TOMA, R.; HOPP, C. Monit. Disponível em: $<$ http://www.tildeslash.com/monit/index.html>. Acesso em: 13 setembro 2004.

JAQUES, P.; OLIVEIRA, F. M. Um experimento com agentes de software para monitorar a colaboração em uma turma virtual. Revista de Informática na Educação, n. 7, setembro 2000.

JIN, H.; CORTES, T.; BUYYA, R. High performance mass storage and parallel I/O. 1. ed. New York, USA: Wiley-IEEE Press, novembro 2001, p. 617-632.

KAISER, G.; PAREKH, J.; GROSS, P.; VALETTO, G. Kinesthetics eXtreme: an external infrastructure for monitoring distributed legacy systems. In: Autonomic Computing Workshop International Workshop on Active Middleware Services, 15., 2003, Seattle, Washington, USA. Proceedings. Seattle, Washington: IEEE, 25 junho, 2003, p. 22-31.

KEPHART, J. O.; CHESS, D. M. The vision ofiautonomic computing. Computer Magazine, Hawthorne, NY, USA, v. 36 n. 1, p.41-50, January 2003.

LAMB, J. What is a Microsoft Cluster? Prentice Hall Professional Technical Reference, Março 2002. Disponível em: <http://www.phptr.com/articles/article.asp?p=25748>. Acesso em: 15 agosto 2004 .

LATHAM, R. Parallel Virtual File System. Version 2, September 2003. Disponível em: http://www.pvfs.org/pvfs2/pvfs2-guide.html.

LM_SENSORS Group. Hardware Monitoring: $1 \mathrm{~m}$ _sensors. Disponível em: < http://secure.netroedge.com/ $/ \operatorname{lm} 78 />$. Acesso em: 05 Abril 2004.

LUCENA, P. Semantic Agent, uma plataforma para desenvolvimento de agentes inteligentes. 2003. $151 \mathrm{fi}$ Dissertação (Mestrado em Ciência da Computação) - Curso de Pós-Graduação em Ciência da Computação e Matemática Computacional, Universidade de São Paulo, São Carlos, SP, 2003.

MAES, P. Designing autonomous agents: theory and practice from Biology to Engineering and Back. 1. ed. Cambridge: The MIT Press/Bradford Books, 1991. 200 p.

MAES, P. Intelligent software. Scientific American - 150 Anniversary Issue, p. 66-68, setembro 1995. 
MAROWSKY-BRÉE, L. Heartbeat tutorial. In: Linux Symposium, 5., 2003, Ottawa, Canada. Proceedings. Ottawa, Canada, julho 2003. 34 p.

MEIIAT, S.; SPRACKETT, Z.; JOHNSON, D.; KATZUNG, J.; HAITZLER, C.. VACM: users and programmers manual. 1. ed. San Mehat \& Linux Systems Inc, 2000. 156 p. Disponível em: $<\mathrm{http}: / / \mathrm{vacm}$.sourceforge.net/docs/vacm_manual.pdf $>$. Acesso em: 13 setembro 2004.

MOREIRA, D. A. Agents: a distributed client/server system for leaficell generation. 1995. 171 fi Tese (Doutorado em Engenharia Elétrica) - Curso de Pós-Graduação em Engenharia Elétrica, Universidade de Canterbury, Canterbury, UK, 1995.

MOREIRA, D. A.; WALCZOWSKI, L. T. Using software agents to gererate VLSI layouts. IEEE Expert Intelligent Systems, v.12, n. 6, p. 26-32, 1997.

NORTEL NETWORKS. Alteon web OS traffic control software. Disponivel em: $<\mathrm{http}: / /$ www.nortelnetworks.com/products/01/alteon/>. Acesso em: 03 outubro 2004.

NUNES, H. M. P. Serviço de busca baseado em agentes móveis para o ambiente Mathnet de ensino cooperativo computadorizado. 2001. $140 \mathrm{fl}$ Dissertação (Mestrado em Engenharia Elétrica) - Departamento de Engenharia Elétrica, Universidade Federal do Maranhão, São Luís, 2001.

NWANA, H. S. Software agents: an overview. Knowledge Engineering Review. Cambridge: Cambridge University Press, v. 11, 1996. p. 42.

ODELL, J. Objects and Agents Compared. Journal of Object Technology, v. 1, n. 1, p. $41-53,2002$.

PAKIN, S.; LAURIA, M.; CHIEN, A. A. High performance messaging on workstations: Illinois Fast Messages (FM) for Myrinet. In: Supercomputing Conference, 9., 1995, San Diego, California, USA. Proceedings. San Diego, California, USA: ACM Press, dezembro 1995. p. 1-22.

PATTERSON, D. A.; BROWN, A.; BROADWELL, P.; CANDEA, G.; CHEN, M.; CUTLER, J.; ENRIQUEZ, P.; FOX, A.; KICIMAN, E.; MERZBACHER, M.; OPPENHEIMER, D.; SASTRY, N.; TETZLAFF, W.; TRAUPMAN, J.; TREUHAFT, N. Recovery-Oriented Computing (ROC): Motivation, Definition, Techniques, and Case Studies. UC Berkeley Computer Science, Berkeley, California, USA: UCB//CSB, março 2002. $16 \mathrm{p}$.

PEREIRA, B. Autonomic computing brings the healing touch to IT. Express Computer, Mumbai, India, n. 1, 19 agosto, 2002.

PRESLAN, K.; TEIGLAND, D.; O'KEEFE, M.; MAUELSHAGEN, Heinz. An overview of Global File System. Disponível em: <http://www.chopen.ch/html/events/LinuxConference/HTML/1H/>. Acesso em: 03 outubro 2004.

RHEA, S.; EATON, P.; GEELS, D.; WEATHERSPOON, H.; ZHAO, B.;

KUBIATOWICZ, J. Pond: the OceanStore prototype. In: USENIX Conference on File and 
Storage Technologies, 2., 2003, Berkeley, California, USA. Proceedings. Berkeley, California, USA: USENIX, March 2003. p. 1-14.

RUSSELL, L. W.; MORGAN, S. P.; CHRON, E. G. Clockwork: a new movement in autonomic systems. IBM Systems Journal, v. 42, n. 1, p. 77-84, março 2003.

RUSSELL, D. M.; MAGLIO, P. P.; DORDICK, R.; NETI, C. Dealing with ghosts: managing the user experience of autonomic computing. IBM Systems Journal, v. 42, n. 1, p.177-188, março 2003.

RUSSEL, S.; NORVIG, P. Artificial intelligence: a modern approach. Upper Saddle River: Prentice Hall, 1995. 932 p.

SATYANARAYANAN, M. Scalable, secure and highly available distributed file access. Los Alamitos, CA, USA: IEEE Computer Society Press, v. 5, n. 23, 1990. p. 9-18, 20-21.

SHOHAM, Y. An overview of agent-oriented programming. In: BRADSHAW, J. M. Software Agents. Cambridge: AAAI Press/ The MIT Press, 1997. p. 271-290.

SOLTIS, F. G. Future directions: are you ready for e-business on demand?, @Server Magazine, n. 18, Asean/SA edition, p. 8-11, April 2003.

STALLINGS, W. Local \& Metropolitan Area Networks. 6. ed. Upper Saddle River, New Jersey: Prentice Hall, 2000. 478 p.

SUTTON, N. eLiza: IBM's guide to IT complexity, takes shape. Computing Canada, 16 Novembro, 2001.

TANAKA, F. Y.; MOREIRA, D. A. Um sistema de controle para web farms baseado em agentes de software. In: WebMedia/LA-Web 2004 Joint Conference, 2004, Ribeirão Preto, SP. Proceedings. Ribeirão Preto, SP: SBC, outubro 2004. 4 p.

TANENBAUM, A. S. Computer Networks. 4. ed. Upper Saddle River, New Jersey: Prentice Hall, 2003. 891 p.

THE APACHE JAKARTA PROJECT. JMeter user's manual. Disponível em: http://jakarta.apache.org/jmeter/usermanual/index.html. Acesso em: 15 setembro 2004.

TROCKI, J. Mon: service monitoring daemon. Disponível em:

<http://www.kernel.org/software/mon/>. Acesso em: 13 setembro 2004.

TURNER, E.; STRONG, P.; CAROLAN, J.; RADEZTSKY, S. N1 Grid architecture realized: Strategic Flexibility. Sun Microsystems, maio 2004. 20 p.

VAIDYA, S.; CHRISTENSEN, K. J. A single system image server cluster using duplicated MAC and IP addresses. In: IEEE Conference on Local Computer Networks, 26., 2001, Florida, USA. Proceedings. Florida, USA: ACM Press, Novembro, 2001 . p. 206-214.

WANT, R.; PERING, T.; TENNENHOUSE, D. Comparing autonomic and proactive 
computing. IBM Systems Journal, v. 42, n. 1, p. 129-135, março 2003.

WALKER, J. B. In troduction to single system image clustering. Compaq, novembro 2001. Disponível em: <http://opensource.compaq.com/ssiintro_edited_v4.pdf $>$. Acesso em: 14 Maio 2004.

WOLF, J. L.; YU, P. S. On balancing the load in a clustered web Farm. ACM Transactions on Internet Technology (TOIT), v. 1, n. 2, p. 231-261, Novembro 2001.

WOOLDRIDGE, M.; JENNINGS, N. Intelligent agents: theory and practice. Knowledge Engineering Review, v. 10, n. 2, p. 115-152, 1995.

WOOLDRIDGE, M.; JENNINGS, N. Agent based computing. Interoperable Communication Networks, v. 1, n. 1, p. 71-97, 1997.

ZAYAS, R. E. AFS-3 programmer's reference: architectural overview. Setembro 2001. $37 \mathrm{p}$.

ZHANG, X.; BARRIENTOS, M.; CHEN, J. B.; SELTZER, M.. HACC: an architecture for cluster-based web servers. In: USENIX Windows NT, 3., 1999, Seattle, WA, USA.

Proceedings. Seattle, WA, USA: USENIX Assoc., 1999. p. 155-164.

ZHANG, W. Linux Virtual Server for scalable network services. In: Linux Symposium, 2. 2000, Ottawa, Canada. Proceedings. Ottawa, Canada, julho 2000. 10 p. 


\section{Apêndice A- Descrição dos Agentes Monitores}

\section{A.1 Agente Monitor de Serviço - SMAg}

O SMAg faz o monitoramento de todos os serviços que estão escritos no arquivo texto "services.cluster". Neste arquivo estão especificados o nome do serviço e nome do processo desse serviço.

Este agente monitora os serviços fazendo uma comparação do nome do processo do serviço que se encontra no arquivo "services.cluster" com o nome de processo dos serviços listados a partir do comando "ps -el". Quando o nome do processo, para esse comando, tiver vários nomes de processos iguais tem-se que acrescentar o identificador de usuário desse processo.

Quando um serviço monitorado sai de operação, o SMAg tenta reiniciar o serviço. Se o serviço não for reiniciado o SMAg escreve o nome do serviço e o nome do processo desse serviço no arquivo "services-off.cluster" e comunica-se com o ManAg dos directors e o MailAg local. Ao ManAg dos directors é enviada uma mensagem informando-o sobre a parada do serviço, como mostrado na, e ao MailAg é solicitada a transmissão de uma mensagem de aviso sobre a parada do serviço à caixa de correio eletrônico do administrador. Se o serviço for reiniciado ele continua a monitoração dos outros serviços normalmente.

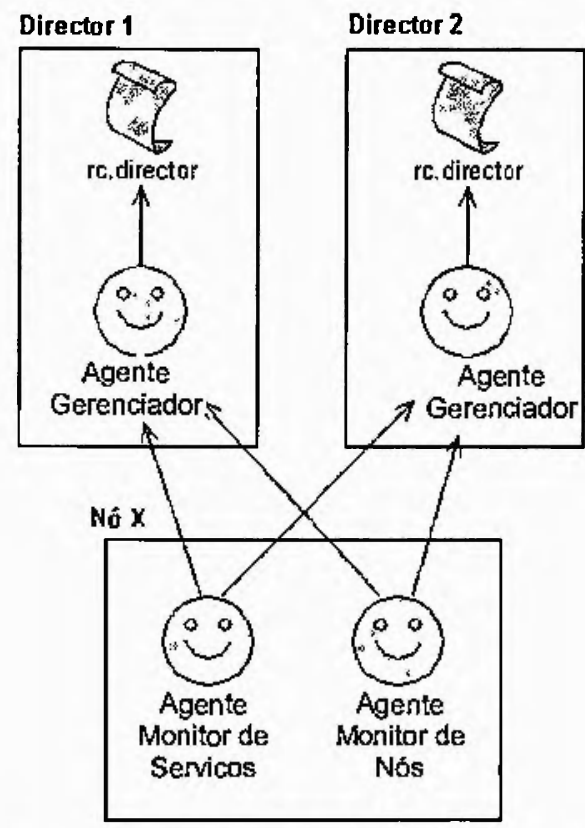

Figura A.1 - Interação do SMAg e NMAg com o ManAg dos directors 


\section{A.2 Agente Monitor de Nós - NMAg}

O NMAg faz o monitoramento de todos os nós que estão escritos no arquivo “/etc/nodes.cluster". Neste arquivo está especificado o nome (hostname) ou o endereço IP de todos os nós de um WFC.

Este agente monitora os nós lançando um comando "ping" a todos os nós de um WFC. Se algum nó não responder a esse comando, o NMAg escreve o nome ou o IP desse nó no arquivo "/etc/nodes-off.cluster" e comunica-se com o ManAg dos directors e o MailAg local. Ao ManAg dos directors é enviada uma mensagem informando-o sobre a parada do nó, como mostra a Figura 6.16; e ao MailAg é solicitada a transmissão de uma mensagem de aviso sobre a parada do nó à caixa de correio eletrônico do administrador.

\section{A.3 Agente Monitor de Ventoinha - FMAg}

O FMAg faz o monitoramento da rotação das ventoinhas existentes em um nó de um WFC. Este agente realiza esse monitoramento fazendo a leitura dos arquivos "fanX" (onde $X \in Z / 1$ $\leq \mathrm{X} \leq$ Quantidade de Ventoinhas) localizados no diretório "/proc/sys/dev/sensors/as99127f i2c-0-2d".

Se a rotação de uma ventoinha ficar abaixo de 4500rpm, o FMAg comunica-se com o MailAg local solicitando a transmissão de uma mensagem de aviso sobre o fato à caixa de correio eletrônico do administrador.

\section{A.4 Agente Monitor de Disco Rígido - HDMAg}

O HDMAg faz o monitoramento do volume de uso de um disco rígido de um nó do WFC. Este agente realiza esse monitoramento fazendo a leitura do resultado do comando "df" do Linux.

Se uma partição de um disco alcançar 95\% de uso, o HDMAg comunica-se com o MailAg local solicitando a transmissão de uma mensagem de aviso sobre o fato à caixa de correio eletrônico do administrador.

\section{A.5 Agente Monitor de Memória - MMAg}

O MMAg faz o monitoramento de uso da memória em um nó de um WFC. Este agente realiza esse monitoramento fazendo a leitura do arquivo "meminfo" que se encontra no diretório "/proc". 
Se o uso da memória de um nó de um WFC atingir a sua capacidade máxima, o MMAg comunica-se com o MailAg local solicitando a transmissão de uma mensagem de aviso sobre o fato à caixa de correio eletrônico do administrador.

\section{A.6 Agente Monitor de Temperatura - TMAg}

O TMAg faz o monitoramento da temperatura dos processadores existentes em um nó de um WFC. Este agente realiza esse monitoramento fazendo a leitura dos arquivos "tempX" (onde $\mathrm{X} \in \mathrm{Z} / 1 \leq \mathrm{X} \leq$ Quantidade de Processadores) localizados no diretório “/proc/sys/dev/sensors/as99127f-i2c-0-2d".

Se a temperatura de um processador atingir $50^{\circ} \mathrm{C}$, o FMAg comunica-se com o MailAg local solicitando a transmissão de uma mensagem de aviso sobre o fato à caixa de correio eletrônico do administrador.

\section{A.7 Agente Monitor de Voltagem - VMAg}

O VMAg faz o monitoramento das voltagens dos componentes existentes em uma "placa mãe". Este agente realiza esse monitoramento fazendo a leitura dos arquivos "inX" (onde $\mathrm{X} \in \mathrm{Z} / 1 \leq \mathrm{X} \leq$ Quantidade de Tipos de Voltagens) localizados no diretório “/proc/sys/dev/sensors/as99127f-i2c-0-2d".

Se a voltagem dos componentes atingir seus limites inferior e superior disponibilizados nos seus respectivos arquivos, o FMAg comunica-se com o MailAg local solicitando a transmissão de uma mensagem de aviso sobre o fato à caixa de correio eletrônico do administrador. 


\section{Apêndice B - Diagrama de Classes UML}

\begin{tabular}{|l|}
\hline \\
\hline -path : String \\
-word : String \\
-tokenSeparator : String \\
-wordMatch : boolean \\
-index: Int \\
\hline +DataProcFileSystem(pathString, wordMatch:boolean, word:String, tokenSeparator.String, breakNamed:boolean, index-ServerSocket) \\
+getContento : String \\
+getContentso : String0
\end{tabular}

$$
\text { +get Contentso: Stringd }
$$

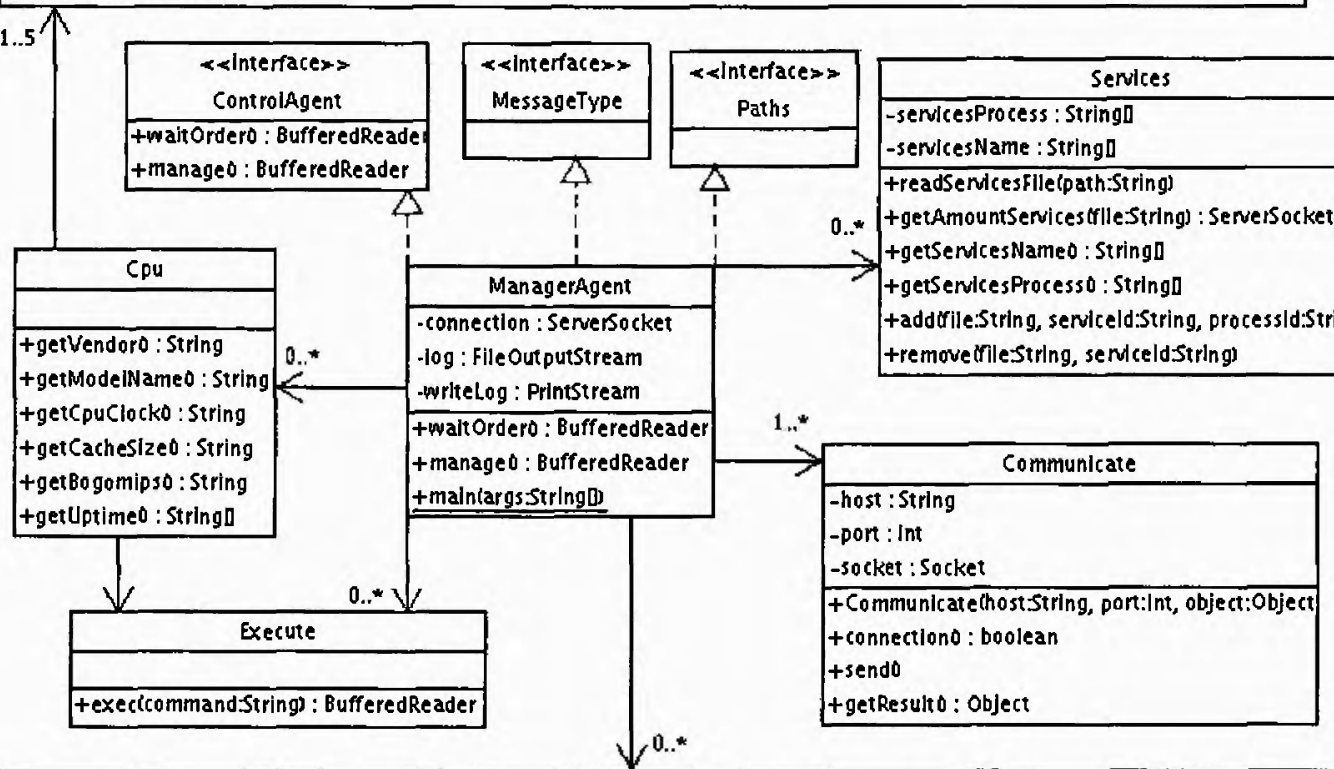

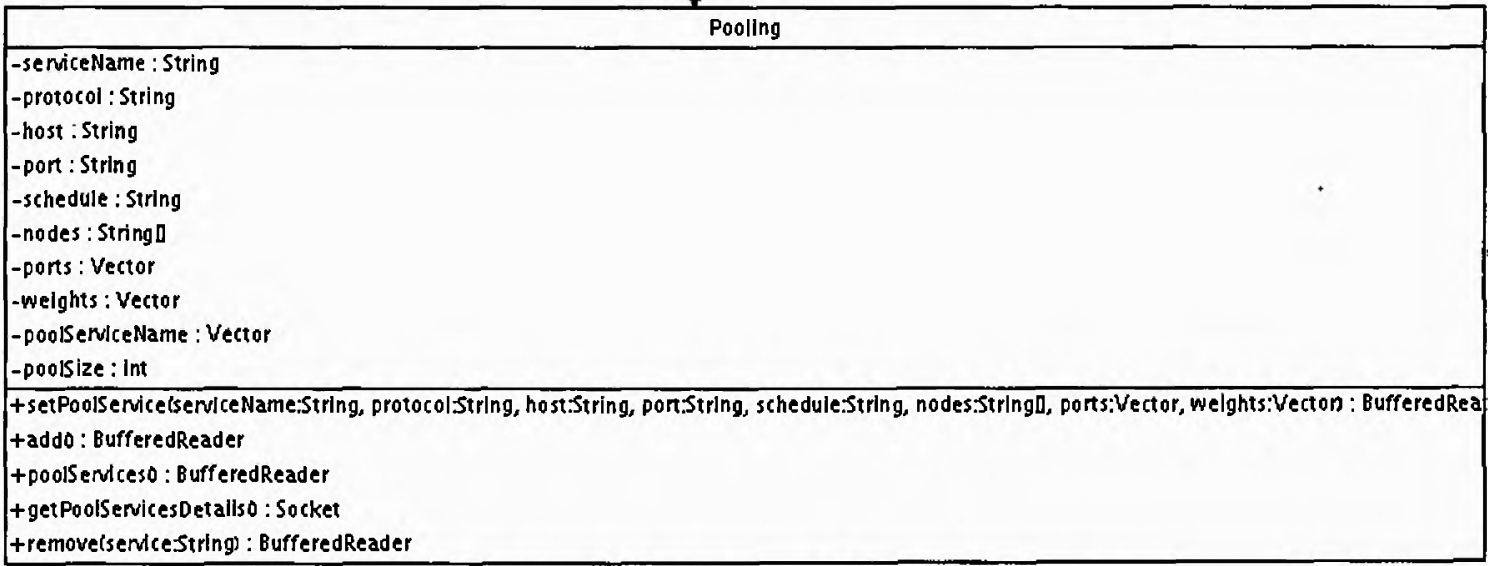

Figura B.1 - Diagrama de classes UML do ManagerAgent 


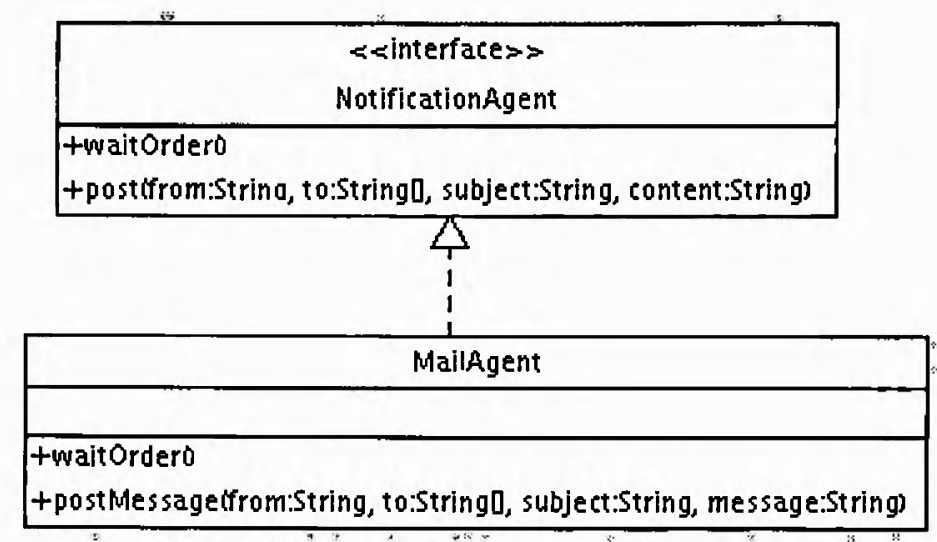

Figura B.2 - Diagrama de classes UML do MailAgent

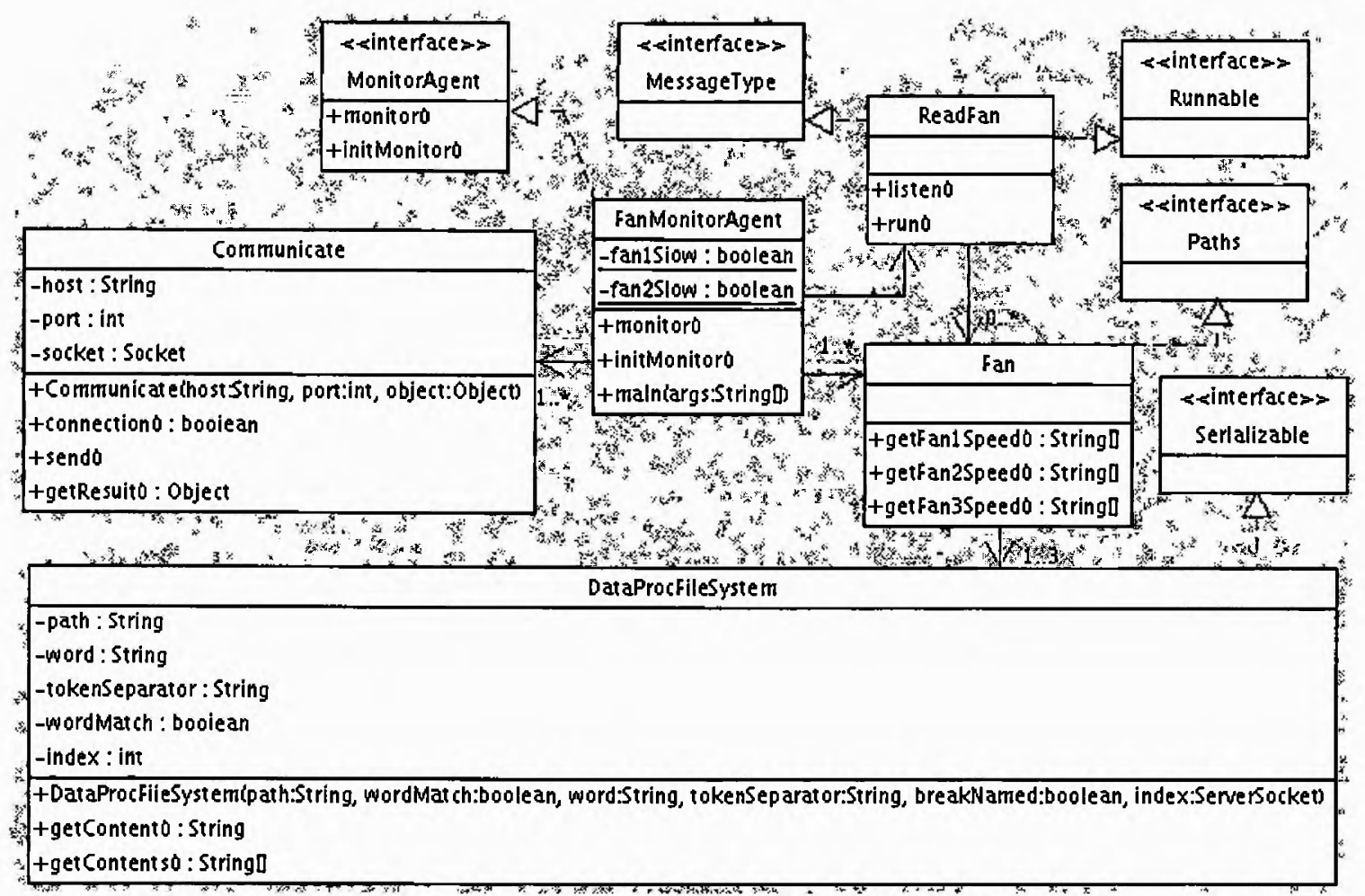

Figura B.3 - Diagrama de classes UML do FanMonitorAgent 


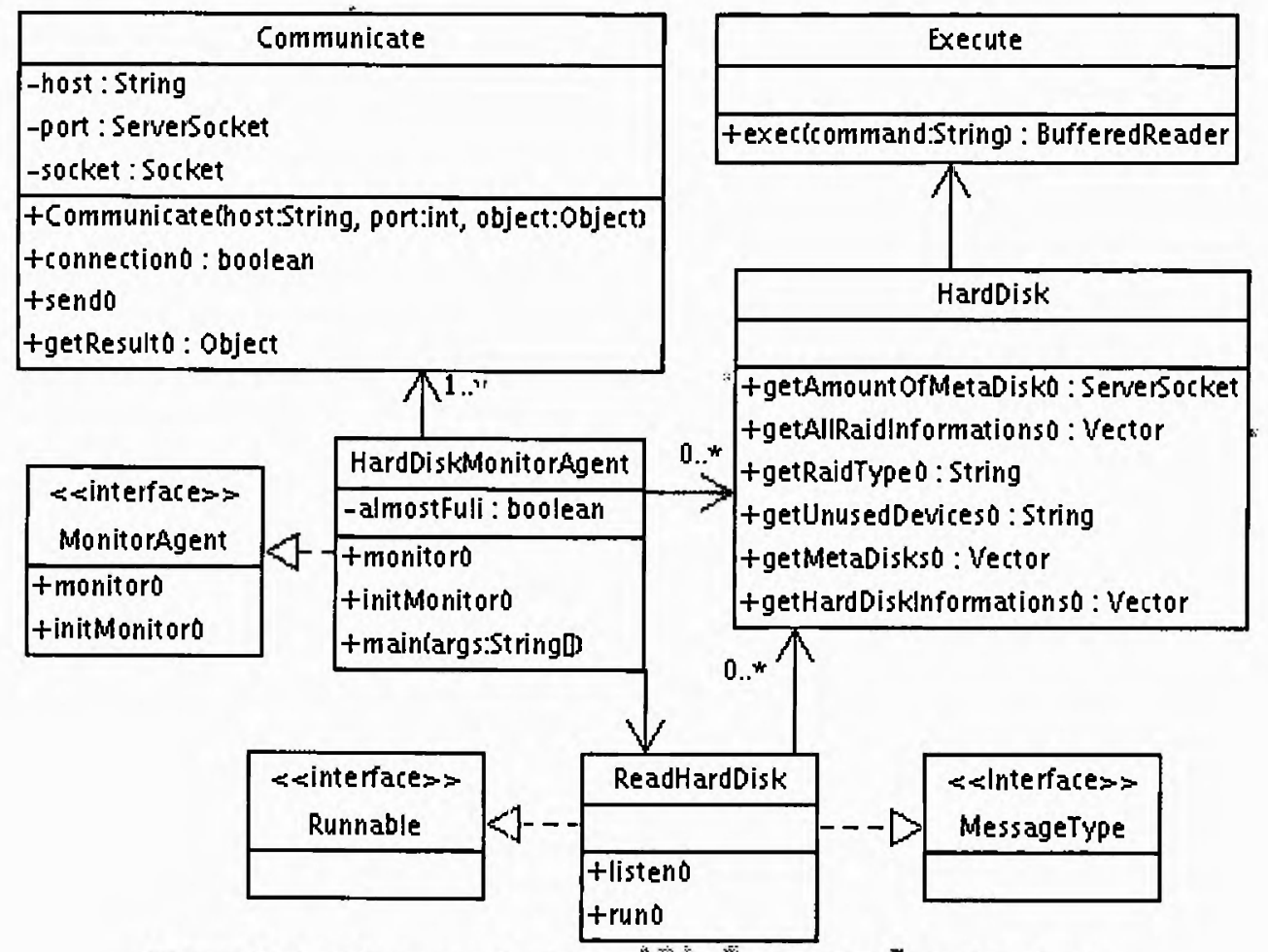

Figura B.4 - Diagrama de classes UML do HardDisk̈MonitorAgent 


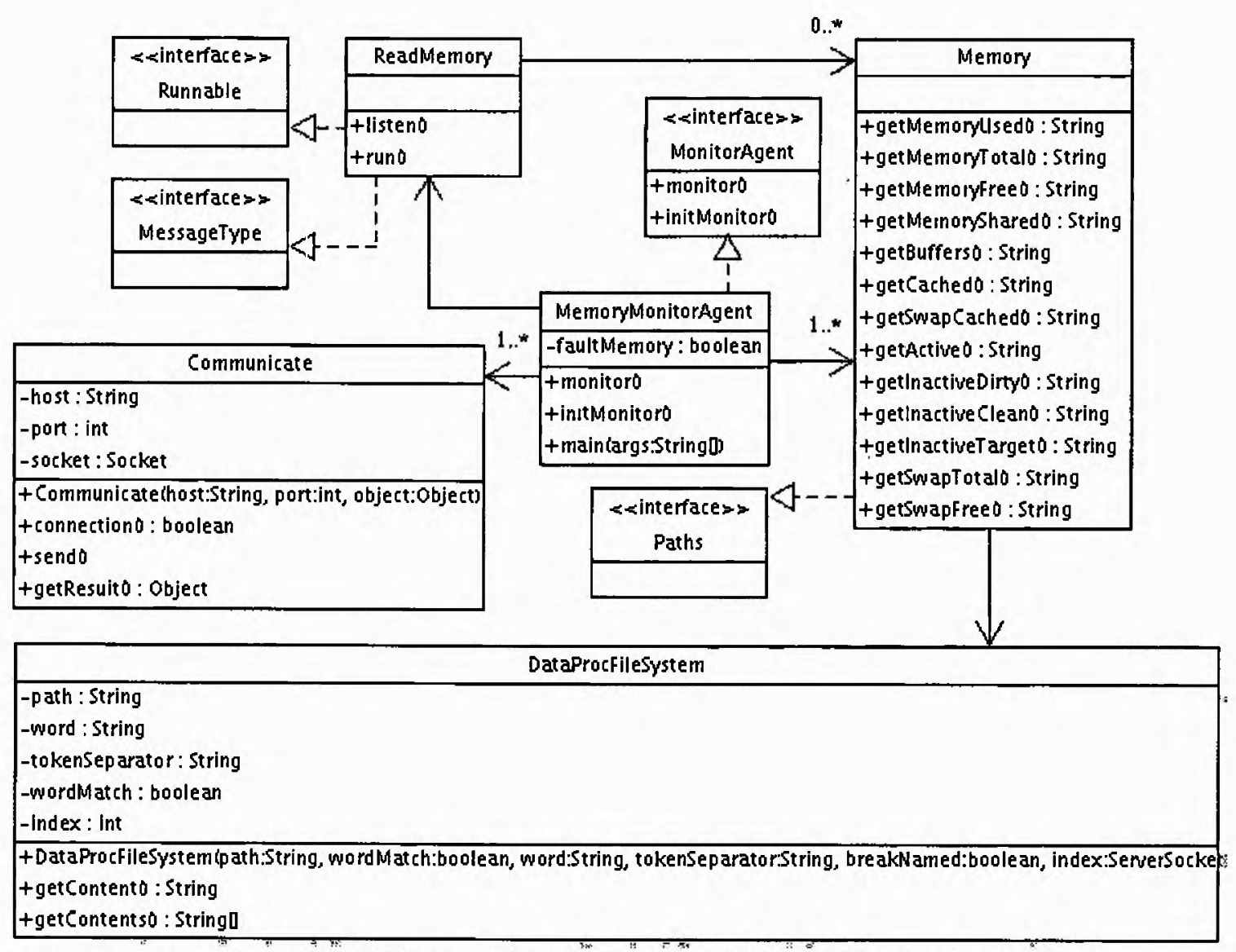

Figura B.5 - Diagrama de classes UML do MemoryMonitorAgent

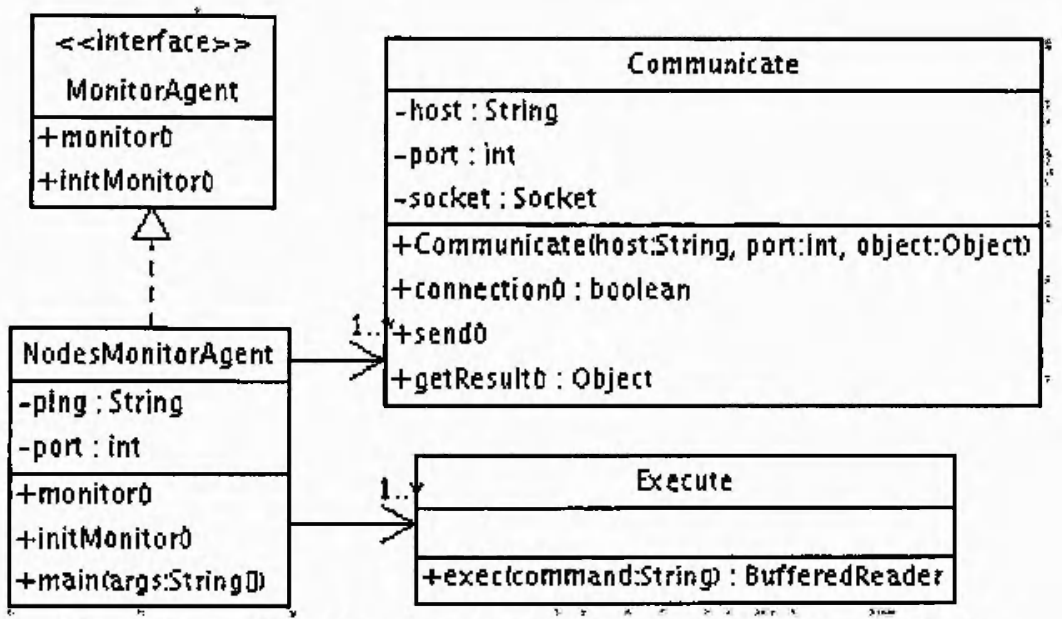

Figura B.6 - Diagrama de classes UML do NodesMonitorAgent 


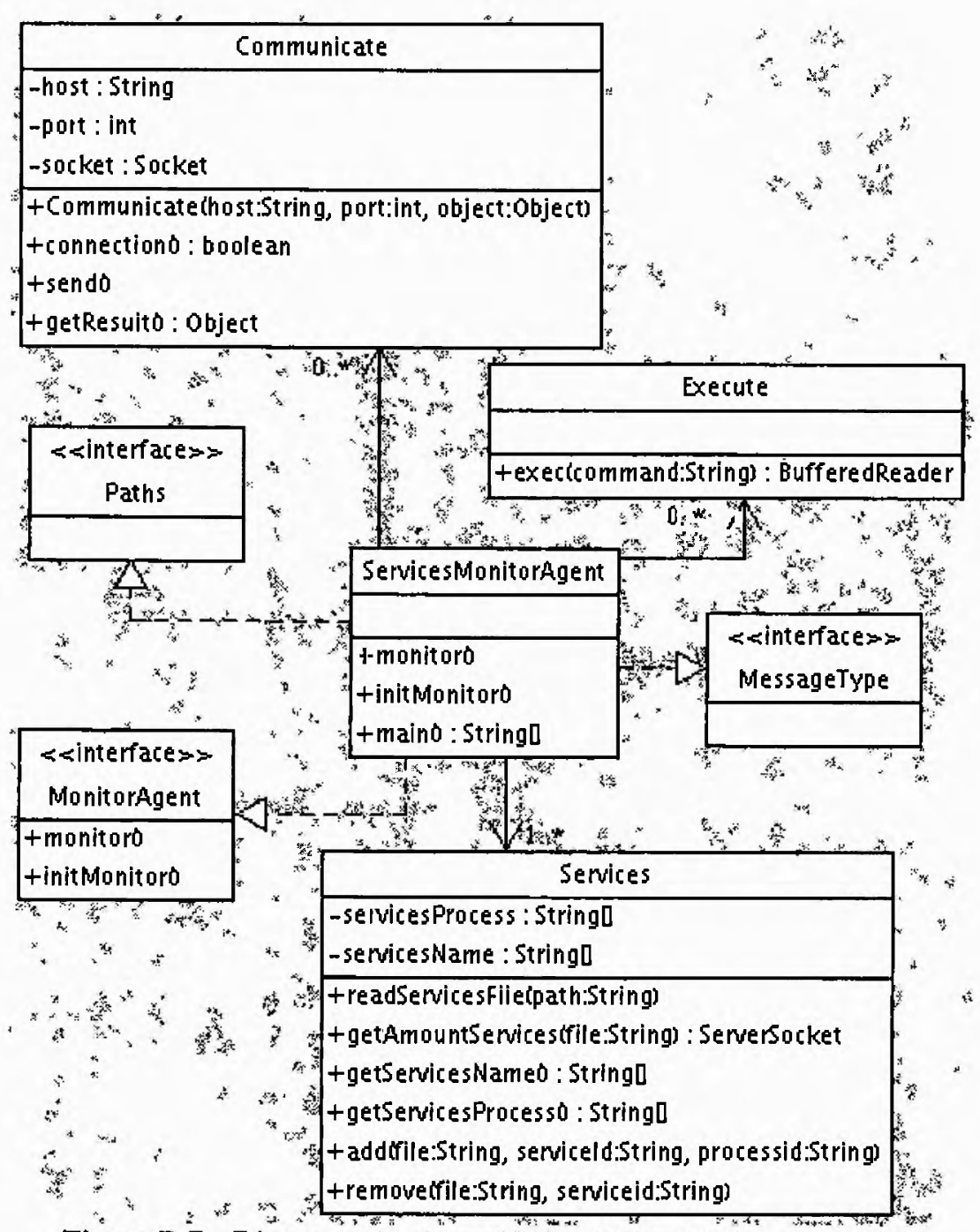

Figura B.7 - Diagrama de classes UML do ServicesMonitorAgent 


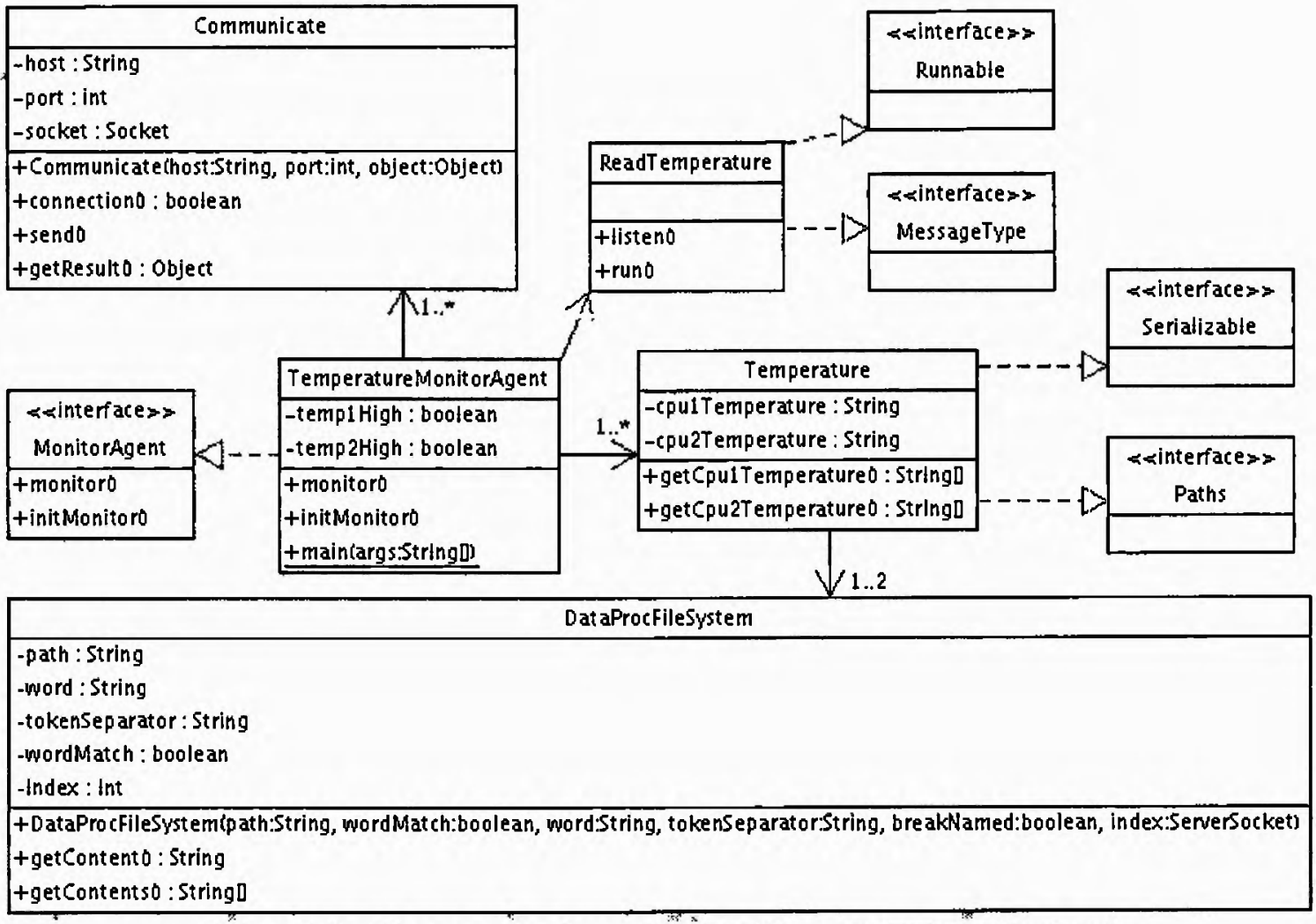

Figura B.8 - Diagrama de classes UML do TemperatureMonitorAgent 


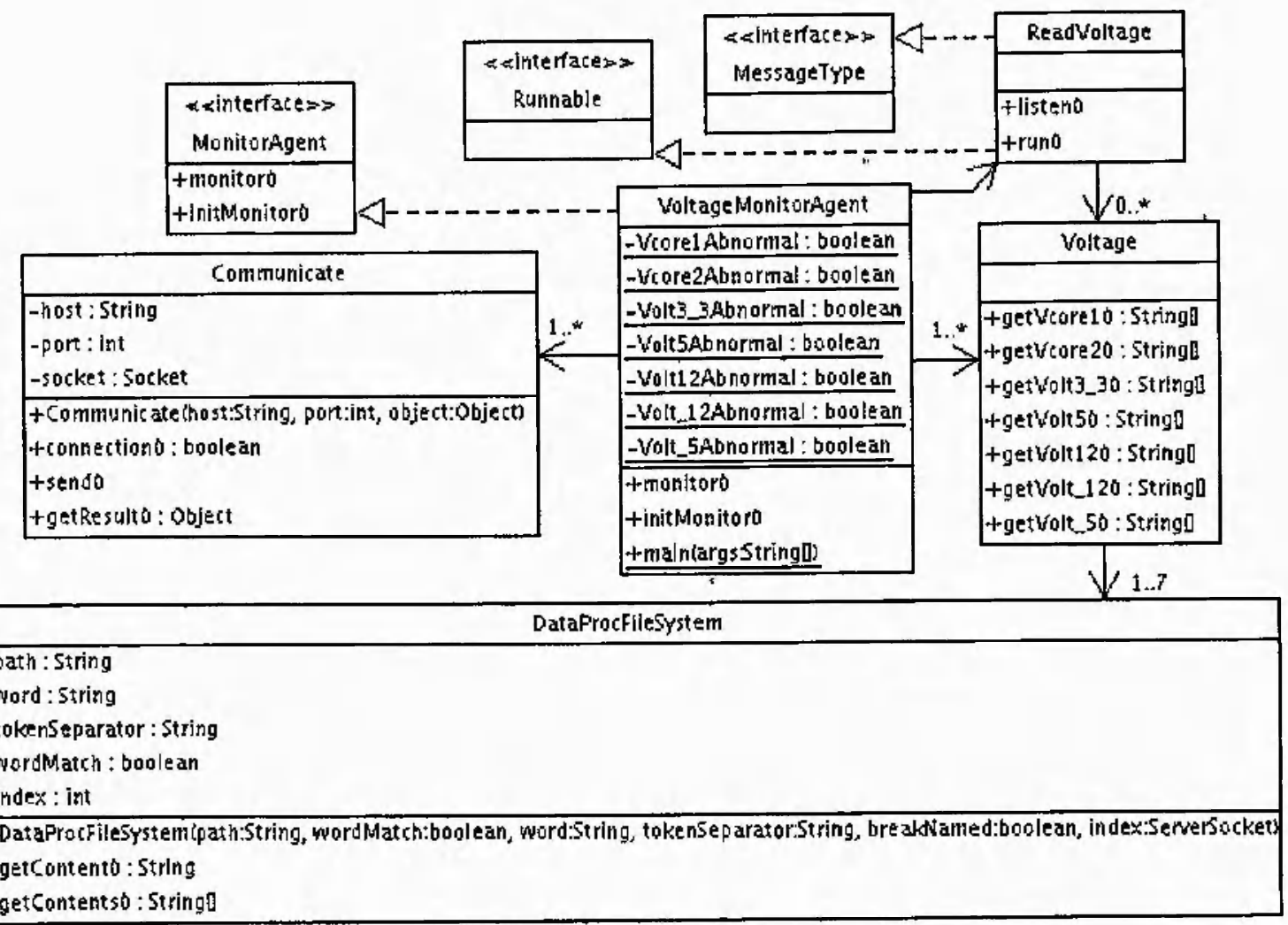

Figura B.9 - Diagrama de classes UML do VoltageMonitor Agent 